\title{
Uso de Ressonância Magnética Nuclear na análise metabolômica de biofluidos de animais tratados com Ivermectina
}

Tese apresentada ao Instituto de Química de São Carlos da Universidade de São Paulo como parte dos requisitos para a obtenção do título de Doutor em Química.

Área de Concentração: Química Analítica

Orientador: Dr. Luiz Alberto Colnago

\section{Exemplar revisado}

O exemplar original encontra-se em acervo reservado na Biblioteca do IQSC-USP

São Carlos 


\section{DEDICATÓRIA}

"Dedico este trabalho a todos os cientistas, que movidos por um ideal maior não se deixam abater diante da grandiosidade e complexidade da Ciência, mesmo ao contemplar sua própria pequenez frente à ela.

Não há obstáculos, somente desafios". 


\section{AGRADECIMENTOS}

Aos meus pais, Antonio e Isabel, e irmãs, Camila e Julia, por mais de uma década de incentivo acadêmico, e quase três no total, sempre me apoiando, dando suporte e mostrando os caminhos mais certos e sólidos do crescimento, tudo isso através de mostras diárias infinitesimais (mas constantes) de princípios e sentimentos que serão para toda a minha vida. E também aos novos membros da família, Alexandre e Marcelo, pelo apoio fraterno quase consanguíneo.

Ao meu orientador e amigo, Dr. Luiz Alberto Colnago, pela orientação, paciência e reconhecimento durante todo o desenvolvimento deste trabalho, contribuindo fortemente para minha formação e aprendizado em uma nova área.

Ao Prof. Dr. Glaucius Oliva, que me abriu as primeiras portas para a pesquisa científica e acreditou no meu trabalho desde o primeiro dia. Muito deste trabalho de doutorado devo ao exemplo deste professor.

Ao Prof. Dr. Adriano Andricopulo, pela orientação e experiência transmitida na iniciação científica e mestrado.

Ao Prof. Dr. Otávio Thiemann, que desde a graduação mostrou-se professor e amigo, incentivando e apoiando a experimentação científica e crescimento pessoal.

Ao Prof. Dr. Tiago Venâncio, por sua disponibilidade e ajuda, que permitiu $o$ enriquecimento deste trabalho, com experimentos $e$ discussões.

À FAPESP, pela bolsa concedida, e ao Serviço de Pós-Graduação do Instituto de Química de São Carlos, em especial à Andreia e Silvia, pelo suporte e auxílio durante todo o desenvolvimento do doutorado.

Aos pesquisadores e funcionários da Embrapa Pecuária Sudeste, em especial a Márcia Cristina de Sena Oliveira e Ana Carolina de Souza Chagas, por suas contribuições no campo da veterinária e sugestões no desenvolvimento dos experimentos com bovinos. 
Aos técnicos e funcionários da Embrapa Instrumentação, Marcelo Simões, Silviane Hubinger, Lucimara Forato, Wilson Lopes da Silva, José Ferrazini Jr., Danilo Tassim, Valentim Monzane, Joana Bresolin, por todo trabalho dedicado à pesquisa científica.

Ao aluno de Mestrado Gustavo Machado Álvares Lima, pela amizade e execução precisa e indispensável dos experimentos com cobaias.

A todos amigos da Embrapa Instrumentação, pelos 4 anos de convívio, em especial aos grandes companheiros do Grupo de Ressonância Magnética Nuclear, Paulo Cobra, Gabriela Carósio, Tatiana Santana, Roberta Manzano, Maiara Santos, Lúcio Barbosa, Antonio Marchi Netto, Luiza Nunes, Tiago Moraes, Danielli Golinelli, Luiz Cabeça, Poliana Santos, Fabiana Diuk, Fayene Souza e Lucinéia Vizotto, que além do excelente convívio, sempre foram excelentes parceiros de trabalho, compartilhando conhecimento e experiências, e aos Fábios (Plotegher e Leite), Fernanda, Larissa e Humberto pela amizade.

Aos amigos "ressonantes" fora da Embrapa Instrumentação, que de alguma forma contribuíram com este trabalho, Prof. Dr. José Daniel Figueroa Villar, Prof. Dr. Rodrigo Bagueira, Dra. Sônia Cabral, Dr. Eduardo Sanches, Francisco "Chicão" Gambarra e Clayton Rodrigues, pelas discussões e debates sobre RMN.

Aos grandes eternos amigos da remota graduação, Caio Moreira (Tamanco), Ranylson Savedra (Tequila) e Elton Sitta (Xororó).

A todos os amigos e companheiros de laboratório do IFSC, que nunca deixaram a amizade morrer nesses anos trabalhando longe: Fernando Bachega (Lerdo), Fernanda Costa, Victor Caldas (Wally), Maria Amélia Oliva (Mamé), Humberto Pereira, Gustavo Mercaldi, Marcelo Liberato (Tavin), Deise Borchardt Moda e Prof. Dr. Rafael Guido.

Ao parceiro e camarada José Antônio Alves Jr. (Zé Polenta), pelas discussões sobre química, e por aquelas nem tão técnicas, mas que sempre serviram para colocar as ideias em ordem. 
Ao grande Tiago Moda (Mulis), pra sempre amigo e companheiro de conversas, cujo ânimo e bom humor foram mais do que exemplos, e pela alegria de ver a família Moda aumentar durante este doutorado.

Ao sempre presente amigo e irmão Bruno Martins (Bilbo), que mesmo de outro hemisfério não deixou de dar suas "magistrais" contribuições para a minha vida e meu trabalho.

Aos companheiros de república e amigos pra toda vida, Giann Braune, William "01" Alves e Cristhiane Maciel, pela fantástica convivência e amizade resultante.

A todos, meus mais sinceros agradecimentos. 


\section{EPÍGRAFE}

"Escolha um trabalho de que goste, e não terá que trabalhar um só dia em sua vida".

Confúcio

"Mesmo uma jornada de mil milhas começa com o primeiro passo". Lao-Tsé 


\section{RESUMO}

A pesquisa bioquímica no campo da Metabolômica/Metabonômica tem se intensificado consideravelmente nos últimos anos, por sua capacidade de adquirir uma grande quantidade de informação a respeito do comportamento de um organismo através de seu metabolismo. Para isso, frequentemente faz uso da aplicação das mais diversas técnicas analíticas, como a Ressonância Magnética Nuclear.

A Ivermectina é um fármaco de amplo uso no Brasil, dada a sua eficiência no controle de verminoses e pragas em gado (e humanos) e está aqui inserida no contexto metabolômico/metabonômico dadas as inúmeras violações ocorridas na carne brasileira exportada. A não observância dos períodos adequados de carência para abate dos animais tratados pode refletir seriamente na qualidade destes produtos. Assim, utilizou-se a Ivermectina como forma de provocar mudanças no metabolismo de bovinos e camundongos, procurando-se correlacionar as variações encontradas à dose aplicada.

Através de ferramentas auxiliares, como RMN-2D e ferramentas quimiométricas exploratórias, fez-se a avaliação de amostras de plasma sanguíneo e urina bovinos, e plasma sanguíneo de camundongos Balb-C, após administração de Ivermectina. Os resultados obtidos mostram que a Ivermectina tem influência no balanço energético do organismo, interferindo nos níveis de lactato e $\beta$-hidróxibutirato, podendo estar ligada ao aparecimento de uma condição metabólica crítica em mamíferos, relacionada à alta concentração de corpos cetônicos na corrente sanguínea dos mesmos.

Palavras-chave: Ressonância Magnética Nuclear, SSFP, Metabolismo. 


\begin{abstract}
The biochemical research in the field of Metabolomics/ Metabonomics has grown considerably in recent years because its capability of acquiring a large amount of information about the behavior of an organism through its metabolism. For this, it often applies several analytical techniques such as Nuclear Magnetic Resonance.

Ivermectin is a drug widely used in Brazil, for its effectiveness in controlling verminosis and pests in livestock (and humans) and is here inserted in the metabolomic/metabonomic context because of the numerous breaches occurred in brazilian beef exports. Failures to comply with the appropriate withdrawal periods for slaughtering treated animals may reflect seriously on the quality of these products. Thus, we used Ivermectin as a metabolism change inducer in cattle and mice, trying to correlate these variations to the applied dose.

Through auxiliary tools such as 2D-NMR and chemometric exploratory tools, we evaluated samples of bovine blood plasma and urine, and blood plasma of Balb-C mice, after Ivermectin administration. The results show that Ivermectin has influence on the organism's energy balance, interfering with lactate and $\beta$-hydroxybutyrate which can be connected to the onset of a critical metabolic condition in mammals, related to the high concentration of ketone bodies in their blood stream.
\end{abstract}

Keywords: Nuclear Magnetic Resonance, SSFP, Metabolism. 


\section{SUMÁRIO}

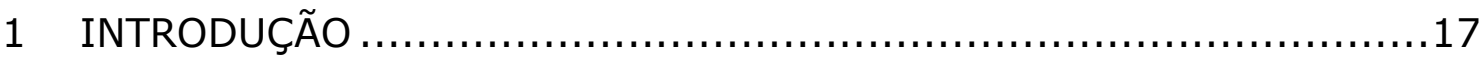

1.1 Fundamentos da Espectroscopia de RMN .........................17

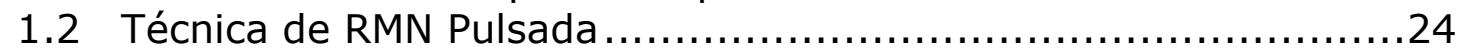

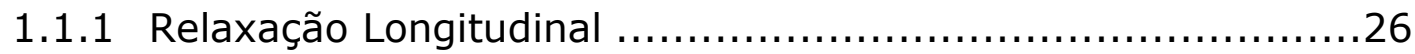

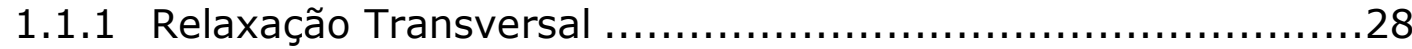

1.2 Teoria Básica da RMN de Precessão Livre no Estado Estacionário

(Steady State Free Precession - SSFP) ...................................30

1.3 Metabolismo e Disfunções Metabólicas ................................33

1.4 Metaboloma vs. Metabonoma......................................... 34

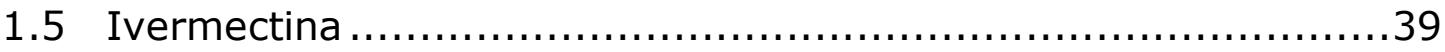

1.6 Aplicação da Informação Gerada ...................................42

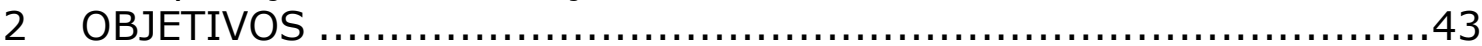

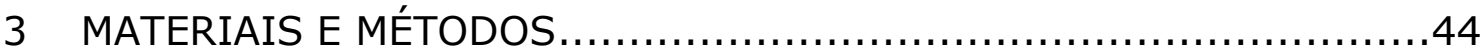

3.1 Tratamento dos Animais.......................................... 44

3.2 Preparação das Amostras ...........................................45

3.3 Análises de Ressonância Magnética Nuclear ........................47

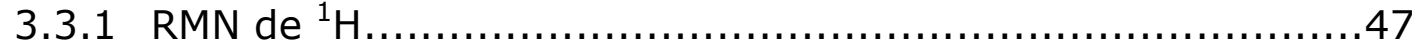

3.3.1.1Supressão do Sinal da Água ...................................49

3.3.1.1.1 Jump-Return............................................. 49

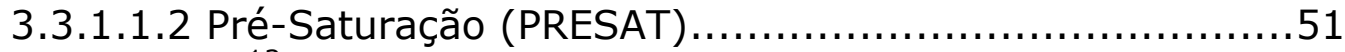

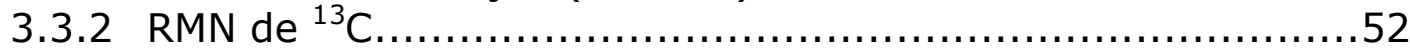

3.3.2.1Técnica Convencional ....................................... 52

3.3.2.2Steady-State Free Precession (SSFP) ........................5 53

3.3.2.3RMN Bidimensional ............................................ 54

3.4 Estudos Quimiométricos ......................................... 54

3.5 Experimento com Camundongos …................................ 59

3.6 Caracterização de Metabólitos .......................................62

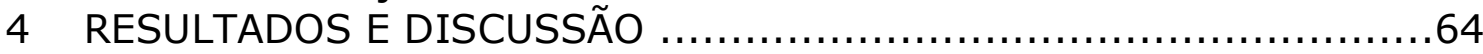

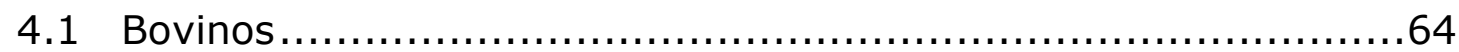

4.1 .1 Preparo das amostras ............................................64

4.1.2 Análises de Ressonância Magnética Nuclear .....................64

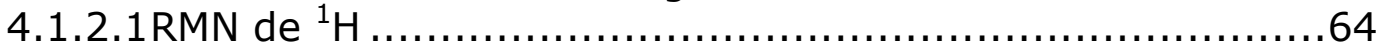

4.1.2.2RMN de ${ }^{13} \mathrm{C}$ (Convencional e SSFP) .........................69

4.1.3 Análise de Exploratória dos Dados ...............................77

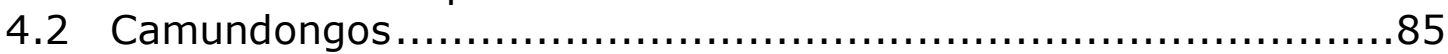

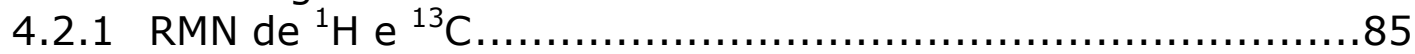

4.2.2 Análise de Exploratória dos Dados ................................. 89

4.3 Caracterização de Metabólitos ........................................99

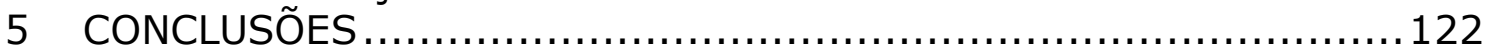

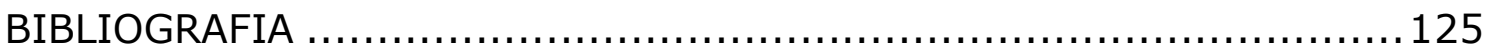




\section{LISTA DE FIGURAS}

Figura 1 - Desdobramento dos níveis de energia para um núcleo com I = $1 / 2$.

Figura 2 - Representação do movimento de precessão de um núcleo quando na presença de $\mathrm{B}_{0}$. 22

Figura 3 - Representação vetorial da aplicação de um pulso de rf a um sistema de spins, empregando o sistema de coordenadas girantes. .25

Figura 4 - Sinal FID para ${ }^{1} \mathrm{H}$ do etanol, com a respectiva Transformada de Fourier, mostrando os picos dos grupos químicos indicados.......................26

Figura 5 - Processo de relaxação longitudinal. No retorno da magnetização à direção $z$, a componente $M_{x y}$ desaparece, extinguindo o sinal 27

Figura 6 - Processo de relaxação transversal, ou spin-spin. Após o pulso, as magnetizações, ou isocromatas de spin, perdem coerência, distribuindo-se pelo plano, eliminando a componente $M_{x y}$ gradualmente. 29 Figura 7 - Cromatograma (íon total) obtido através de HPLC (High Performance Liquid Chromatography) mostrando uma grande quantidade de picos correspondentes a metabólitos encontrados na casca do tomate. (Fonte: adaptado de Plant Physiology). ${ }^{48}$

Figura 8 - Espectro de $\mathrm{RMN}{ }^{1} \mathrm{H}$ a $600 \mathrm{MHz}$ de urina de rato, mostrando os sinais de inúmeros metabólitos. Este tipo de espectro é útil no estabelecimento de perfis metabólicos para diversos organismos. (Fonte: adaptado de Nature Protocols $)^{35}$

Figura 9 - Estruturas químicas da Abamectina e Ivermectina.

FIGURA 10 - Notícia veiculada pela agência Reuthers em maio de 2010, sobre a interrupção nas exportações de carne da JBS para os EUA. (Fonte: Reuters) ${ }^{54}$

Figura 11 - Bezerro da raça Holandês Holstein-Frísia. 44

Figura 12 - Diagrama da coleta de plasma sanguíneo para análise por RMN.

Figura 13 - Sequência padrão convencional para ${ }^{1} \mathrm{H}$, composta por um tempo de espera (delay time), pulso e tempo de aquisição. 48

Figura 14 - Espectro de RMN de ${ }^{1} \mathrm{H}$ de uma amostra biológica sem a devida supressão do sinal da água $(4,8 \mathrm{ppm})$. O único pico visível encobre os demais sinais, menos intensos, prejudicando a leitura. Abaixo, ampliação de 1000 vezes da região mostrada.

Figura 15 - Distribuição vetorial das magnetizações durante a aplicação da técnica jump-return e sequência de pulsos empregada. Inicialmente, um pulso de $90^{\circ} \mathrm{x}$ desloca a magnetização para o plano $\mathrm{xy}$, analogamente à técnica de $\mathrm{RMN}-{ }^{1} \mathrm{H}$ convencional (a). Após decorrido um tempo $\tau$, as magnetizações individuais deslocam-se de acordo com a sua frequência, adiantando-se ou atrasando-se em relação ao sinal da água em offset (b). Finalmente, um pulso de $90^{\circ}$ - desloca todos os vetores para o plano $x z$, fazendo com que o sinal inicialmente em offset seja alinhado com o eixo $z$, não restando componente $x y$ do mesmo, eliminando-o 
Figura 16 - Representação da sequência de pulsos empregada na técnica PreSat. Enquanto a aquisição emprega pulsos e intervalos convencionais, uma frequência contínua adicional é mantida em irradiação sobre o núcleo a ser suprimido, impedindo que o mesmo entre em processo de relaxação.

Figura 17 -Sequência padrão para análise de ${ }^{13} \mathrm{C}$, com pulso de $30^{\circ} \ldots \ldots .53$

Figura 18 - Representação geral dos dados de RMN e sua preparação para a análise de PCA. Os dados são compostos por valores de intensidade relativos à frequência coberta pelo espectro (tabela superior). Após a transposição, os dados são compostos por intensidades relativas a cada animal, sendo os valores de frequência uma espécie de amostragem (tabela inferior). NOTA: valores da escala de frequência meramente ilustrativos.

Figura 19 - Exemplo de uma análise de componentes principais. O gráfico de loadings considera todos os pontos do conjunto de dados, ao redor das componentes.

Figura 20 - Dados de $\mathrm{RMN}^{-1} \mathrm{H}$ para amostra de urina bovina. As regiões mostradas em amarelo correspondem aos pontos situados nos $2^{\circ}$ e $3^{\circ}$ quadrantes no gráfico de loadings (Figura 19).

Figura 21 - Dendrograma de HCA, onde os "ramos" da árvore indicam a similaridade entre as amostras.

Figura 22 - Camundongo Balb-C com 6 semanas de vida.

Figura 23 - Esquema do experimento com camundongos, divididos em 6 grupos, sendo um grupo basal e cinco grupos de tratamento. Os animais mostrados em cinza representam os indivíduos controle de cada grupo...61 Figura 24 - Espectro de $\mathrm{RMN}-{ }^{1} \mathrm{H}$ para uma amostra de plasma sanguíneo bovino, empregando a técnica de supressão jump-return. O sinal marcado corresponde ao residual da água.

Figura 25 - Espectro de $\mathrm{RMN}-{ }^{1} \mathrm{H}$ para uma amostra de plasma sanguíneo, empregando a técnica de supressão jump-return, aplicando-se a correção de fase para sinais com deslocamento químico maiores ou iguais a 4,8 ppm. Neste caso, a supressão do sinal da água foi de cerca de 80 vezes.66 Figura 26 - Espectros de $\mathrm{RMN}-{ }^{1} \mathrm{H}$ de amostras de urina bovina, antes $(A)$ e após (B) a implementação dos novos protocolos de aquisição de dados. a qualidade dos dados obtidos, refletida sobretudo pela resolução espectral, pode ser notada nas regiões em destaque.

Figura 27 - Espectros de $\mathrm{RMN}-{ }^{1} \mathrm{H}$ de plasma sanguíneo bovino obtidos antes (A) e após (B) a implementação dos protocolos de tratamento e aquisição de dados.

Figura 28 - Espectro de $\mathrm{RMN}-{ }^{13} \mathrm{C}$ obtido para amostra de urina bovina, a partir da técnica convencional.

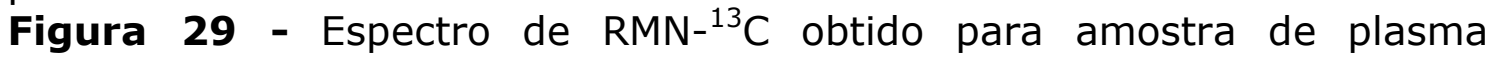
sanguíneo bovino, a partir da técnica convencional. 71

Figura 30 - Sinal de $\mathrm{RMN}-{ }^{13} \mathrm{C}$ no domínio do tempo, obtido com a técnica SSFP para uma amostra de plasma sanguíneo.

Figura 31 - Espectro resultante da transformada de Fourier diretamente do sinal FID, sem qualquer tipo de tratamento. 73 
Figura 32 - Espectro de RMN-SSFP após a utilização de apodização e zero filling, para urina (A) e plasma sanguíneo (B). Apesar de ainda serem visíveis algumas distorções nos sinais encontrados, a qualidade dos dados finais é bastante melhor. 74

Figura 33 - Espectros de $\mathrm{RMN}^{-13} \mathrm{C}$ de uma amostra de plasma bovino, empregando a sequência de pulsos convencional (A) e a técnica SSFP (B).

.75

Figura 34 - Análise de componentes principais para urina bovina a partir de dados de $\mathrm{RMN}-{ }^{1} \mathrm{H}$, modelo contendo 17 animais. Mesmo considerandose as componentes de maior peso estatístico, não há uma separação clara das amostras. 80

Figura 35 - Gráfico de scores para PCA de um modelo para plasma sanguíneo bovino contendo 8 animais a partir de dados de $R M N-{ }^{1} \mathrm{H}$. Mesmo considerando-se as componentes de maior peso estatístico, não há uma separação clara das amostras. .......................................................... 82

Figura 36 - Gráfico de Scores para PCA a partir de dados de RMN- ${ }^{1} \mathrm{H}$ resultante da seleção de regiões com melhor poder de modelagem.

Figura 37 - Separação das amostras na PCA por animais. Amostras de um mesmo animal tendem a se agrupar com o refinamento do modelo. .84 Figura 38 - Espectro de $\mathrm{RMN}-{ }^{1} \mathrm{H}$ obtido para plasma sanguíneo de um camundongo Balb-C. Analogamente aos espectros para bovinos, é possível observar uma quantidade satisfatória de sinais.

Figura 39 - Comparativo entre espectros obtidos para plasma sanguíneo de camundongo através das sequência convencional (A) e SSFP (B) ........87 Figura 40 - Gráfico de scores da PCA para o modelo gerado com as amostras de camundongos a partir de dados de $\mathrm{RMN}-{ }^{1} \mathrm{H}$, mostrando animais controle e grupo basal (azul) e tratados (vermelho). Análise realizada com todo o perfil do espectro. . .90

Figura 41 - Gráfico de scores da PCA para o modelo gerado com as amostras de camundongos a partir de dados de $\mathrm{RMN}-{ }^{1} \mathrm{H}$, mostrando animais controle e grupo basal (azul) e tratados (vermelho). Análise conduzida após refinamento por regiões de alto poder de modelagem.....92 Figura 42 - PCA ilustrada na figura 20, utilizando classificação por grupos. . .93

Figura 43 - Gráfico de loadings da PCA. Utilizando-se as melhores componentes da PCA para gerar o gráfico, é possível selecionar as variáveis mais provavelmente responsáveis pela distinção do modelo. As imagens referem-se aos loadings antes (A) e após (B) o refinamento......94 Figura 44 - Através da seleção das variáveis desejadas, as mesmas são destacadas em todo o modelo, inclusive nos dados originais, mostrando as regiões de interesse no espectro. 96

Figura 45 - Sobreposição espectral de dados de $\mathrm{RMN}-{ }^{1} \mathrm{H}$ das regiões indicadas pela PCA.

Figura 46 - Dendrograma de HCA para amostras de plasma sanguíneo de camundongos a partir de dados de $\mathrm{RMN}-{ }^{1} \mathrm{H}$. A linha pontilhada mostra a divisão das amostras em dois grandes grupos.

Figura 47 - Espectros de $\mathrm{RMN}^{1}{ }^{1} \mathrm{H}$ para um camundongo do grupo basal (preto) e tratados: GT-3 (azul) e GT-5 (vermelho). A região ilustrada 
mostra alterações na composição do plasma sanguíneo destes animais ao longo do experimento. As linhas pontilhadas unem sinais equivalentes nos diferentes espectros. 100

Figura 48 - Região espectral em torno de 1,3 ppm, mostrando o dubleto com constante de acoplamento de $6,97 \mathrm{~Hz}$. 101

Figura 49 - Espectro COSY para amostra de plasma sanguíneo de camundongo. Mostrando as correlações entre átomos de hidrogênio em grupos imediatamente vizinhos. 102

Figura 50 - Espectro HQSC para amostra de plasma sanguíneo de camundongo (somente regiões contendo correlações são mostradas). As regiões destacadas mostram correlações $\mathrm{C}-\mathrm{H}$ para os sinais levantados no COSY. 103

Figura 51 - Espectro HMBC para amostra de plasma sanguíneo de camundongo. As regiões destacadas mostram as correlações a longa distância para os sinais encontrados no COSY. 104 Figura 52 - Estrutura química do lactato, deslocamentos químicos $\left({ }^{1} \mathrm{H}\right.$ e ${ }^{13} \mathrm{C}$ ) e multiplicidades. 105

Figura 53 - Assinalamento dos metabólitos encontrados no plasma sanguíneo de camundongos controle (A) e tratado (B). Região de 0,5 a 2,5 ppm. 106

Figura 54 - Assinalamento dos metabólitos encontrados no plasma sanguíneo de camundongos controle (A) e tratado (B). Região de 2,5 a 5,5 ppm. 107

Figura 55 - Assinalamento de sinais de metabólitos para espectro de RMN $-{ }^{13} \mathrm{C}$ (técnica convencional). No detalhe, a região de carbonilas. (pir. = piruvato; succ. $=$ succinato).

Figura 56 - Assinalamento de sinais de metabólitos para espectro de $\mathrm{RMN}-{ }^{13} \mathrm{C}$ (SSFP). No detalhe, a região de carbonilas. (glic. = glicose; pir. = piruvato; succ. = succinato .

Figura 57 - Comparação entre espectros de $\mathrm{RMN}-{ }^{1} \mathrm{H}$ de um camundongo controle (preto) e um medicado (verm.), na região de 1,1 a 1,6 ppm....114

Figura 58 - Via de gliconeogênese. 115

Figura 59 - Via de cetogênese. 116

Figura 60 - Ciclo de Krebs 117

Figura 61 - Espectro de $\mathrm{RMN}-{ }^{1} \mathrm{H}$ para uma amostra de plasma bovino de um animal controle, com destaque para o sinal da acetona (2,24 ppm).119 Figura 62 - Espectro de $\mathrm{RMN}-{ }^{1} \mathrm{H}$ para plasma bovino de um animal tratado, mostrando o considerável aumento do sinal da acetona e do $\beta$ hidroxibutirato entre Oh (animal sem tratamento, A) e 30h após a aplicação da primeira de duas doses de Ivermectina (B). 


\section{LISTA DE TABELAS}

Tabela 1 - Relação entre espécies nucleares e momento de spin. 18

Tabela 2 - Razão magnetogírica $(\gamma)$ e abundância natural de alguns núcleos. 19

Tabela 3 - Comparação entre os parâmetros das sequências de pulsos convencional e SSFP para a aquisição de espectros de ${ }^{13} \mathrm{C}$, para um período de aquisição de 3 horas.

Tabela 4 - Sinais encontrados nos espectros de RMN- ${ }^{13} \mathrm{C}$ convencional e SSFP para uma mesma amostra de plasma bovino (Figura 33). .76

Tabela 5 - Percentual do modelo descrito por cada uma das componentes do modelo gerado para urina bovina a partir de dados de $\mathrm{RMN}-{ }^{1} \mathrm{H}$ (todo o perfil do espectro).

Tabela 6 - Percentual do modelo descrito por cada uma das componentes do modelo gerado para urina bovina a partir de dados de $\mathrm{RMN}-{ }^{1} \mathrm{H}$ (pós refinamento).

Tabela 7 - Percentual do modelo descrito por cada uma das componentes do modelo gerado para plasma sanguíneo bovino (todo o perfil do espectro).

Tabela 8 - Percentual do modelo descrito por cada uma das componentes do modelo gerado para plasma sanguíneo bovino (pós refinamento). 82 Tabela 9 - Assinalamento de picos para os espectros mostrados na Figura 39.

Tabela 10 - Percentual descrito pelas componentes do modelo gerado para dados de $\mathrm{RMN}-{ }^{1} \mathrm{H}$ de plasma sanguíneo de camundongo (todo o perfil do espectro).

Tabela 11 - Percentual descrito pelas componentes do modelo gerado para dados de $\mathrm{RMN}-{ }^{1} \mathrm{H}$ de plasma sanguíneo de camundongo (todo o perfil do espectro).

Tabela 12 - Percentual descrito pelas componentes do modelo gerado para dados de $\mathrm{RMN}-{ }^{1} \mathrm{H}$ de plasma sanguíneo de camundongo (pós refinamento).

Tabela 13 - Estruturas químicas, deslocamentos químicos $\left({ }^{1} \mathrm{H}\right.$ e $\left.{ }^{13} \mathrm{C}\right)$ e multiplicidade $\left({ }^{1} \mathrm{H}\right)$ para os sinais assinalados na figura 54 . (Multiplicidades: $\mathrm{s}=$ singleto; $\mathrm{d}=$ dubleto; $\mathrm{dd}=$ duplo dubleto; $\mathrm{t}=$ tripleto; q quarteto; $\mathrm{m}=$ multipleto). 108 


\section{LISTA DE ABREVIATURAS E SÍMBOLOS}

Acetil-CoA - Acetil coenzima A

ADP - Adenosina Difosfato

ATP - Adenosina Trifosfato

$B_{0}$ - Campo magnético estático ( $T$ )

$B_{1}$ - Campo magnético oscilante $(T)$

CoA-SH - Coenzima A

COSY - Correlation Spectroscopy

DSS - Ácido 2,2-dimetil-2-silapentano-5-sulfônico

FID - Free Induction Decay

FT - Transformada de Fourier

GABA - Ácido $\gamma$-aminobutírico

HCA - Hierarchical Cluster Analysis

HMBC - Heteronuclear Multiple Bond Correlation Spectroscopy

HMG-CoA - 3-hidroxi-3-metilglutaril-coenzima A

HPLC - High Performance Liquid Chromatography

HSQC - Heteronuclear Single-Quantum Correlation Spectroscopy

$\mathrm{Hz}-$ Hertz

I - Número quântico de spin

IUPAC - International Union of Pure and Applied Chemistry

k - Constante de Boltzman

$\mathrm{LD}_{50}$ - Dose letal mediana

mM - milimol por litro

$M_{0}$ - Magnetização resultante no equilíbrio térmico

$M_{x y}$ - Componente transversal da magnetização

$M_{y}$ - Componente longitudinal da magnetização

$\mathrm{N}_{\mathrm{a}}$ - População de spins no nível de menor energia

$N_{\beta}$ - População de spins no nível de maior energia

PBS - Phosphate Buffered Saline

PCA - Principal Component Analysis

ppm - partes por milhão 
rf - Radiofreqüência

RMN - Ressonância Magnética Nuclear

SSFP - Steady State Free Precession

$\mathrm{T}_{\mathrm{p}}$ - Intervalo de tempo entre os pulsos

$\mathrm{T}_{1}$ - Constante de tempo de relaxação longitudinal

$\mathrm{T}_{2}$ - Constante de tempo de relaxação transversal

$\mathrm{T}_{2}{ }^{*}$ - Constante de tempo de relaxação transversal aparente

TMAO - N-óxido de trimetilamina

TMS - Tetrametilsilano

$\alpha$ - Nível de energia fundamental

$\beta$ - Nível de energia excitado

$\theta$ - Ângulo de rotação

$\mu$ - Momento magnético nuclear

a - Momento angular

$\gamma$ - Razão magnetogírica

$\tau$ - Duração do pulso (pw) 


\section{INTRODUÇÃO}

\subsection{Fundamentos da Espectroscopia de RMN}

Desde 0 surgimento das bases teóricas para seu desenvolvimento, na década de $20,{ }^{1-3}$ a Ressonância Magnética Nuclear (RMN) teve uma participação crescente no cenário da Química Analítica moderna. ${ }^{4-13}$ Desde essa época, os cientistas associaram propriedades magnéticas ao núcleo da matéria, e como nas demais técnicas espectroscópicas, a RMN baseia-se no conceito de interação entre matéria e radiação eletromagnética, mais precisamente uma interação entre esta e as propriedades dos núcleos atômicos.

Numa abordagem clássica, pode-se inferir que estes fenômenos são produtos do movimento de rotação do núcleo em torno de seu próprio eixo, analogamente ao que ocorre no caso do spin eletrônico. O "movimento" de spin nuclear gera um momento de spin, expresso pelo número quântico de spin magnético e representado por I.

Via de regra, é possível determinar este número através da contagem de prótons e nêutrons contidos no núcleo atômico. Cada uma destas partículas possui um momento de spin individual, cujo valor adotado é convencionalmente $1 / 2$. Quando dois prótons ou dois nêutrons encontram-se "emparelhados", seus momentos anulam-se. Logo, o momento de spin total do núcleo é determinado pela somatória de todos os momentos individuais de prótons e nêutrons desemparelhados, uma vez que prótons e nêutrons não emparelham entre si.

A Tabela 1 mostra a relação entre o número quântico magnético e os números atômicos e de massa de um núcleo. 
Tabela 1 - Relação entre espécies nucleares e momento de spin.

\begin{tabular}{c|c|c}
\hline No. de Massa & No. Atômico & No. Quântico Magnético (I) \\
\hline Ímpar & $\begin{array}{c}\text { Par ou Ímpar } \\
\text { Par }\end{array}$ & $\begin{array}{c}\text { Par } \\
\text { Par }\end{array}$ \\
Ímpar & 0 \\
\hline
\end{tabular}

No caso de ambos estarem presentes em número par, o momento total é nulo, e o núcleo em questão não é detectável por RMN. Nos casos de momento de spin não-nulo, a propriedade magnética dos núcleos detectáveis é denominada momento magnético nuclear, representado pela letra $\boldsymbol{\mu}$, sempre orientado na direção do eixo do spin. O valor de $\mu$ é diretamente proporcional ao momento angular a do núcleo e sua razão magnetogírica, como mostra a Equação 1.

$$
\boldsymbol{\mu}=\boldsymbol{\gamma} \cdot \boldsymbol{a}
$$

Equação 1

A razão magnetogírica é característica para cada núcleo e é utilizada como parâmetro para se definir a sensibilidade do mesmo para a ressonância magnética nuclear. De acordo com a Equação 1, o momento magnético será tanto maior quanto a razão magnetogírica, fazendo com que haja mais interação deste núcleo com o campo magnético aplicado.

Outro fator determinante na aplicação da RMN é a abundância natural do núcleo em questão. Por exemplo, dentre os isótopos do carbono, somente $0{ }^{13} \mathrm{C}$ é detectável por $\mathrm{RMN}$, visto que o ${ }^{12} \mathrm{C}$ possui momento magnético nulo. Aproximadamente $98,9 \%$ de todo carbono presente na natureza está forma de ${ }^{12} \mathrm{C}$, restando apenas $1,1 \%$ na forma de ${ }^{13} \mathrm{C}$. Assim sendo, somente uma pequena fração dos átomos de carbono em uma determinada amostra produzirão sinal durante a análise de RMN. A Tabela 2 reporta alguns valores de $\gamma$ e abundância natural para os núcleos mais comuns estudados em RMN. 
Tabela 2 - Razão magnetogírica $(\gamma)$ e abundância natural de alguns núcleos.

\begin{tabular}{cccc}
\hline Isótopo & Spin $(\mathbf{I})$ & $\gamma\left(\mathbf{x 1 0}^{\mathbf{7}} \mathbf{~ r a d ~}^{\mathbf{- 1}} \mathbf{~}^{\mathbf{- 1}}\right)$ & Abundância (\%) \\
\hline${ }^{1} \mathrm{H}$ & $1 / 2$ & 26,75 & 99,98 \\
${ }^{2} \mathrm{H}$ & 1 & 4,10 & 0,01 \\
${ }^{11} \mathrm{~B}$ & $3 / 2$ & 8,58 & 80,42 \\
${ }^{13} \mathrm{C}$ & $1 / 2$ & 6,72 & 1,1 \\
${ }^{14} \mathrm{~N}$ & 1 & 1,93 & 99,63 \\
${ }^{15} \mathrm{~N}$ & $1 / 2$ & $-2,71$ & 0,37 \\
${ }^{17} \mathrm{O}$ & $5 / 2$ & $-3,62$ & 0,037 \\
${ }^{19} \mathrm{~F}$ & $1 / 2$ & 25,18 & 100 \\
${ }^{29} \mathrm{Si}$ & $1 / 2$ & $-5,31$ & 4,7 \\
${ }^{31} \mathrm{P}$ & $1 / 2$ & 10,83 & 100 \\
\hline
\end{tabular}

Para se determinar a receptividade relativa entre dois núcleos para a RMN, deve-se levar em conta ambos os fatores. Se compararmos, por exemplo os núcleos de ${ }^{13} \mathrm{C}$ e ${ }^{1} \mathrm{H}$, teremos:

$$
\begin{gathered}
\text { Sensibilidade do }{ }^{13} \mathrm{C} / \text { Sensibilidade do }{ }^{1} \mathrm{H}=\left(\gamma^{13} \mathrm{C} / \gamma^{1} \mathrm{H}\right)^{3} \\
\left(6,72 \times 10^{7} / 26,75 \times 10^{7}\right)^{3}=\mathbf{0 , 0 1 6}
\end{gathered}
$$

Relacionando-se as abundâncias naturais dos dois nuclídeos:

Abundância do ${ }^{13} \mathrm{C} /$ Abundância do ${ }^{1} \mathrm{H}=1,1 \%$ / 99,9\% = 0,011

A receptividade do núcleo de ${ }^{13} \mathrm{C}$ para a $\mathrm{RMN}$, em relação ao núcleo de ${ }^{1} \mathrm{H}$ é dada por:

$$
0,016 \times 0,011=\mathbf{1}, 76 \times \mathbf{1 0}^{-4}
$$

Assim, a receptividade do núcleo de ${ }^{1} \mathrm{H}$ é cerca de 5700 vezes maior que a do ${ }^{13} \mathrm{C}$, tornando necessário o acúmulo de mais médias para $\mathrm{o}$ mesmo, a fim de se obter um espectro com boa razão sinal-ruído para leitura.

Quando uma amostra contendo núcleos com spins I $\neq 0$ com é inserida em um campo magnético, há uma interação entre o $\boldsymbol{\mu}$ do núcleo 
em questão e o campo magnético aplicado $\left(B_{0}\right)$, que leva a um desdobramento dos níveis de energia em 2I +1 níveis, sendo que alguns núcleos se orientam a favor, e outros contra o campo. Esse efeito de desdobramento dos níveis de energia é denominado efeito Zeeman. ${ }^{1,2} \mathrm{Na}$ Figura 1, é mostrado um diagrama dos níveis de energia para um núcleo com $\mathrm{I}=1 / 2$, quando inserido em um campo magnético externo $B_{0}$.

Figura 1 - Desdobramento dos níveis de energia para um núcleo com $\mathrm{I}=1 / 2$.

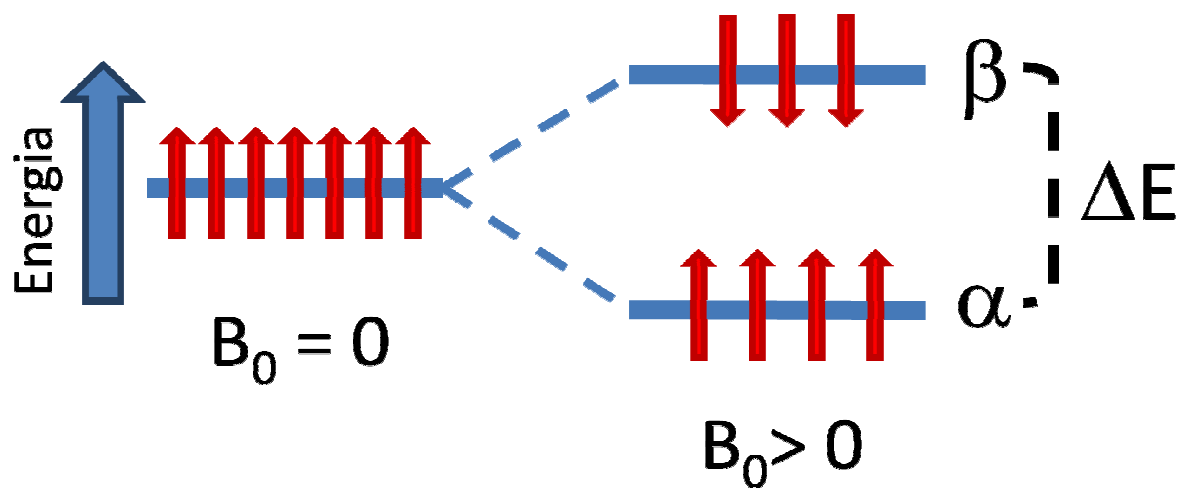

$\mathrm{Na}$ ausência de um campo magnético externo aplicado, não é possível distinguir energeticamente os estados $\alpha$ e $\beta$ dos núcleos, níveis de menor e maior energia, respectivamente, encontrando-se os mesmos degenerados. Contudo, uma vez presente $B_{0}$, há uma separação energética entre os estados, denominada $\Delta \mathrm{E}$. Os spins posicionados a favor do campo $(\alpha)$ encontram-se em um estado energético mais baixo, enquanto o oposto se observa para os núcleos posicionados contra o campo ( $\beta)$. Nesta condição, diz-se que o sistema encontra-se em equilíbrio térmico.

A energia associada a cada um desses níveis é dada por:

Equação 2

onde $\mathrm{m}_{\mathrm{I}}$ é a relação entre momento magnético e o spin nuclear, que leva a uma série de estados quânticos magnéticos observáveis, 
denominados número quântico direcional, e que podem assumir valores inteiros dados por $m_{I}=-I,-I+1,-I+2, \ldots,-1,0,1, \ldots, I-1, I$.

Desta forma, para um sistema de spins com $\mathrm{I}=1 / 2$, existem dois possíveis estados de energia, dados por:

$$
\begin{aligned}
& E_{\alpha}=1 / 2 \gamma \hbar B_{0} \\
& E_{\beta}=-1 / 2 \gamma \hbar B_{0}
\end{aligned}
$$

Equação 3

Equação 4

Através das equações 3 e 4, podemos estabelecer que a diferença de energia entre os níveis de energia dos estados $\alpha$ e $\beta$ é:

$$
\Delta \boldsymbol{E}=\boldsymbol{E}_{\alpha^{-}} \boldsymbol{E}_{\boldsymbol{\beta}}=\boldsymbol{\gamma} \hbar \boldsymbol{B}_{0}
$$

Equação 5

Energeticamente, o nível $\alpha$ é mais favorecido e, portanto, tem uma população ligeiramente maior que a do nível $\beta$. Essa diferença populacional pode ser calculada através da equação da distribuição de Boltzmann, a saber:

$$
N_{\alpha} / N_{\beta}=\exp (\Delta E / k T)
$$

Equação 6

onde $\mathrm{N}_{\alpha}=$ população de spins no nível de menor energia $\mathrm{N}_{\beta}=$ população de spins no nível de maior energia $\Delta \mathrm{E}=$ diferença de energia entre os níveis $\mathrm{k}=$ constante de Boltzmann $\left(1,3806 \times 10^{-23} \mathrm{~J} \cdot \mathrm{K}^{-1}\right)$ $\mathrm{T}=$ temperatura $(\mathrm{K})$

Desta ligeira diferença de populações entre os níveis $\alpha$ e $\beta$ surge um momento magnético resultante ou magnetização total do sistema, 
denominada $M_{0}$, posicionada sempre a favor de $B_{0}$, uma vez que corresponde ao excesso populacional no nível $\alpha$.

Devido à interação da magnetização do sistema $\left(M_{0}\right)$ com o campo magnético aplicado $B_{0}$ (e por convenção, na direção $z$ ), surge um movimento de rotação do núcleo em torno da direção $z$. Esse movimento, aliado à rotação natural do núcleo em torno de seu próprio eixo, leva a uma visão clássica análoga ao movimento de um pião girando, ao mesmo tempo em que é influenciado pelo campo gravitacional terrestre. A esse movimento resultante dá-se o nome de precessão. Uma imagem representativa do movimento de precessão do núcleo atômico é mostrada na Figura 2.

Figura 2 - Representação do movimento de precessão de um núcleo quando na presença de $B_{0}$.

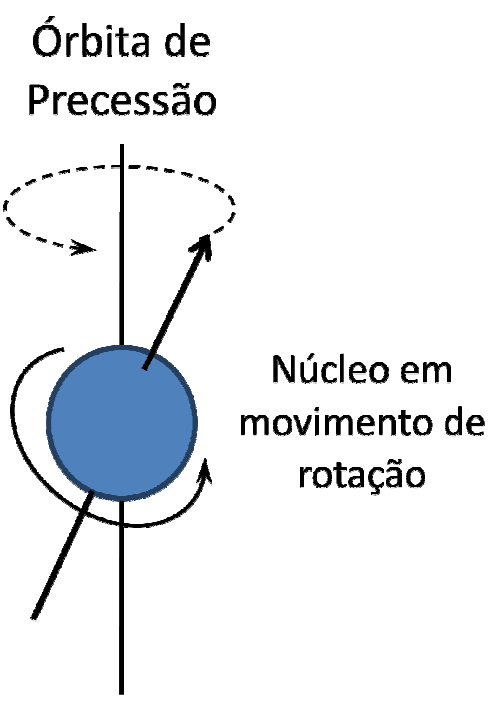

A frequência com que este núcleo precessiona em torno do eixo $z$ é denominada frequência de precessão de Larmor, designada por $v_{0}$, e pode ser relacionada com o campo magnético $B_{0}$ e a razão magnetogírica através da equação 7: 
ou em termos da velocidade angular:

$$
\omega_{0}=\gamma B_{0}
$$

Equação 8

A Equação 7 (Larmor) é considerada a equação fundamental da RMN, uma vez que permite a determinação da frequência do núcleo alvo em termos de sua razão magnetogírica e do campo aplicado.

Dentro de uma mesma molécula, porém, átomos de um mesmo elemento podem experimentar diferentes ambientes químicos, levando-os a frequências de ressonância ligeiramente distintas, causadas pelo campo magnético efetivo que incide sobre o átomo. Este é uma somatória do campo gerado pelo aparelho e do campo local, gerado por átomos vizinhos e por sua própria eletrosfera, num fenômeno denominado blindagem. O campo magnético que a eletrosfera gera em oposição ao campo principal será tão intenso quanto menor for a distância da mesma ao núcleo. Núcleos de ${ }^{1} \mathrm{H}$ (assim como qualquer outro núcleo a ser analisado por RMN) ligados a átomos mais eletronegativos tem sua densidade eletrônica diminuída, sofrendo assim uma menor oposição do campo local, e consequentemente mais influência do campo principal, ressonando em frequências mais altas.

Para efeitos de comparação, a referência da escala de frequências é o TMS (tetrametilsilano), e para soluções aquosas o DSS (ácido 2,2dimetil-2-silapentano-5-sulfônico), cujos átomos de hidrogênio são fortemente blindados. Porém, a frequência de ressonância do núcleo depende do campo magnético total aplicado, sendo que atualmente, existem aparelho que operam em campos de 4,7 T (200 MHz para o átomo de $\left.{ }^{1} \mathrm{H}\right)$ a $23,5 \mathrm{~T}(1 \mathrm{GHz})$. Assim, a comparação entre sinais obtidos para o mesmo núcleo em campos diferentes torna-se trabalhosa, dada a diferença de frequência.

Para contornar este obstáculo, utiliza-se a escala de deslocamento químico, que considera a frequência do núcleo em questão em relação à referência, em partes por milhão (ppm), como demonstra a Equação 9. 


$$
\delta=\frac{\left(v-v_{0}\right)(\mathrm{Hz})}{\text { Frequência do Aparelho }(\mathrm{MHz})}
$$

Equação 9

Uma vez que a frequência dos núcleos é dada em $\mathrm{Hz}$ e a frequência do aparelho em $\mathrm{MHz}$, a unidade de deslocamento químico ( $\delta$ ) é ppm, tornando espectros obtidos em quaisquer aparelhos comparáveis diretamente.

\subsection{Técnica de RMN Pulsada}

A condição de ressonância é atingida quando um campo magnético oscilante, linearmente polarizado $B_{1}$, na forma de $\mathrm{rf}$ é aplicado perpendicularmente a $B_{0}$, fazendo com que haja transição de spins entre os dois níveis de energia. O resultado é o deslocamento momentâneo dos spins do eixo $z$ para o plano $x y$. Porém, o movimento de precessão contínuo dificulta a compreensão deste fenômeno. Para isso, adota-se o sistema de coordenadas girantes, no qual o plano $x y$ (agora denominado $x^{\prime} y$ ) gira em torno do eixo $z$ com a mesma frequência de precessão do núcleo (frequência de Larmor). A Figura 3 ilustra vetorialmente o processo de aplicação de um pulso de rf $B_{1}$ a um sistema de spins em equilíbrio com $\mathrm{B}_{0}$. 
Figura 3 - Representação vetorial da aplicação de um pulso de rf a um sistema de spins, empregando o sistema de coordenadas girantes.
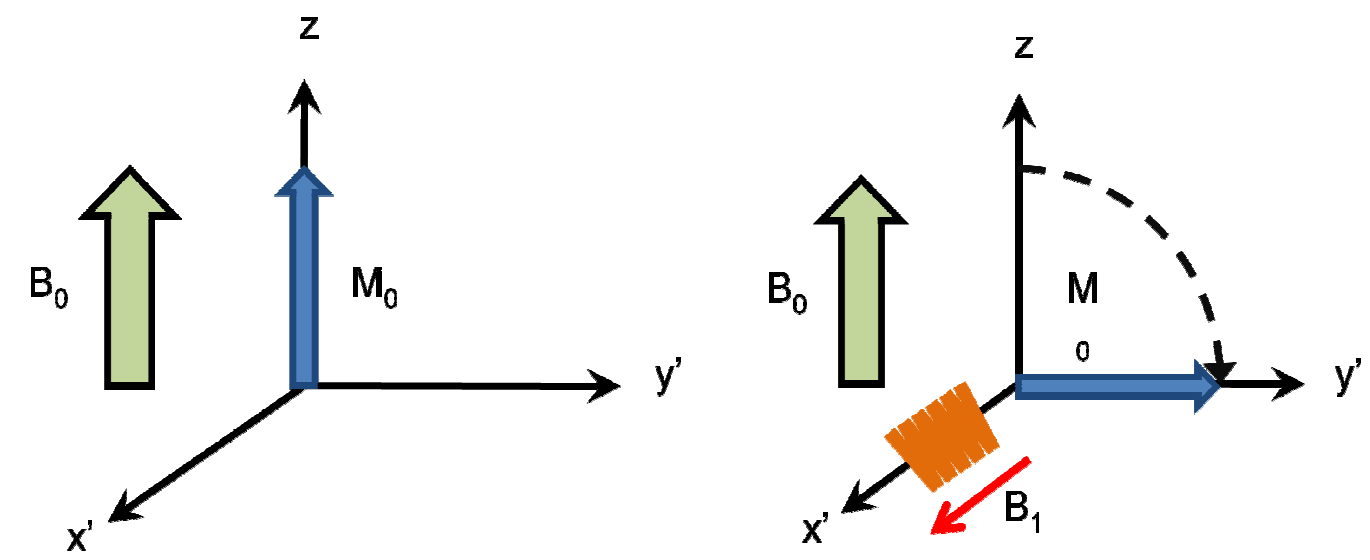

Durante a aplicação do pulso, surge um torque na direção perpendicular à de $B_{1}$, que leva a magnetização para o plano $x^{\prime} y^{\prime}$, através da rotação em torno do eixo $x^{\prime}$. Essa rotação esta associada a um ângulo $\theta$, que é diretamente proporcional ao tempo de duração do pulso, conforme a equação 10:

Equação 10

Onde $\quad \theta=$ ângulo de rotação da magnetização (rad)

$\gamma=$ razão magnetogírica

$\mathrm{B}_{1}=$ pulso de $\mathrm{rf}(\mathrm{T})$

$\mathrm{T}_{\mathrm{p}}=$ Tempo de pulso (s)

Usualmente, para experimentos envolvendo transformada de Fourier, ${ }^{8,9}$ escolhe-se um ângulo $\theta=90^{\circ}$ que gerará o máximo de sinal. Isso se deve ao fato de que com o deslocamento da magnetização para o plano $x^{\prime} y^{\prime}$, surge uma componente $M_{x y}$, responsável pela geração do sinal de RMN, através da indução de corrente elétrica em uma bobina estrategicamente situada a fim de receber tal sinal.

O sinal obtido é caracterizado por um máximo no instante $t=0$, ao final do qual o pulso $B_{1}$ é desligado. Neste instante, a magnetização, sujeita apenas à interferência de $\mathrm{B}_{0}$ tende a retornar à orientação na 
direção $z$. Este processo é conhecido como relaxação e após um período de tempo, não há mais componente magnética no plano $x^{\prime} y^{\prime}$, extinguindose o sinal. Esse tipo de sinal é denominado decaimento de indução livre (FID, do inglês Free Induction Decay) e encontra-se no domínio do tempo. Geralmente este sinal é convertido para o domínio da frequência através da transformada de Fourier (FT), gerando espectros de RMN com deslocamentos químicos para cada grupo de núcleos atômicos presentes na amostra. A Figura 4 mostra um exemplo de sinal FID, com a respectiva transformada de Fourier.

Figura 4 - Sinal FID para ${ }^{1} \mathrm{H}$ do etanol, com a respectiva Transformada de Fourier, mostrando os picos dos grupos químicos indicados.

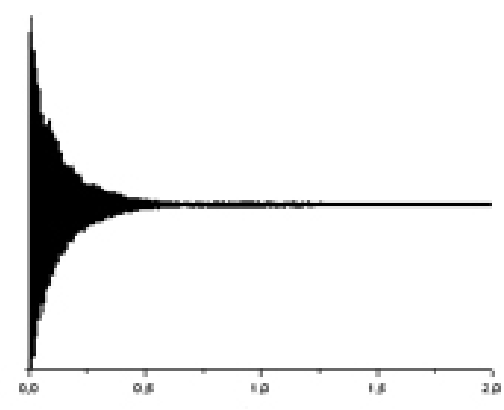

t $(s)$

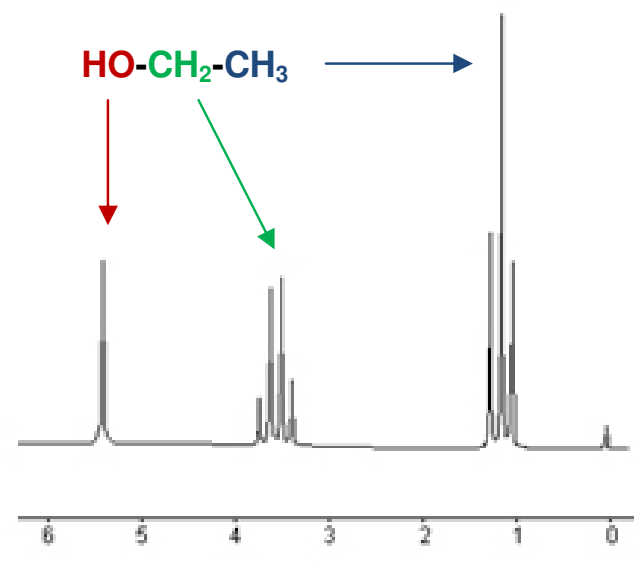

ppm

Existem dois processos distintos de relaxação durante o retorno da magnetização à condição de equilíbrio: a relaxação longitudinal, também denominada spin-rede, e a relaxação transversal, ou spin-spin.

\subsubsection{Relaxação Longitudinal}

Imediatamente após o pulso $\mathrm{B}_{1}$, a magnetização é transferida para o plano $x^{\prime} y^{\prime}$, o que significa uma alteração nos níveis populacionais $\alpha$ e $\beta$. Quando o sistema é excitado, estas populações tendem a se igualar. Após o desligamento do pulso, o sistema tende a retornar à condição inicial de equilíbrio. Contudo, a energia do estado de spins $\beta$ é maior que a do 
estado $\alpha$, como já visto, e para o retorno à condição inicial, o sistema tem de devolver a energia absorvida para o meio, na forma de calor. Por isso este processo é chamado de relaxação spin-rede, pois envolve o sistema de spins e o meio em que o mesmo se encontra. $O$ processo de relaxação longitudinal, ou spin-rede, compreende o gradual desaparecimento da componente $M_{x y}$ devido ao retorno da magnetização à direção $z$, como mostrado na Figura 5.

Figura 5 - Processo de relaxação longitudinal. No retorno da magnetização à direção $z$, a componente $M_{x y}$ desaparece, extinguindo o sinal.
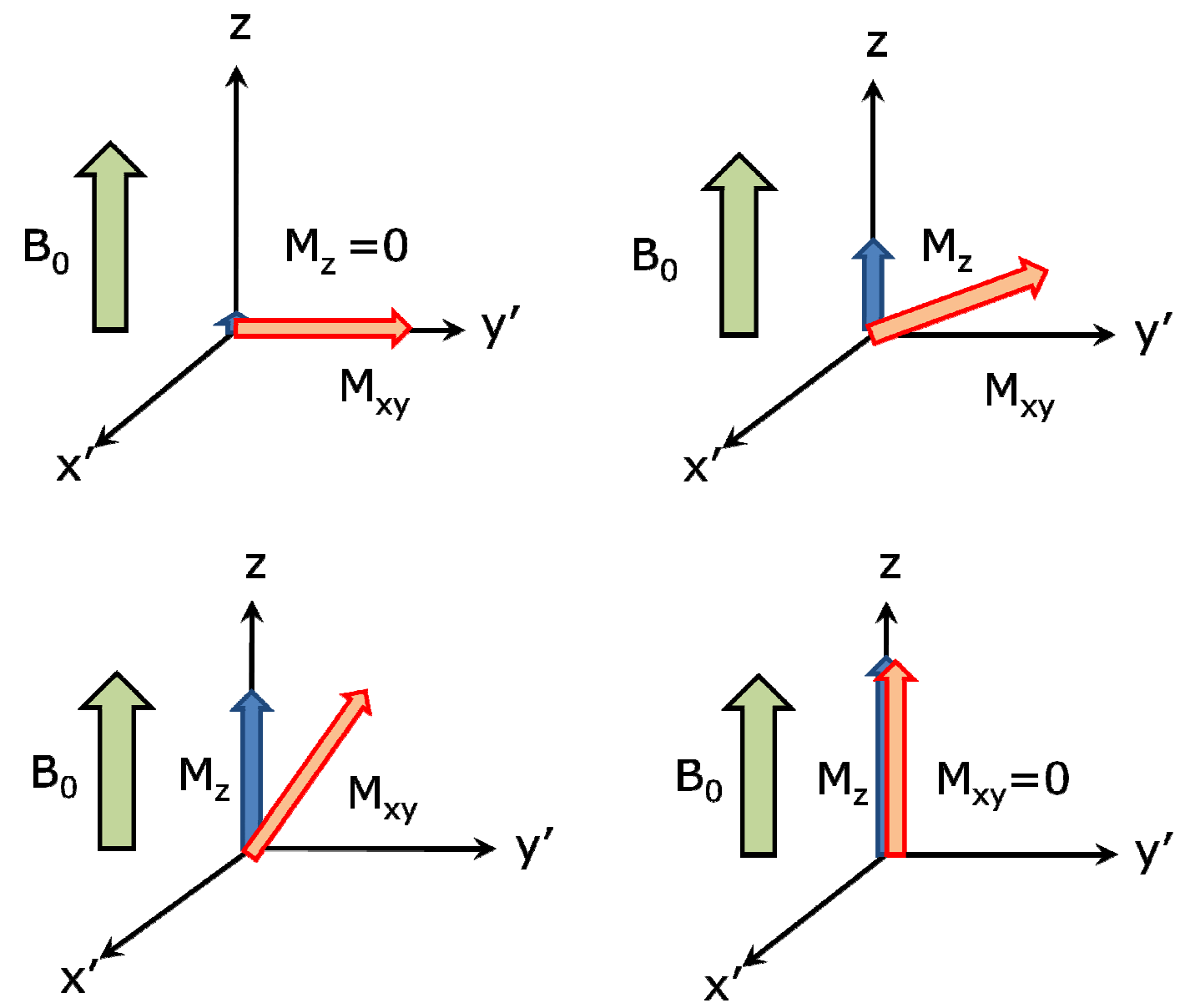

A relaxação spin-rede é regida por uma constante de tempo $T_{1}$, que determina a taxa de recuperação do sistema à condição inicial, através da equação: 


$$
M_{z}(t)=M_{0}\left[1-\exp \left(-t / T_{1}\right)\right] \quad \text { Equação } 11
$$

onde $\mathrm{T}_{1}$ é a constante de tempo de relaxação longitudinal.

Quando comparada a outras técnicas espectroscópicas, a RMN apresenta baixa sensibilidade, o que leva à necessidade de se acumular muitos espectros para se obter uma boa razão sinal/ruído (s/r). Neste ponto, o conhecimento de $T_{1}$ torna-se fundamental para o planejamento experimental, uma vez que se deve aguardar um tempo igual a $5 \mathrm{~T}_{1}$, tempo necessário para que 99,3\% da magnetização retornem à condição inicial de equilíbrio térmico. Dependendo do núcleo analisado, o valor de $\mathrm{T}_{1}$, demasiadamente longo, associado à baixa abundância e baixa razão magnetogírica, o tempo de análise pode chegar a várias horas, tornandose inviável em alguns casos. Portanto, novas metodologias têm se mostrado necessárias e desejadas para melhorar a análise de RMN, encurtando o tempo de experimento, principalmente pela diminuição do intervalo de tempo entre dois pulsos.

\subsubsection{Relaxação Transversal}

A relaxação transversal, ou spin-spin, inicia-se simultaneamente à longitudinal, e ocorre pela perda de coerência das magnetizações individuais de cada núcleo da amostra. Após o pulso, todos os núcleos tendem a precessionar juntos no plano $x^{\prime} y^{\prime}$. Decorrido certo tempo, cada vetor individual assumirá posições distintas ao longo do plano, enquanto retorna à direção $z$. Uma vez dispersos os por todo o plano, os vetores individuais não geram, ou geram apenas uma pequena resultante $M_{x y}$, reduzindo assim a intensidade do sinal de RMN. A Figura 6 ilustra o processo de relaxação transversal. 
Figura 6 - Processo de relaxação transversal, ou spin-spin. Após o pulso, as magnetizações, ou isocromatas de spin, perdem coerência, distribuindo-se pelo plano, eliminando a componente $M_{x y}$ gradualmente.
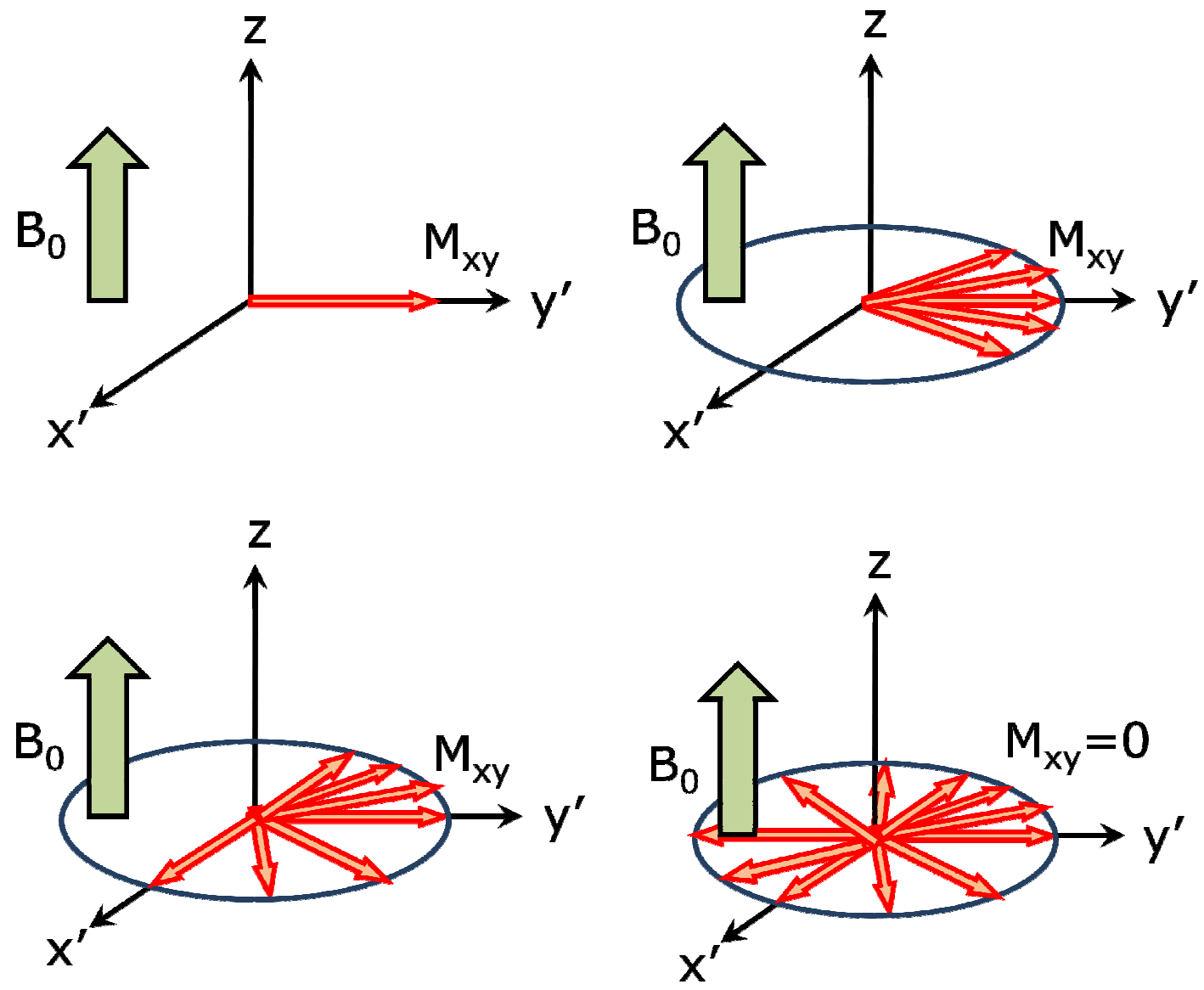

Diferentemente da relaxação longitudinal, a relaxação transversal não implica em perdas de energia para o meio. Ao contrário, durante o processo de relaxação, existe apenas um intercâmbio de espécies $\alpha$ e $\beta$, sem, contudo, alterar as populações individuais de cada nível, o que leva ao nome spin-spin devido à troca de energia exclusivamente interna entre as espécies. Este processo é governado por uma constante de tempo denominada $T_{2}$, de acordo com a equação:

Equação 12

Apesar de serem processos simultâneos, a relaxação transversal é geralmente mais rápida que a longitudinal, sendo a determinante para o 
perfil do sinal FID, uma vez que a largura do sinal de RMN é proporcional à taxa de decaimento do sinal FID.

Em condições reais, porém, deve-se levar em conta a heterogeneidade de $\mathrm{B}_{0}$, que leva a decaimentos mais rápidos que os esperados para uma amostra. Neste caso, o sinal FID é determinado por uma constante de tempo $\mathrm{T}_{2}{ }^{*}$, denominada constante de tempo $\mathrm{T}_{2}$ aparente, e que engloba tanto a constante de tempo $T_{2}$ como a falta de homogeneidade do campo magnético $B_{0}$, a saber:

$$
\frac{1}{T_{2}^{*}}=\frac{1}{T_{2}}+\gamma \Delta B_{0}
$$

Equação 13

onde $\Delta \mathrm{B}_{0}$ é a não-homogeneidade do campo magnético.

\subsection{Teoria Básica da RMN de Precessão Livre no Estado Estacionário (Steady State Free Precession - SSFP) ${ }^{14-17}$}

O regime de estado estacionário é estabelecido quando um sistema de spins é submetido a um trem de pulsos de mesma duração e intensidade, e espaçados por um mesmo intervalo de tempo $\left(T_{p}\right)$. Neste caso, as componentes da magnetização se comportam como funções periódicas do tempo com o período $T_{p}$.

Cada pulso da sequência desloca a magnetização resultante, fazendo-a girar ao redor de X' (do sistema de coordenadas girantes). Esse deslocamento é descrito por um ângulo de rotação, $\boldsymbol{\theta}$, formado entre o vetor magnetização e o eixo $\mathrm{z}$. Associado à rotação da magnetização $\mathrm{M}$ ao redor do eixo $x^{\prime}$ existe um operador $R_{x}(\theta)$, que aplicado à magnetização no equilíbrio térmico $\left(M_{0}\right)$ resultará na magnetização imediatamente após o pulso (M):

$$
\boldsymbol{M}=\boldsymbol{R}_{\boldsymbol{x}}(\boldsymbol{\theta}) \boldsymbol{M}_{\mathbf{0}}
$$


Com o término do pulso, a magnetização $M_{x y}$ (Figura 6 ) precessiona durante o intervalo de tempo $T_{p}$ ao redor do eixo $z$. Um ângulo de precessão, $\psi$, está relacionado à frequência de precessão desta magnetização, e é formado entre a projeção da magnetização no plano $x^{\prime} y^{\prime}$ e o eixo $y^{\prime}$. A equação que descreve esse movimento é dada por:

$$
\psi=\left(\omega-\omega_{0}\right) T_{p}
$$

Equação 15

na qual, $\omega_{0}$ é a frequência no referencial rotativo. A diferença entre essas duas frequências de precessão pode ser dada por:

$$
\Delta \omega=\left(\omega-\omega_{0}\right)
$$

Equação 16

A intensidade da componente transversal da magnetização irá decair com uma constante de tempo $\mathrm{T}_{2}$; enquanto que a componente longitudinal crescerá com uma constante de tempo $\mathrm{T}_{1}$. Para descrever todo o processo de relaxação existe um operador $S$, que é uma função dos tempos de relaxação $T_{1}$ e $T_{2}$, e ainda do intervalo de tempo $T_{p}$; como mostra a sua definição.

$$
S\left(T_{p}, T_{1}, T_{2}\right)=\left|\begin{array}{ccc}
E_{2}\left(T_{p}\right) & 0 & 0 \\
0 & E_{2}\left(T_{p}\right) & 0 \\
0 & 0 & E_{1}\left(T_{p}\right)
\end{array}\right|
$$

Equação 17

$\mathrm{E}_{2}\left(\mathrm{~T}_{\mathrm{p}}\right)$ e $\mathrm{E}_{1}\left(\mathrm{~T}_{\mathrm{p}}\right)$ são parâmetros de relaxação, sendo $E_{2}\left(T_{p}\right)=e^{-\frac{T_{p}}{T_{2}}} \mathrm{e}$ $E_{1}\left(T_{p}\right)=e^{-\frac{T_{p}}{T_{1}}}$.

Para um tempo $t$ qualquer, durante $o$ intervalo de tempo $T_{p}$, a magnetização resultante pode ser obtida através da seguinte equação:

$$
M(t)=M_{0}\left(1-E_{1}(t)\right)+M^{+} R_{z}(\psi) S\left(T_{p}, T_{1}, T_{2}\right) \quad \text { Equação } 18
$$


na qual $R_{z}(\psi)$ é um operador que descreve a rotação em torno do eixo $z$. Esse operador é descrito por uma matriz dada por:

$$
R_{z}(\psi)=\left|\begin{array}{ccc}
\cos \psi & \sin \psi & 0 \\
-\sin \psi & \cos \psi & 0 \\
0 & 0 & 1
\end{array}\right|
$$

Equação 19

Com a equação 19 é possível determinar a intensidade da magnetização em qualquer intervalo de tempo. Para atingir o regime de estado estacionário a magnetização antes do pulso deve ser igual a $M(t)$ no intervalo $T_{p}$.

De forma geral, as componentes da magnetização em cada uma das orientações do sistema de coordenadas girantes são dadas pelas equações a seguir:

$$
\begin{array}{ll}
M_{x^{\prime}}^{-}=\frac{M_{0}\left(1-E_{1}\right)\left[E_{2} \sin \alpha \sin \psi\right]}{D} & \text { Equação } 20 \\
M_{y^{\prime}}^{-}=\frac{M_{0}\left(1-E_{1}\right)\left[E_{2} \sin \alpha \cos \psi-E_{2}^{2} \sin \alpha\right]}{D} & \text { Equação } 21 \\
M_{z^{\prime}}^{-}=\frac{M_{0}\left(1-E_{1}\right)\left[1-E_{2} \cos \psi-E_{2} \cos \alpha\left(\cos \psi-E_{2}\right)\right]}{D} & \text { Equação } 22 \\
M_{y^{\prime}}^{+}=\frac{M_{0}\left(1-E_{1}\right)\left[\left(1-E_{2} \cos \psi\right) \sin \alpha\right]}{D} & \text { Equação } 23 \\
M_{x^{\prime}}^{+}=M_{x^{\prime}}^{-} & \\
M_{z^{\prime}}^{-}=\frac{M_{0}\left(1-E_{1}\right)\left[E_{2}\left(E_{2}-\cos \psi\right)+\left(1-E_{2} \cos \psi\right) \cos \alpha\right]}{D} & \text { Equação } 24
\end{array}
$$$$
D=\left[\left(1-E_{1} \cos \alpha\right)\left(1-E_{2} \cos \psi\right)\right]-\left[\left(E_{1}-\cos \alpha\right)\left(E_{2}-\cos \psi\right) E_{2} \text { Equação } 26\right.
$$ 
No caso em que $T_{p}<<T_{1}, T_{2}$ e $\psi=(2 n+1) \pi$, onde $n$ é um número inteiro, as componentes da magnetização no eixo $\mathrm{y}^{\prime}$, regidas pelas equações 20 e 23, atingem um valor máximo e são proporcionais à razão $T_{2} / T_{1}$, de acordo com a seguinte equação:

$$
\left|M_{y^{\prime}}^{-}\right|=\left|M_{y^{\prime}}^{+}\right|=\frac{M_{0} T_{2}}{\left(T_{1}+T_{2}\right)}
$$

Equação 27

Entretanto, quando a magnetização transversal não decai a zero, durante o intervalo de tempo entre os pulsos, ou seja, $T_{p}<T_{2}, T_{1}, o$ sistema de spins atinge não somente o regime de estado estacionário, como restabelece a intensidade da magnetização transversal antes de cada pulso sob a forma de eco, aqui representado pela magnetização $\mathrm{M}^{-}$. Para o caso de amostras de composição complexa (considerável presença de sais e íons metálicos), como as aqui mostradas, nem sempre a refocalização das isocromatas na forma de eco é visível, por provocarem um relaxamento mais rápido da magnetização.

Contudo, uma vez que o valor da magnetização $\mathrm{M}^{+}$não depende mais de $T_{p}$, mas somente dos valores de $T_{1}$ e $T_{2}$ (inerentes da amostra), a teoria da SSFP abre a possibilidade da aplicação de pulsos consideravelmente mais rápidos, encurtando o tempo de análise, e vem sendo utilizada crescentemente como técnica rápida para aquisição de dados de RMN para núcleos menos sensíveis, além de já ser uma técnica expressiva na geração de imagens por ressonância. ${ }^{13,18-24}$

\subsection{Metabolismo e Disfunções Metabólicas}

Os processos bioquímicos ocorrem ininterruptamente em todas as células de cada organismo vivo. Toda a maquinaria celular gera uma grande variedade de produtos, conhecidos como metabólitos. Estes, por sua vez, têm dois destinos possíveis: atuar como substrato para a próxima etapa bioquímica, seja ela no mesmo compartimento celular ou 
não, ou então ser excretado do organismo, na forma de resíduo. De qualquer maneira, cada processo tem sua marca característica, determinada pelas alterações que produz nos níveis de um ou vários metabólitos simultaneamente.

Essa ideia sugere que desordens nos processos de manutenção da célula, as quais podem conduzir a disfunções desde leves até gravíssimas ou letais, podem ser monitoradas através dos metabólitos que geram. De fato, encontram-se atualmente inúmeros relatos na literatura de doenças graves relacionadas a desordens metabólicas. Entre estas, pode-se citar diabetes, ${ }^{25-26}$ gota (hiperuricemia), ${ }^{27}$ fenilcetonúria, ${ }^{28}$ doença de Parkinson, ${ }^{29}$ mal de Alzheimer ${ }^{30}$ e alguns tipos de câncer. ${ }^{31-33}$

Assim, a pesquisa científica focada na investigação das variações metabólicas e desordens associadas, que já vem sendo conduzida, representa uma grande inovação no campo dos diagnósticos, apresentando como principais vantagens: i) necessidade de pouco tecido para análise, que muitas vezes pode ser obtido de maneira não invasiva (saliva, leite, urina, fezes, etc.) ou através uma pequena amostra de sangue (plasma); ii) análise química multivariada, permitindo detectar simultaneamente vários compostos, levando a um diagnóstico mais robusto e confiável, e; iii) detecção da disfunção com uma margem de tempo bastante larga, sendo que muitas vezes a constatação da doença dá-se bem antes de os sintomas se manifestarem.

Desta forma, a pesquisa na área de metabolismo tem-se intensificado nos últimos anos, ganhando espaço dentro da ciência.

\subsection{Metaboloma vs. Metabonoma}

Dentro do panorama atual da biologia molecular, o interesse pela pesquisa gênica como fonte de informações para a descoberta de novos tratamentos tem ganhado grande destaque, por incorporar a busca pelos mecanismos de expressão destes genes e as técnicas analíticas tradicionais, em uma grande área multidisciplinar. 
Uma das etapas mais complexas destes mecanismos é a transcrição gênica, que envolve uma grande rede de maquinaria molecular, envolvendo centenas de enzimas, proteínas e fatores de transcrição. A informação capaz de ser gerada a partir destes processos pode ser a chave para a intervenção eficaz em diversas desordens, surgindo assim o termo Transcriptoma, como a área a bioquímica e biologia molecular responsável por estudar os genes e seus produtos de transcrição.

Mais adiante na sequência de manutenção bioquímica da célula, as proteínas atuam como reguladores, realizando funções estruturais, catalíticas e de carreamento molecular. Mudanças na expressão ou funcionamento das proteínas podem alterar drasticamente o comportamento da célula, o que frequentemente está associado ao aparecimento de doenças. Sendo assim, uma nova frente de pesquisa bioquímica desenvolveu-se, denominada Proteoma, com a finalidade de esclarecer as correlações entre proteínas e as funções vitais das células.

No entanto, a complexidade dos processos de transcrição gênica e das funções proteicas dentro da célula torna a sua interpretação bastante intrincada, fazendo necessário o uso de todas as ferramentas possíveis de maneira simultânea para esclarecê-los.

Ao nível metabólico, ou de pequenas moléculas, esforços semelhantes têm sido realizados, sendo que muito antes do surgimento dos "-omas", a análise de metabólitos ganhou espaço dentro da pesquisa médica e bioquímica como forma de se compreender os processos celulares em geral. A grande característica da pesquisa metabólica reside no fato de que cada processo bioquímico de transformação ocorrido dentro de uma célula, seja ela procariótica ou eucariótica, pode ser classificado como metabolismo, e como tal, deixa atrás de si um conjunto característico de moléculas, geralmente exclusivo para um dado processo, e que é entendido como uma "impressão digital" química. Esta nova frente visa, sobretudo, o desenvolvimento de novos métodos para análises laboratoriais, exames e diagnósticos mais precisos e rápidos no futuro. Deste contexto surgem também os termos Metaboloma e 
Metabonoma. ${ }^{34}$ Ambos referem-se aos padrões metabólicos, às impressões digitais bioquímicas dos processos celulares. O termo Metaboloma refere-se ao estudo sistemático do perfil metabólico de um organismo, quando em condições saudáveis. São os níveis normais de metabólitos encontrados em um organismo sadio. O termo Metabonoma está relacionado à resposta destes níveis a estímulos externos, tais como doenças, stress, desequilíbrio alimentar, a própria idade e fatores genéticos inerentes ao organismo em questão ou a introdução de um agente (ou agentes) estranhos ao organismo, como no caso de um fármaco. ${ }^{35}$

Estes termos são complementares, e no atual panorama da bioquímica e biomedicina tornam-se um campo bastante amplo para a exploração de novas técnicas de análise de tecidos e materiais biológicos. Atualmente, as análises clínicas através de metabólitos são consideravelmente caras, já que são feitas componente a componente, detectando-se um único metabólito por vez, o que torna a procura por técnicas de análise simultânea e multivariada mais robustas e eficazes atraente, elevando o interesse na pesquisa metabolômica/metabonômica. Atualmente, centros de pesquisa em todo o mundo aplicam as técnicas tradicionais no desenvolvimento de novos protocolos de análise, como ressonância magnética nuclear, ${ }^{36-44}$ cromatografias líquida e gasosa ${ }^{35,44-47}$ e espectrometria de massas, ${ }^{44,48-50}$ e menos frequentemente, espectrofotometria na região de infravermelho. ${ }^{51}$ A Figura 7 mostra exemplos de análises metabólicas por cromatografia associada à espectrometria de massas. 
Figura 7 - Cromatograma (íon total) obtido através de HPLC (High Performance Liquid Chromatography) mostrando uma grande quantidade de picos correspondentes a metabólitos encontrados na casca do tomate. (Fonte: adaptado de Plant Physiology). ${ }^{48}$

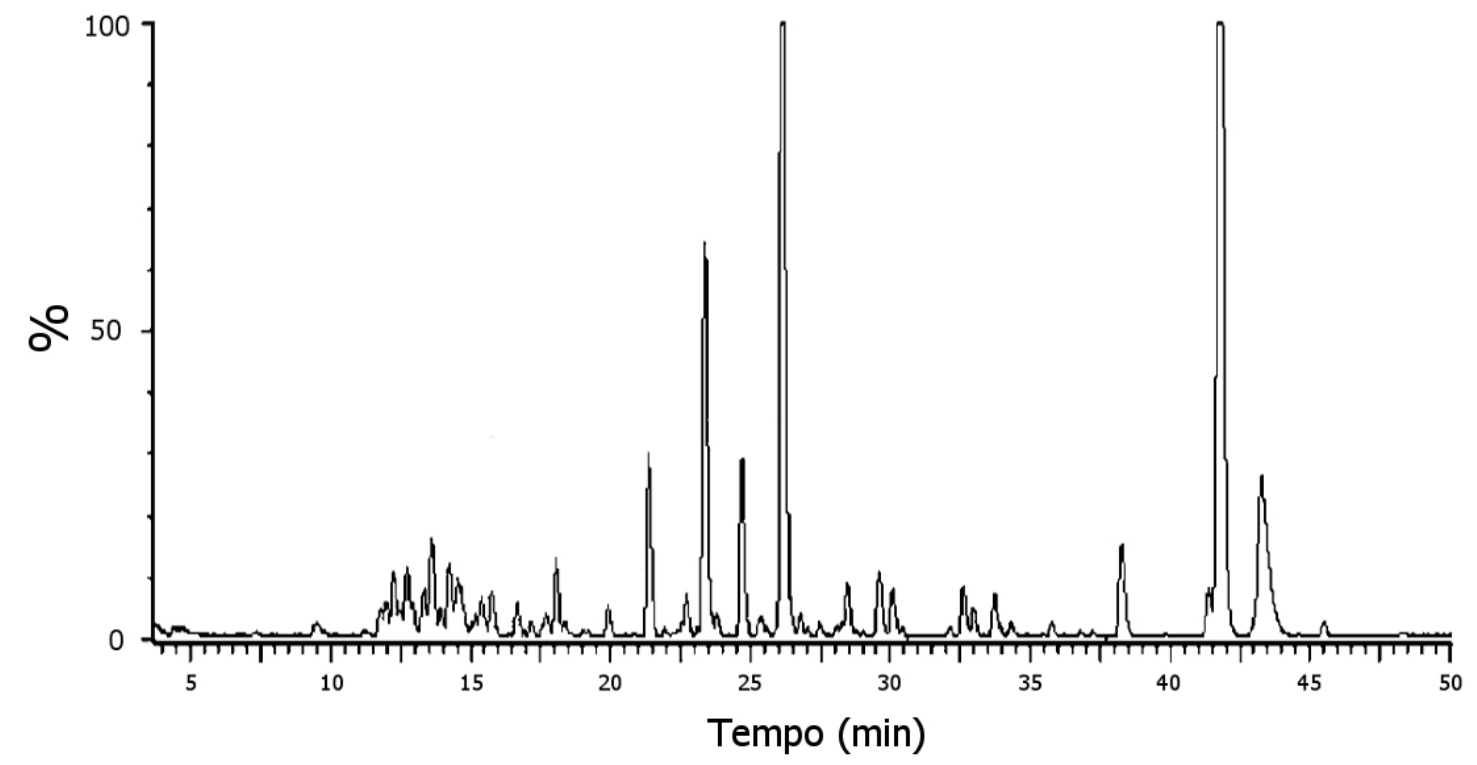

Dentre as técnicas utilizadas, a espectroscopia de Ressonância Magnética Nuclear tem sido uma das mais escolhidas, a despeito da menor sensibilidade, tendo se mostrado eficiente nos estudos de metabolomas. Isso se deve ao fato de que, com um único espectro, uma grande quantidade de informação é gerada, como mostrado na Figura 8. É possível notar sinais bem distintos para diversos metabólitos, como hipurato, taurina, creatinina, alantoína, ureia e citrato, entre outros.

Figura 8 - Espectro de $\mathrm{RMN}{ }^{1} \mathrm{H}$ a $600 \mathrm{MHz}$ de urina de rato, mostrando os sinais de inúmeros metabólitos. Este tipo de espectro é útil no estabelecimento de perfis metabólicos para diversos organismos. (Fonte: adaptado de Nature Protocols $)^{35}$ 


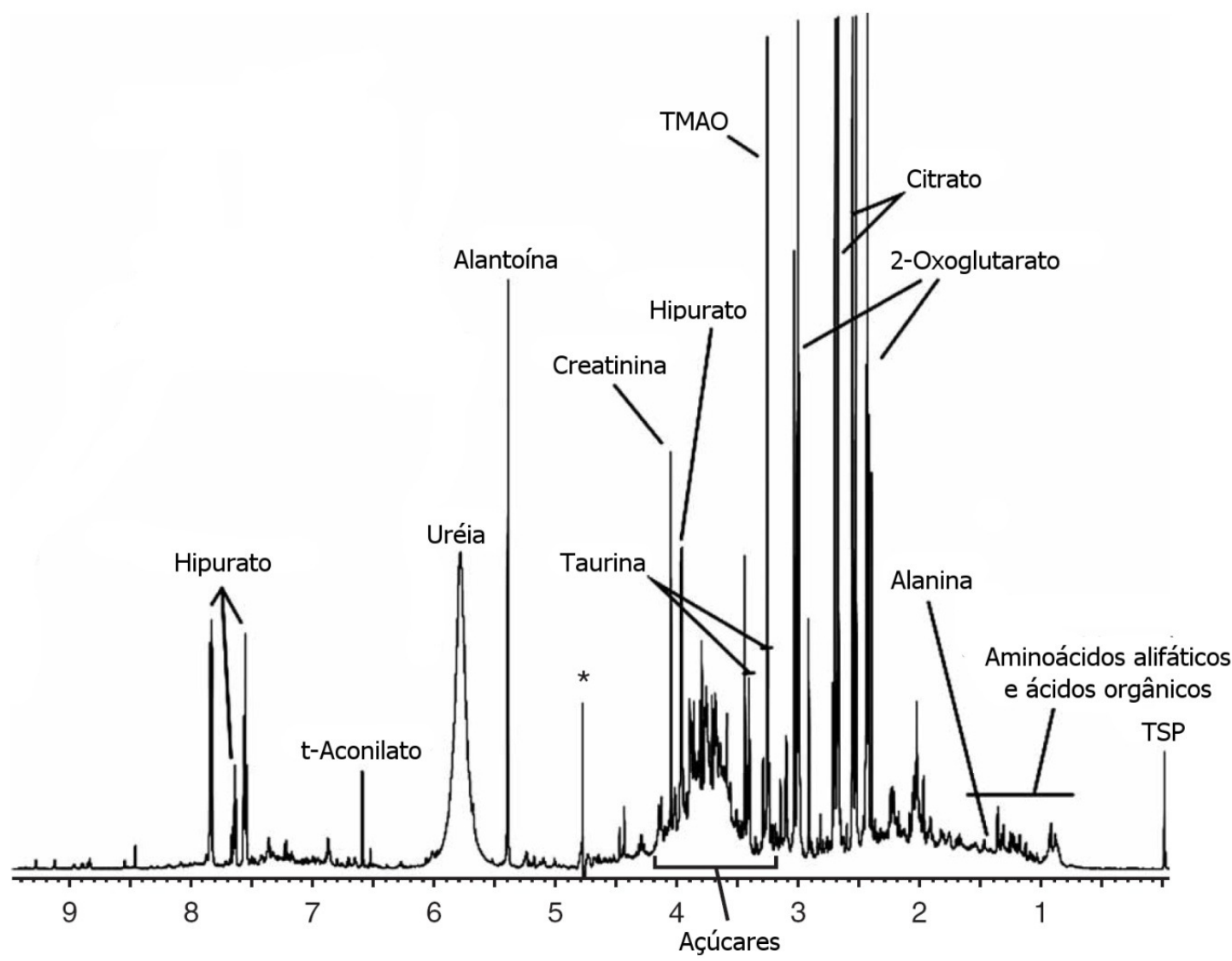

Além de ter a robustez e eficácia na geração da informação metabólica, a RMN tem as características de requerer uma pouca quantidade de amostra, (da ordem de $\mu \mathrm{L}$ para amostras líquidas) e empregar volumes consideravelmente menores de solvente, quando comparada à cromatografia, por exemplo. Além disso, quando se trata de amostras biológicas, o solvente original presente na amostra é água, permitindo que a análise seja conduzida em água deuterada $\left(\mathrm{D}_{2} \mathrm{O}\right)$. Com a atual conscientização mundial a respeito da preservação do meio ambiente, a não utilização de solventes orgânicos, sempre que possível, torna este aspecto da RMN um de seus pontos mais favoráveis. Finalmente, dentre todas as técnicas citadas, é a única que não destrói a amostra durante a análise, além de não necessitar, ou necessitar raramente do uso de um padrão interno.

Sua grande desvantagem em relação às técnicas mais comuns é a sensibilidade, que invariavelmente leva a tempos de análise 
excessivamente longos, principalmente para isótopos como ${ }^{13} \mathrm{C}$ e ${ }^{31} \mathrm{P}$. Isso faz necessário o acúmulo de muitos espectros, tornando a RMN pouco competitiva. Assim, para mudar este quadro, torna-se imprescindível o desenvolvimento de uma técnica mais rápida para análise de núcleos pouco sensíveis. Com o uso da técnica de Ressonância Magnética Nuclear de Precessão Livre no Estado Estacionário (SSFP) para análise metabolômica, espera-se que a informação seja gerada num espaço de tempo mais curto, aumentando a aplicabilidade da RMN.

\subsection{Ivermectina}

Avermectinas são moléculas derivadas de lactonas macrocíclicas, largamente empregadas atualmente em veterinária e criação de gado para corte graças à sua reconhecida atividade como anti-helmíntico de largo espectro, bem como por sua eficácia no controle de pragas externas, principalmente artrópodes (piolhos e carrapatos). Além da Ivermectina, majoritariamente empregada, outras avermectinas também são comuns para tais fins, como a Abamectina (ambas mostradas na Figura 9), e a Doramectina, e a Moxidectina (não mostradas). ${ }^{52}$

Figura 9 - Estruturas químicas da Abamectina e Ivermectina.

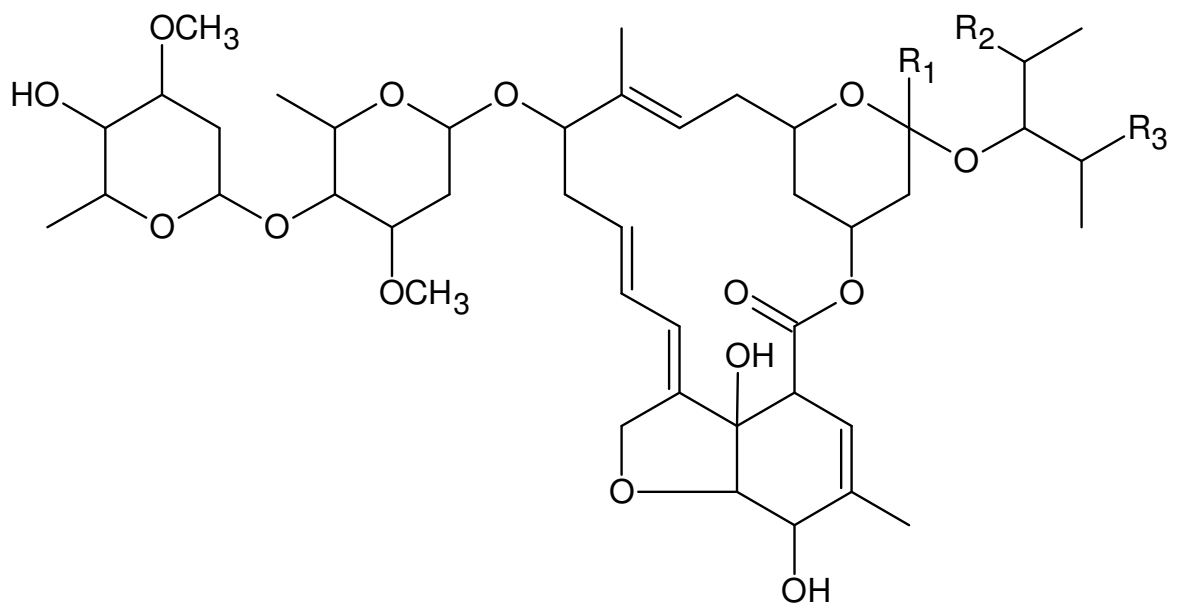




$$
\begin{array}{ll}
\text { Abamectina B1a: } \mathrm{R}_{1} \mathrm{R}_{2}=-\mathrm{CH}=\mathrm{CH}- & \mathrm{R}_{3}=\mathrm{C}_{2} \mathrm{H}_{5} \\
\text { Abamectina B1b: } \mathrm{R}_{1} \mathrm{R}_{2}=-\mathrm{CH}=\mathrm{CH}- & \mathrm{R}_{3}=\mathrm{CH}_{3} \\
\text { Ivermectina H2B1a: } \mathrm{R}_{1} \mathrm{R}_{2}=-\mathrm{CH}_{2}-\mathrm{CH}_{2} & \mathrm{R}_{3}=\mathrm{C}_{2} \mathrm{H}_{5} \\
\text { Ivermectina H2B1b: } \mathrm{R}_{1} \mathrm{R}_{2}=-\mathrm{CH}_{2}-\mathrm{CH}_{2} & \mathrm{R}_{3}=\mathrm{CH}_{3}
\end{array}
$$

No Brasil, onde a bovinocultura movimenta bilhões de reais por ano, a Ivermectina, comercializada sob vários nomes, é o fármaco de escolha no tratamento de verminoses em animais de corte, além de possuir também aplicação em humanos. Contudo, sob esta alta demanda, aliada a uma fiscalização precária por parte das autoridades de vigilância sanitária e inspeção de alimentos, é inevitável que violações ocorram, como o ocorrido em Maio/Junho de 2010 (Figura 10), com a devolução de toneladas de carne bovina brasileira pelos EUA e Rússia, após a constatação de contaminação por traços de Ivermectina, levando a um prejuízo econômico bastante alto, além de impactar a imagem do país como exportador de produtos derivados de bovinos. Neste contexto, vale destacar que dentre todas as irregularidades observadas no uso de avermectinas, a Ivermectina responde por mais de $70 \%$ dos casos. ${ }^{53}$

FIGURA 10 - Notícia veiculada pela agência Reuthers em maio de 2010, sobre a interrupção nas exportações de carne da JBS para os EUA. (Fonte: Reuters) ${ }^{54}$

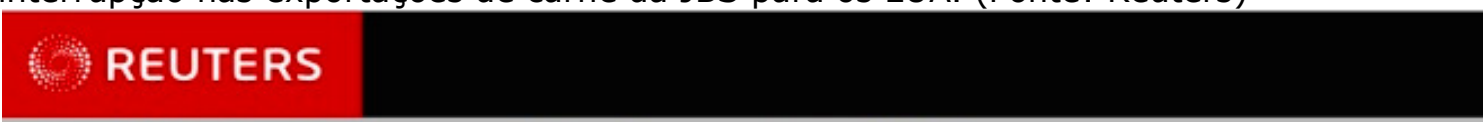

Brazil JBS plant stops Beef exports to U.S.

Fri, May 212010

SAO PAULO, May 21 (Reuters) - The world's largest beef processor, Brazil's JBS (JBSS3.SA: Quote, Profile, Research, Stock Buzz), said exports to the United States from one of its plants had stopped after U.S authorities detected fraces of medicine in its meat above permitted levels.

JBS said in a filing late on Thurs day the meat processed at the Li $\sigma$ plant in Sao aulo state was being recalled and the unit would not make further shipments to the U.S. until it was determined how meat with exc (ss Ivermectin, a) rmifuge or medicine that expels intestinal worms, entered the supply. It said it had been intormed of the problem by the Brazilian Agricul re leinistry

The company said its other plants would serve the U.S. market while it investigates, making the financial impact on the firm negligible, adding that produce from the Lins plant would continue to serve other markets. (Reporting by Bruno Marfinati; Writing by Peter Murphy; Editing by Jon Loades-Carter)

๑ Thomson Reuters 2010. All rights reserved. Users may download and print extracts of content from this website for their own personal and non-commercial use only. Republication or redistribution of Thomson Reuters content, induding by framing or similar means, is expressly prohibited without the prior written consent of Thomson Reuters. Thomson Reuters and its logo are registered trademarks or trademarks of the Thomson Reuters group of companies around the world.

Thomson Reuters journalists are subject to an Editorial Handbook which requires fair presentation and disclosure of relevant interests. 
Estas violações ocorrem por diversas razões, sobretudo pelo uso de doses excessivas do medicamento e principalmente a não-observação do período de carência (tempo entre a medicação e o abate) apropriado, que no caso de bovinos é de 35 dias (25 para caprinos e ovinos e 18 para suínos. A Ivermectina não é recomendada para uso em vacas leiteiras)..$^{55}$ Este tipo de conduta reflete diretamente na contaminação da carne por quantidades de Ivermectina muito acima das permitidas pelas legislações internacionais. Nos EUA, onde as leis de inspeção de alimentos são particularmente rigorosas, o ocorrido levou não só ao veto das exportações, mas também ao questionamento do Brasil e sua capacidade de manter a qualidade exigida internacionalmente. Frases como a publicada no site Common Dreams: "Há fármacos veterinários brasileiros em sua carne enlatada?" ${ }^{\prime 56}$ em 17 de junho de 2010, geram alarme e desconfiança por parte dos consumidores, mostrando que além do impacto econômico direto, pode haver efeitos colaterais agravantes, levando os mercados importadores da carne brasileira a reavaliar esta relação econômica.

Isso se deve ao fato de que no organismo humano, a Ivermectina pode apresentar uma série de efeitos indesejados, como dores nas juntas, dores de cabeça, apatia e em altas concentrações, ataxia. ${ }^{57}$

Nos vermes e artrópodes, a Ivermectina tem seu meio de ação baseado na ativação dos canais de cloro mediados por glutamato, ${ }^{44,52,58}$ levando os parasitas à morte por paralisia tônica muscular. Por ser pouco permeável à barreira hematoencefálica, ${ }^{59}$ os efeitos da Ivermectina no sistema nervoso central de animais são associados à sua interferência com os receptores de GABA (ácido $\gamma$-aminobutírico), ${ }^{60-61}$ levando então aos sintomas descritos.

Pelo seu contexto no cenário da pecuária brasileira, bem como por ser um fármaco de fácil acesso para experimentação, a Ivermectina foi escolhida neste trabalho como agente responsável para possíveis induções no metabolismo de bovinos, a fim de se avaliar a utilização da RMN para este tipo de análise. 


\subsection{Aplicação da Informação Gerada}

Evidentemente, no atual cenário da bioquímica, as análises metabolômicas têm tido um impacto crescente sobre a pesquisa cientifica, aliando técnicas robustas a métodos de alta reprodutibilidade. Com os futuros avanços das técnicas analíticas, será possível uma melhor interpretação dos dados obtidos, permitindo, portanto uma maior compreensão do funcionamento de um organismo complexo como o humano, através da integração entre Transcriptoma, Proteoma e Metaboloma. ${ }^{62}$

A informação gerada pelas análises de metabólitos por RMN pode ser empregada na construção de bases de dados, na forma de perfis metabólicos, contendo informações essenciais sobre os níveis de metabólitos normais nos mais diferentes tecidos. Este conjunto de dados é útil, pela quantidade de informação contida, para a construção de modelos que permitem, através do emprego ferramentas multivariadas de análise, ${ }^{25,37,38,47,50,63,64}$ identificar desordens resultantes de alterações na dieta, administração irregular de fármacos, stress em geral e doenças parasitárias e metabólicas. Todo este panorama ilustra claramente a importância da RMN para o desenvolvimento e progresso da pesquisa metabolômica/metabonômica, tornando-se uma poderosa ferramenta para a construção de um novo método, eficaz, seguro e robusto de análise médica e veterinária. 


\section{OBJETIVOS}

O objetivo principal desta tese de doutorado é a investigação do uso de ferramentas analíticas convencionais de $\operatorname{RMN}\left({ }^{1} \mathrm{H} \mathrm{e}{ }^{13} \mathrm{C}\right)$ para deteç̧ão de variações metabólicas em bovinos e camundongos após tratamento com Ivermectina, bem como o uso da técnica de Precessão Livre no Estado Estacionário (SSFP), como forma de aquisição rápida para dados de ${ }^{13} \mathrm{C}$, avaliando seu uso como ferramenta auxiliar no processo de levantamento do perfil metabólico de mamíferos, através das seguintes metas específicas:

- Estabelecimento de um protocolo confiável para o tratamento/processamento das amostras biológicas provenientes de bovinos, e posteriormente de camundongos;

- Análise das amostras obtidas por RMN de ${ }^{1} \mathrm{H}$ convencional, com a correspondente escolha da técnica adequada;

- Análise por RMN de ${ }^{13} \mathrm{C}$, realizando a comparação entre as técnicas convencional e SSFP;

- Tratamento dos dados de RMN-SSFP apropriado às distorções de fase encontradas;

- Utilização dos dados de $\mathrm{RMN}-{ }^{1} \mathrm{H}$ na construção de modelos quimiométricos;

- Caracterização dos metabólitos presentes nas amostras estudadas, através do uso de bases de dados e experimentos bidimensionais. 


\section{MATERIAIS E MÉTODOS}

Para os experimentos realizados durante este projeto de doutoramento, optou-se por estudar inicialmente amostras de plasma sanguíneo e urina bovinos, além de haver a possibilidade da integração posterior de análises de leite.

Todas as amostras foram cedidas pela Embrapa Pecuária Sudeste, e analisadas na Embrapa Instrumentação, ambas localizadas em São Carlos - SP. Os animais doadores foram novilhos da raça Holstein-Frísia, também conhecida por Holandês Preto-e-Branco (Figura 11), saudáveis, tratados com Ivermectina subcutânea $4 \%$ na dose (terapêutica) de $1 \mathrm{~mL} / 50 \mathrm{Kg}$.

Figura 11 - Bezerro da raça Holandês Holstein-Frísia.

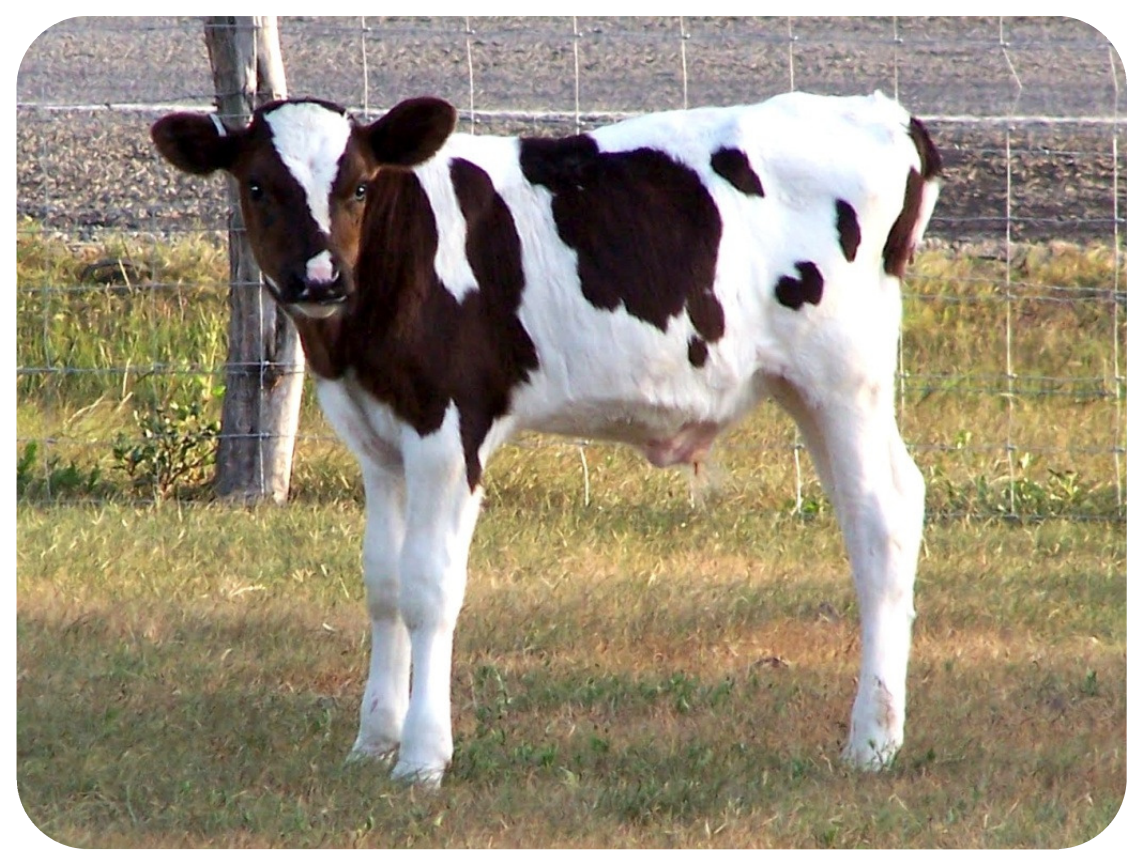

\subsection{Tratamento dos Animais}

A fim de se provocar mudanças no metabolismo animal, e procurar acompanhá-las por um período de tempo, os animais medicados tiveram suas amostras de sangue e urina coletadas imediatamente antes da 
aplicação de Ivermectina (tempo 0), e duas coletas após a administração, em 3 e $6 h$.

As mudanças observadas com a aplicação de uma única dose terapêutica, contudo foram pouco significativas para os modelos de análise exploratória. Assim sugeriu-se que, no lugar de uma única dose, os animais recebessem duas doses terapêuticas separadas por um intervalo de $24 \mathrm{~h}$ e somente o plasma sanguíneo foi estudado. As coletas foram feitas imediatamente antes de cada aplicação de Ivermectina, após $3 \mathrm{~h}$ e após $6 \mathrm{~h}$ das mesmas, em $0 \mathrm{~h}, 3 \mathrm{~h}, 6 \mathrm{~h}, 24 \mathrm{~h}, 27 \mathrm{~h}$ e $30 \mathrm{~h}$, como mostra a Figura 12.

Figura 12 - Diagrama da coleta de plasma sanguíneo para análise por RMN.

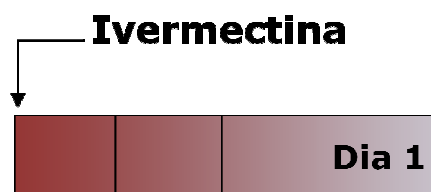

Oh $3 h \quad 6 h$

\section{Ivermectina}

Este formato de tratamento tem por finalidade acentuar as alterações causadas pela administração da Ivermectina, visto que em estudos anteriores, a mudança causada por uma única dose de Ivermectina não foi suficiente para separar as amostras nos estudos quimiométricos. Este tratamento foi proposto por nosso grupo com o auxílio de um veterinário de forma a não prejudicar a saúde destes animais.

\subsection{Preparação das Amostras}

Devido ao caráter não-estéril das amostras de urina, o principal passo do tratamento das amostras consiste na centrifugação e filtração das mesmas. A primeira tem por objetivo remover partículas sólidas, como possíveis precipitados e resíduos de pelo animal que frequentemente são levados para dentro do tubo durante a coleta. A 
última, feita em membrana sintética porosa, com diâmetro de poro de $0,45 \mu \mathrm{m}$, elimina bactérias e fungos presentes, que podem proliferar-se e contaminar a amostra. Já as amostras de plasma, devido à sua esterilidade natural, necessitam menos tratamento em relação às amostras de urina, sendo o processamento da amostra mais breve.

Durante os experimentos iniciais, notou-se que os espectros de RMN obtidos eram de baixa qualidade, mostrando poucos sinais. Atribuindo-se este fator à baixa concentração das amostras, optou-se por realizar a liofilização total das amostras, com dois objetivos agregados: retirando a água da amostra, a concentração dos metabólitos presentes poderia ser posteriormente elevada pela ressuspensão do extrato em um volume de água menor que o original, além de permitir o acondicionamento mais seguro da amostra, uma vez que o meio seco dificulta a proliferação de bactérias e fungos.

Contudo, este procedimento é bastante trabalhoso, uma vez que necessita do congelamento total, e posterior permanência durante cerca de $16 \mathrm{~h}$ para total secagem das amostras. Após este processo, as mesmas são ressuspendidas em $\mathrm{D}_{2} \mathrm{O} 20 \%$. A liofilização completa levou apenas a uma ligeira melhora na qualidade dos espectros obtidos, incentivando a adaptação do protocolo a um outro procedimento.

Assim, utilizando-se uma centrífuga SpeedVac (Thermo Fisher Scientific Inc., modelo SC210A), foi possível a realização de uma liofilização apenas parcial das amostras in natura, aplicando-se a rotação padrão do equipamento e à temperatura ambiente, dispensando o congelamento prévio e garantindo o aumento da concentração dos componentes presentes.

Posteriormente, são adicionados outros componentes às amostras, preparando-as para análise:

- Tampão fosfato de sódio $\left(\mathrm{K}_{2} \mathrm{HPO}_{3} / \mathrm{KH}_{2} \mathrm{PO}_{3}\right) 100 \mathrm{mM}(\mathrm{pH} 7,4$ para plasma, pH 8,0 para urina) ${ }^{35}$

- Ácido 2,2-dimetil-2-silapentano-5-sulfônico (DSS) $1,7 \mathrm{mg} / \mathrm{mL}$ 
Somente para a urina, além destes acrescenta-se azida sódica $\left(\mathrm{NaN}_{3}\right)$ a $3 \mathrm{mM}^{35}$ que tem por finalidade esterilizar a solução, evitando a contaminação bacteriana/fúngica após a preparação. Sua presença na solução não interfere na análise de RMN, sendo um bactericida largamente empregado em análises biológicas. O tampão fosfato tem a função de estabilizar o pH da solução sendo este um aspecto importante na análise de RMN de ${ }^{1} \mathrm{H}$. O DSS fornece o sinal de referência $(0 \mathrm{ppm})$ para soluções em água, analogamente ao TMS (tetrametilsilano).

\subsection{Análises de Ressonância Magnética Nuclear}

As análises de RMN realizadas neste trabalho foram conduzidas em um espectrômetro com ímã Oxford de 9,4 T e 53 mm de bore, operado com um console Varian INOVA 400. Este ímã fornece frequências de 400 $\mathrm{MHz}$ e $100,3 \mathrm{MHz}$ para ${ }^{1} \mathrm{H}$ e ${ }^{13} \mathrm{C}$ respectivamente. Foi empregada uma sonda para líquidos, que emprega tubos de $5 \mathrm{~mm}$ onde no mínimo $500 \mu \mathrm{L}$ de amostra são inseridos, e durante as análises, mantidas à temperatura ambiente, os mesmos foram submetidos à rotação de $28 \mathrm{~Hz}$. A sintonia e shimming (ajuste de homogeneidade de campo) foram feitos manualmente, utilizando-se ganho de sinal automático durante os experimentos. O software que comanda o console é o VNMRj (Varian, Inc.), operando em plataforma Linux versão RedHat.

Para a análise dos espectros obtidos foi empregado o ACD NMR Processor versão 12.0, disponível em nossos laboratórios. As análises gráficas foram conduzidas no programa Origin 8.0.

\subsubsection{RMN de ${ }^{1} \mathrm{H}$}

As análises de $\mathrm{RMN}-{ }^{1} \mathrm{H}$ foram inicialmente conduzidas utilizando-se uma sequência padrão, contida na biblioteca Varian, a qual emprega um único pulso de $6,8 \mu$ s de largura. Este pulso provoca uma deflexão de $90^{\circ}$ 
na magnetização do núcleo de hidrogênio na potência escolhida. A sequência padrão é ilustrada na Figura 13.

Figura 13 - Sequência padrão convencional para ${ }^{1} \mathrm{H}$, composta por um tempo de espera (delay time), pulso e tempo de aquisição.

Delay

Time

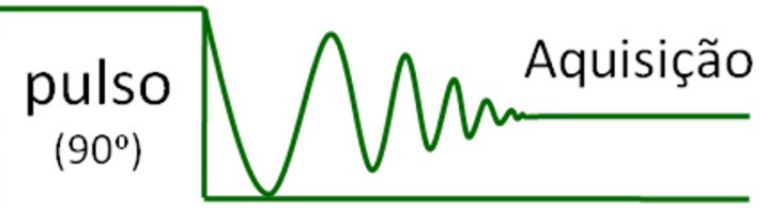

Contudo, por se tratar de amostras biológicas, há uma grande interferência por parte do sinal da água (região de 4,8 ppm). Isso torna necessária a utilização de uma técnica de supressão deste sinal, que é cerca de 1000 vezes mais intenso que os sinais dos metabólitos contidos na amostra, como ilustra a Figura 14.

Figura 14 - Espectro de $R M N$ de ${ }^{1} \mathrm{H}$ de uma amostra biológica sem a devida supressão do sinal da água $(4,8 \mathrm{ppm})$. O único pico visível encobre os demais sinais, menos intensos, prejudicando a leitura. Abaixo, ampliação de 1000 vezes da região mostrada.

(continua)

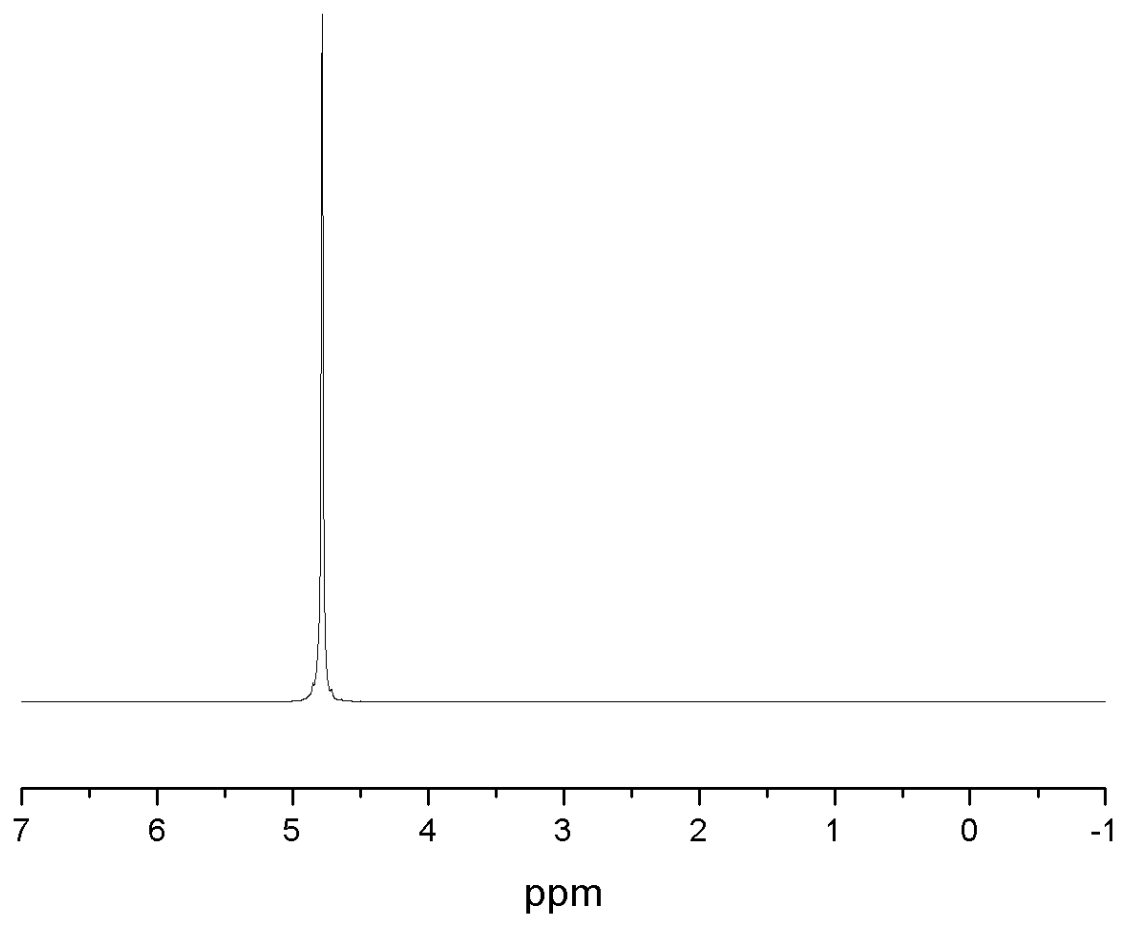


Figura 14 - Espectro de $\mathrm{RMN}$ de ${ }^{1} \mathrm{H}$ de uma amostra biológica sem a devida supressão do sinal da água $(4,8 \mathrm{ppm})$. O único pico visível encobre os demais sinais, menos intensos, prejudicando a leitura. Abaixo, ampliação de 1000 vezes da região mostrada.

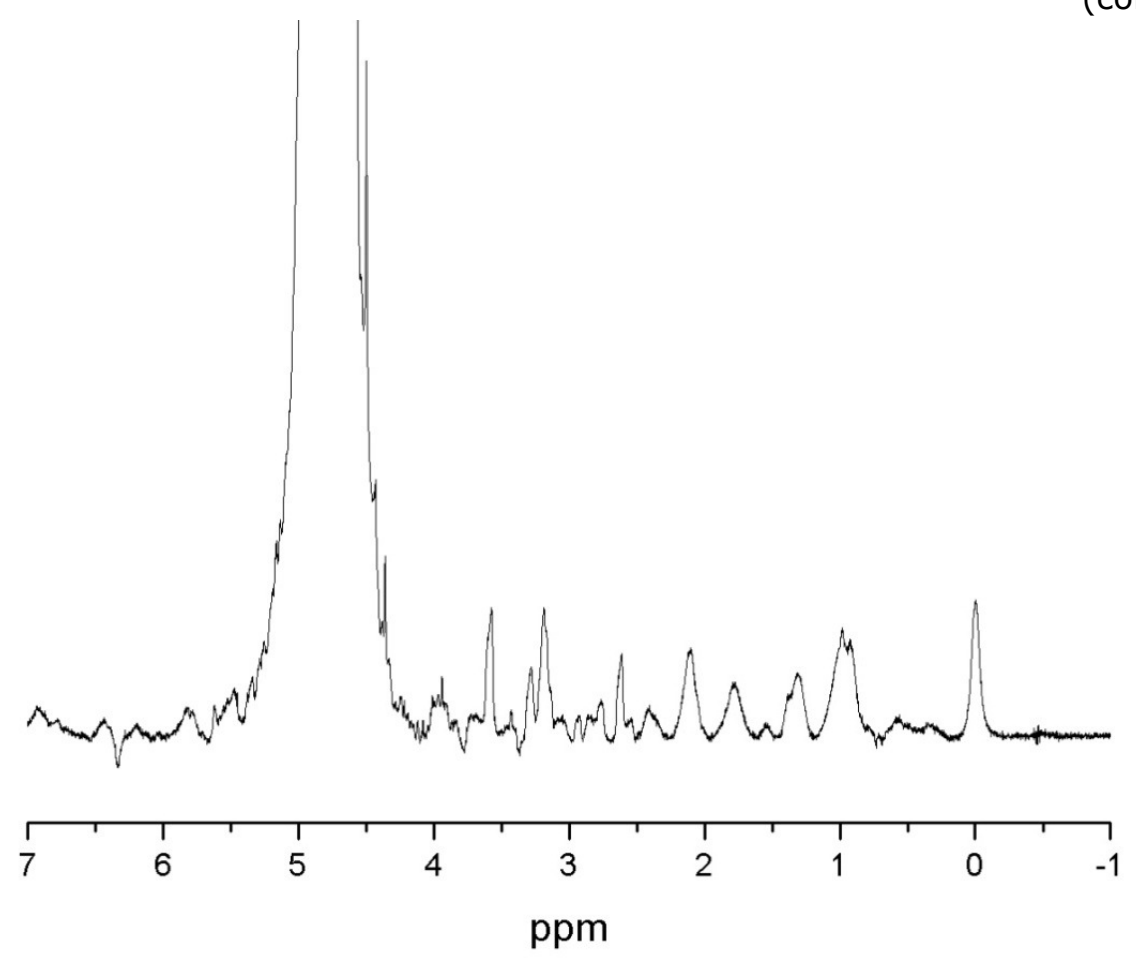

(conclusão)

\subsubsection{Supressão do Sinal da Água}

\subsection{Jump-Return}

A técnica jump-return ${ }^{65-67}$ consiste na aplicação de uma sequência de 2 pulsos de $90^{\circ}$ separados por um intervalo de tempo $\tau$ e deve-se colocar o sinal que se deseja suprimir em condição de ressonância, neste caso a água. Os pulsos são aplicados nas direções $x$ e $-x$, respectivamente. O primeiro pulso $\left(90^{\circ}\right)$ tem por finalidade deslocar a magnetização total para o plano $x y$ (Figura 15, a). Após o intervalo de tempo $\tau$, há uma defasagem dos demais sinais presentes em relação ao da água, devido às diferentes frequências de precessão (Figura 15, b). Decorrido este tempo, o pulso de $90^{\circ}$-x desloca toda a magnetização para o plano $x z$ (Figura 15, c). Uma vez que se encontra em offset, o sinal da água será deslocado exatamente para cima do eixo $z$, não gerando, em 
teoria, uma resultante em $x^{\prime} y^{\prime}$. Na prática, o que se observa é uma redução considerável (cerca de 400 vezes) na magnitude do sinal.

Figura 15 - Distribuição vetorial das magnetizações durante a aplicação da técnica jump-return e sequência de pulsos empregada. Inicialmente, um pulso de $90^{\circ}$ desloca a magnetização para o plano $x y$, analogamente à técnica de $\mathrm{RMN}-{ }^{1} \mathrm{H}$ convencional (a). Após decorrido um tempo $\tau$, as magnetizações individuais deslocam-se de acordo com a sua frequência, adiantando-se ou atrasando-se em relação ao sinal da água em offset (b). Finalmente, um pulso de $90^{\circ}{ }_{-x}$ desloca todos os vetores para o plano $x z$, fazendo com que o sinal inicialmente em offset seja alinhado com o eixo $z$, não restando componente $x y$ do mesmo, eliminando0 .
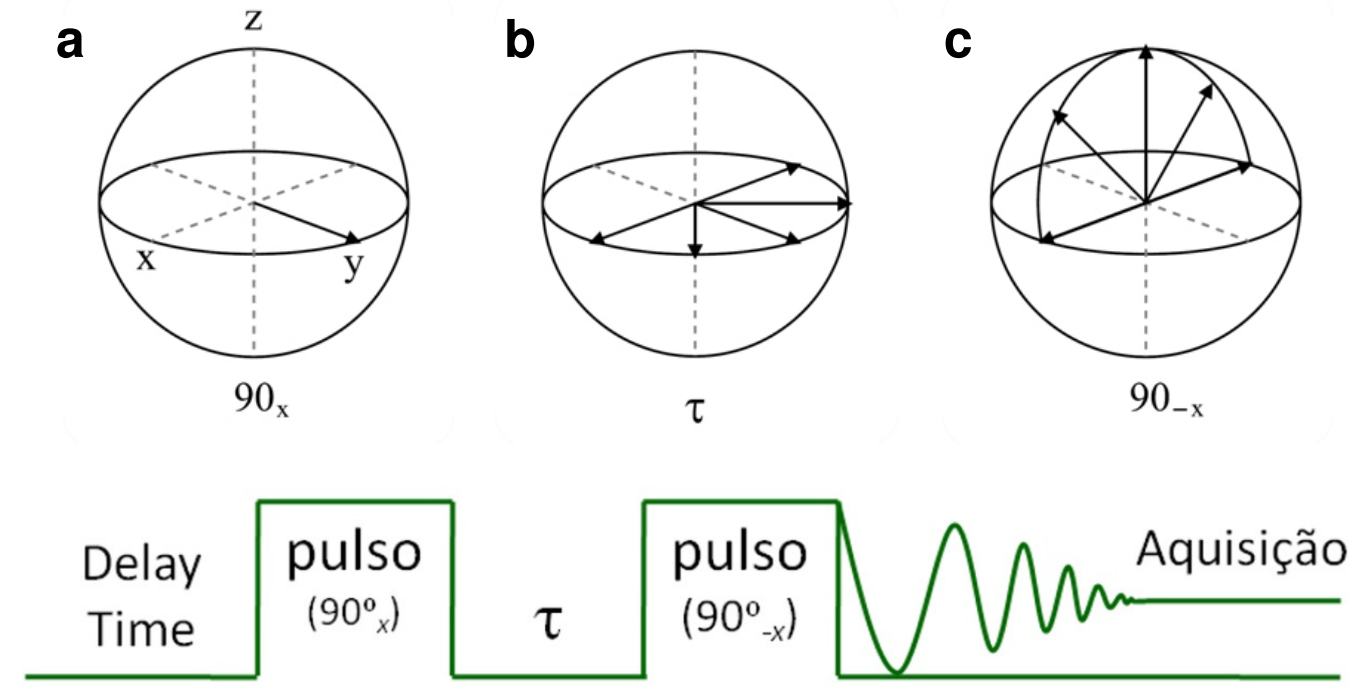

Os principais inconvenientes da técnica jump-return são: i) como na maioria das técnicas de supressão, observa-se uma distorção no espectro na região do sinal suprimido, além de haver a perda de informação caso algum analito apresente um sinal sob, ou muito próximo do da água; e ii) quando o pulso de $90^{\circ}$ é aplicado, os sinais com frequência maior que a da água são deslocados para a região negativa na direção $x$, o que faz com que os sinais que apresentam deslocamentos químicos maiores que a água apareçam invertidos em relação àqueles que possuem deslocamentos químicos menores. Este problema, no entanto, pode ser corrigido de maneira 
simples, pela inversão do sinal de todos os pontos correspondentes à esta parte do gráfico.

\subsection{Pré-Saturação (PRESAT) ${ }^{35}$}

Por suas limitações técnicas, o método jump-return, empregado inicialmente, foi descartado, uma vez que após a melhora na qualidade espectral decorrente do tratamento das amostras, a técnica PreSat mostrou-se mais eficiente. Mesmo resultando em supressões colaterais indesejadas como hidrogênios de grupos $\mathrm{OH}$ e $\mathrm{NH}$ (pela troca destes com átomos de deutério provenientes da água), a pré-saturação proporcionou uma supressão satisfatória, sem contudo causar distorções nos espectros, como a inversão de fase dos sinais, além de empregar uma sequência de pulsos mais curta, resultando em menor tempo de análise.

Na técnica PreSat, um pulso contínuo é mantido ligado na frequência que se deseja suprimir, saturando-o. Durante a aquisição, este sinal leva um tempo consideravelmente mais longo para retornar ao estado relaxado, e assim, seu sinal é eliminado do espectro. O diagrama que ilustra a sequência de pulsos utilizados na técnica PreSat é mostrado na Figura 16.

Figura 16 - Representação da sequência de pulsos empregada na técnica PreSat. Enquanto a aquisição emprega pulsos e intervalos convencionais, uma frequência contínua adicional é mantida em irradiação sobre o núcleo a ser suprimido, impedindo que o mesmo entre em processo de relaxação.

Saturação

Aquisição
Pulso Contínuo 
Todos os espectros mostrados foram adquiridos a partir da sequência descrita, somando-se para cada experimento 32 médias, e mantendo-se a amostra sob constante giro, a uma frequência de $28 \mathrm{~Hz}$, o que garante uma melhor resolução espectral. Nenhuma apodização foi utilizada para os espectros de ${ }^{1} \mathrm{H}$, sendo a fase ajustada manualmente e o ajuste de linha de base feito pelo método de reconstrução do FID, disponível no software ACD 12.0. Outro fator importante é o número de pontos contidos em cada espectro, valor este que deve ser constante, dada a intenção de se realizar análises quimiométricas posteriormente. Todos os espectros de RMN $-{ }^{1} \mathrm{H}$ para bovinos foram adquiridos com $8192 \mathrm{e}$ processados com 16384 pontos.

\subsubsection{RMN de ${ }^{13} \mathrm{C}$}

\subsubsection{Técnica Convencional}

As análises de ${ }^{13} \mathrm{C}$ foram conduzidas inicialmente, empregando-se uma sequência convencional padrão, com a finalidade de se comparar a mesma à técnica de precessão livre no estado estacionário (SSFP), foco deste trabalho. A sequência de análise empregada consiste de um único pulso de largura 4,7 $\mu \mathrm{s}$, que provoca uma deflexão de $30^{\circ}$ na magnetização dos núcleos de ${ }^{13} \mathrm{C}$, seguido do tempo de aquisição. ${ }^{11} \mathrm{O}$ pulso de $30^{\circ}$ é utilizado em vez do pulso de $90^{\circ}$, em virtude de o tempo de relaxação do carbono ser consideravelmente mais longo que o do hidrogênio, permitindo assim um tempo de repetição menor entre os pulsos. Antes do pulso, um tempo de espera (delay time) é empregado para que o sistema atinja o equilíbrio térmico. Ao mesmo tempo, é aplicada uma radiação ininterrupta na frequência do ${ }^{1} \mathrm{H}$, a fim de se eliminar o acoplamento carbono-hidrogênio. A sequência empregada na análise de ${ }^{13} \mathrm{C}$ é ilustrada na Figura 17. 
Figura 17 -Sequência padrão para análise de ${ }^{13} \mathrm{C}$, com pulso de $30^{\circ}$.

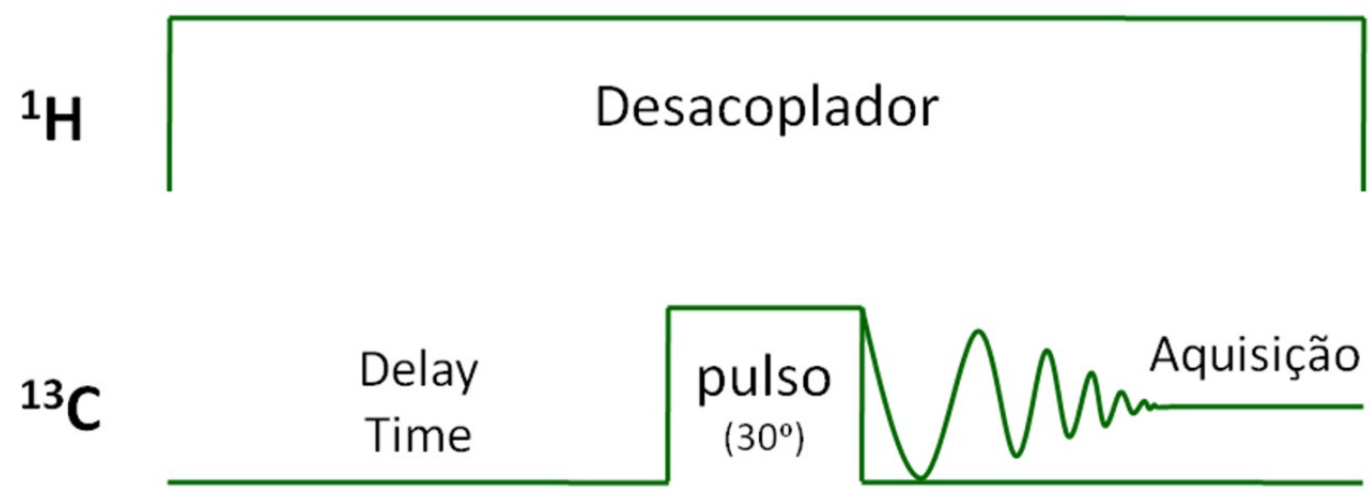

Devido à baixa abundância do núcleo de ${ }^{13} \mathrm{C}$ na amostra, é necessário que se faça um acúmulo consideravelmente maior de médias para se obter uma boa razão sinal ruído, que permita a caracterização de picos. Isso invariavelmente leva a um tempo de análise mais longo, muitas vezes uma relação custo-benefício desfavorável.

\subsubsection{Steady-State Free Precession (SSFP)}

Tendo em vista que as informações obtidas através do espectro de ${ }^{13} \mathrm{C}$ são complementares às obtidas com a espectroscopia de ${ }^{1} \mathrm{H}$, torna-se interessante desenvolver um método de análise de carbono que seja ao mesmo tempo mais rápido e com a mesma quantidade de informações que o método convencional. A fim de se satisfazer este propósito, a técnica SSFP pode representar um ganho de tempo considerável aliado à obtenção de informações importantes para a elucidação metabólica de espectros de RMN.

A sequência SSFP é bastante similar à sequência convencional, no que diz respeito à sua estrutura (pulso único), diferindo apenas nos tempos de espera e aquisição. A Tabela 3 mostra a comparação entre a sequência de pulsos convencional ${ }^{22}$ e a sequência SSFP para aquisição de espectros de ${ }^{13} \mathrm{C}$. 
Tabela 3 - Comparação entre os parâmetros das sequências de pulsos convencional e SSFP para a aquisição de espectros de ${ }^{13} \mathrm{C}$, para um período de aquisição de 3 horas.

\begin{tabular}{ccc}
\hline Parâmetro & Técnica Convencional $^{\mathbf{6 8}}$ & SSFP \\
\hline Delay time & $900 \mathrm{~ms}$ & $50 \mathrm{~ms}$ \\
Tempo de pulso, $30^{\circ}$ & $6,0 \mu \mathrm{s}$ & $6,0 \mu \mathrm{s}$ \\
Tempo de aquisição & $480 \mathrm{~ms}$ & $100 \mu \mathrm{s}$ \\
No. de médias obtidas & 8192 & $\approx 250.000$ \\
\hline
\end{tabular}

Como é claramente notado, a técnica SSFP permite, em um mesmo intervalo de tempo, um número de médias consideravelmente maior em relação á técnica convencional, representando um interessante ganho de tempo, viabilizando assim a utilização em larga escala da espectroscopia de ${ }^{13} \mathrm{C}$ para a aquisição de dados.

\subsubsection{RMN Bidimensional}

Adicionalmente, foram feitos espectros bidimensionais para algumas amostras de plasma sanguíneo de camundongo (experimento descrito a seguir), a fim de se facilitar a caracterização dos metabólitos presentes, empregando-se as seqüências COSY (COrrelation SpectroscopY), técnica homonuclear que permite a verificação de acoplamentos diretos entre hidrogênios em grupos vizinhos, HSQC (Heteronuclear Single-Quantum Correlation Spectroscopy), que possibilita a análise de acoplamentos entre ${ }^{1} \mathrm{H}$ e ${ }^{13} \mathrm{C}$ ligados entre si, e HMBC (Heteronuclear Multiple Bond Correlation Spectroscopy), utilizada para verificar acoplamentos entre ${ }^{1} \mathrm{H}$ e ${ }^{13} \mathrm{C}$ a longa distância (mais de uma ligação de separação). Estas análises foram conduzidas em um espectrômeto Bruker com campo de 11,75 T, que gera uma frequência de ressonância para o átomo de ${ }^{1} \mathrm{H}$ de $500 \mathrm{MHz}$, localizado no Departamento de Química da Universidade Federal de São Carlos.

\subsection{Estudos Quimiométricos}


Os estudos quimiométricos deste trabalho foram conduzidos através de duas ferramentas contidas no software Pirouette 4.0 (Infometrix, Inc.): a Análise de Componentes Principais (PCA, Principal Component Analysis), ${ }^{25,50,64}$ e Análise Hierárquica de Clusters (HCA, Hierarchical Cluster Analysis) que consistem na transformação ortogonal de um conjunto de variáveis possivelmente correlacionadas, como os pontos de um espectro de RMN, em um conjunto de valores linearmente nãocorrelacionados denominados componentes principais. Para realizar-se este estudo, todos os espectros coletados tiveram seus pontos visualizados em forma de uma tabela de dados, sendo que a região correspondente ao sinal da água foi excluída em todos, a fim de se evitar possíveis interferências nos cálculos. Isso se deve ao fato de que mesmo com a aplicação de uma técnica de supressão, existe um sinal residual presente, frequentemente maior que a maioria dos sinais de interesse. Portanto, todos os espectros adquiridos neste trabalho foram tratados, de forma que não possuem quaisquer sinais no intervalo de 4,0 a 4,8 ppm.

Os dados de RMN são inicialmente compostos por intensidades variáveis $(Y)$ como função de um parâmetro fixo (frequência, X). Na PCA, a transposição dos dados é necessária, para que cada frequência seja uma variável de entrada. A Figura 18 ilustra o aspecto geral dos dados originais de RMN e seu formato final, quando é submetido à análise de PCA. 
Figura 18 - Representação geral dos dados de RMN e sua preparação para a análise de PCA. Os dados são compostos por valores de intensidade relativos à frequência coberta pelo espectro (tabela superior). Após a transposição, os dados são compostos por intensidades relativas a cada animal, sendo os valores de frequência uma espécie de amostragem (tabela inferior). NOTA: valores da escala de frequência meramente ilustrativos.

\begin{tabular}{c|c|c|c}
\hline $\begin{array}{c}\text { Frequência } \\
\text { (ppm) }\end{array}$ & \multicolumn{3}{|c}{ Intensidade } \\
\cline { 2 - 4 } & Animal 1 & Animal 2 & Animal 3 \\
\hline $\mathbf{0 , 1}$ & $\mathrm{X}_{1}$ & $\mathrm{Y}_{1}$ & $\mathrm{Z}_{1}$ \\
\hline $\mathbf{0 , 2}$ & $\mathrm{X}_{2}$ & $\mathrm{Y}_{2}$ & $\mathrm{Z}_{2}$ \\
\hline $\mathbf{0 , 3}$ & $\mathrm{X}_{3}$ & $\mathrm{Y}_{3}$ & $\mathrm{Z}_{3}$ \\
\hline $\mathbf{0 , 4}$ & $\mathrm{X}_{4}$ & $\mathrm{Y}_{4}$ & $\mathrm{Z}_{4}$ \\
\hline $\mathbf{0 , 5}$ & $\mathrm{X}_{5}$ & $\mathrm{Y}_{5}$ & $\mathrm{Z}_{5}$ \\
\hline$\vdots$ & $\mathrm{X}_{6}$ & $\mathrm{Y}_{6}$ & $\mathrm{Z}_{6}$ \\
\hline & $\mathrm{X}_{\mathrm{n}}$ & $\mathrm{Y}_{\mathrm{n}}$ & $\mathrm{Z}_{\mathrm{n}}$ \\
\hline
\end{tabular}

\begin{tabular}{|c|c|c|c|c|c|c|c|c|}
\hline \multicolumn{2}{|c|}{$\begin{array}{l}\text { Frequência } \\
(\text { ppm) }\end{array}$} & 0 & 0,1 & 0,2 & 0,3 & 0,4 & 0,5 & ... \\
\hline \multirow{3}{*}{ 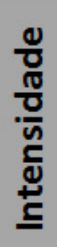 } & Animal 1 & $x_{1}$ & $x_{2}$ & $x_{3}$ & $X_{4}$ & $x_{5}$ & $x_{6}$ & $x_{n}$ \\
\hline & Animal2 & $Y_{1}$ & $Y_{2}$ & $Y_{3}$ & $Y_{4}$ & $Y_{5}$ & $Y_{6}$ & $Y_{n}$ \\
\hline & Animal3 & $z_{1}$ & $z_{2}$ & $z_{3}$ & $\mathrm{z}_{4}$ & $Z_{5}$ & $\mathrm{z}_{6}$ & $Z_{n}$ \\
\hline
\end{tabular}

Para que a análise de PCA seja bem sucedida, é fundamental que todos os espectros sejam coletados em condições padrão, especialmente no que diz respeito ao número de pontos, para que no momento da transposição, não haja variáveis (frequências) sem seu valor de entrada associado.

A seguir, os dados são normalizados, passo fundamental para que os dados possam ser comparados, já que as intensidades em RMN são dadas em unidades arbitrárias. Isso faz com que, muitas vezes, dois espectros da mesma amostra sejam completamente diferentes quando têm suas intensidades comparadas. Através da normalização pela área 
unitária, espectros antes discrepantes apesar de possuírem frequências correspondentes, agora podem ser sobrepostos e analisados de maneira segura, revelando diferenças em sua composição.

Posteriormente, os dados foram auto-escalados a fim de que todos os sinais, independentemente de sua intensidade relativa, tenham o mesmo peso estatístico quando comparados. ${ }^{37,69}$ Essa medida tem por finalidade evitar que, por exemplo, uma variação mínima em um sinal de grande intensidade seja mais pesada que uma grande variação em um sinal pouco intenso. Dessa forma, a despeito de suas intensidades, os sinais são comparados igualmente.

Após a análise, cada ponto do espectro é lançado em um gráfico de loadings, que correlaciona cada entrada (variável) do modelo a um dado peso estatístico, de acordo com sua posição relativa a cada uma das componentes consideradas. Paralelamente, um gráfico similar é construído (gráfico de scores), distribuindo as amostras e seus valores associados ao longo das componentes do modelo. A Figura 19 ilustra os resultados da análise de PCA após estas etapas.

Figura 19 - Exemplo de uma análise de componentes principais. O gráfico de loadings considera todos os pontos do conjunto de dados, ao redor das componentes.

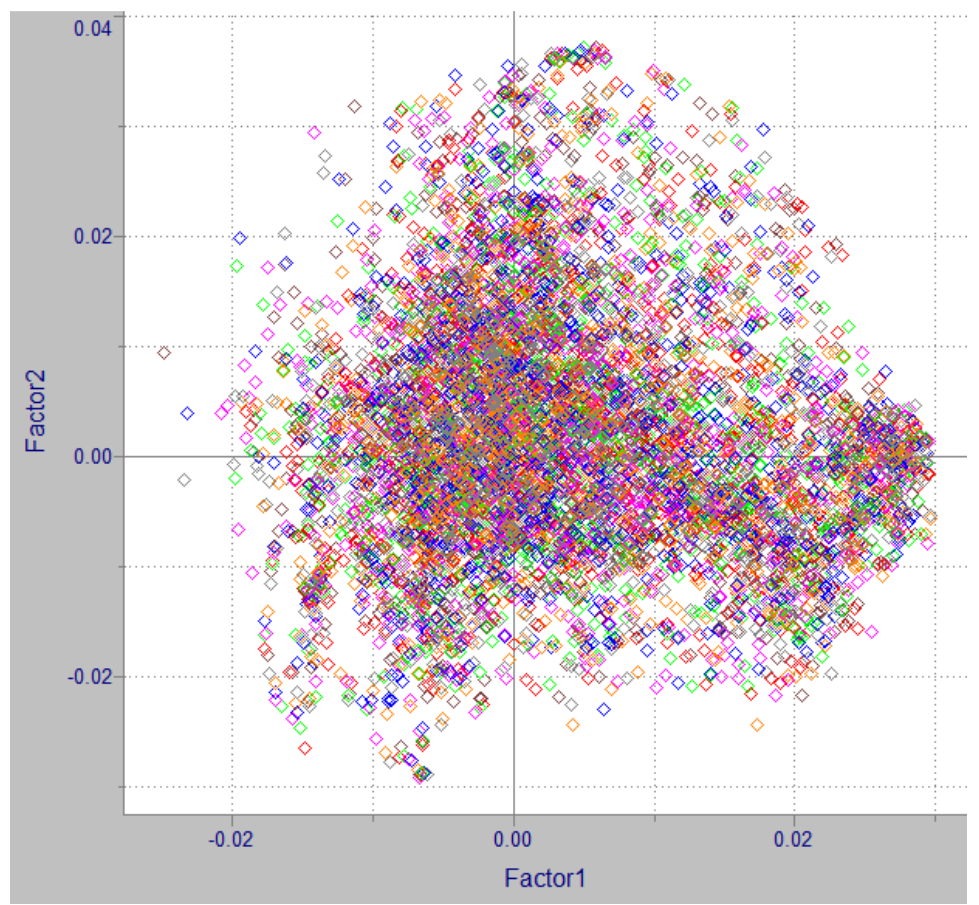


Selecionando-se uma região de interesse no gráfico de loadings, as regiões do(s) espectro(s) original (is) formadas por aqueles pontos são tarjadas, como mostra a Figura 20.

Figura 20 - Dados de $\mathrm{RMN}-{ }^{1} \mathrm{H}$ para amostra de urina bovina. As regiões mostradas em amarelo correspondem aos pontos situados nos $2^{\circ}$ e $3^{\circ}$ quadrantes no gráfico de loadings (Figura 19).

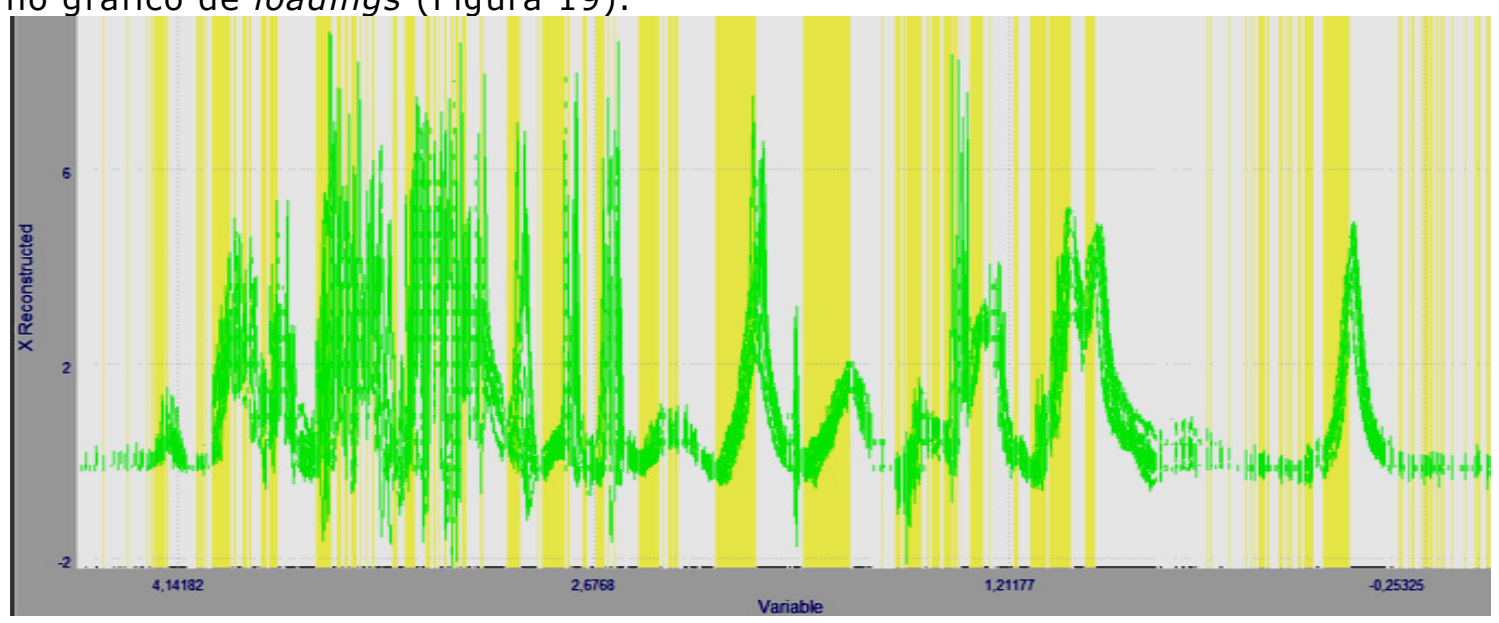

Desta maneira, é possível identificar sinais responsáveis por distinguir os espectros e identificá-los como evidências de mudanças metabólicas sofridas pelos animais.

Utilizando os mesmos dados originários da PCA, a HCA classifica as amostras criando uma espécie de "árvore genealógica" denominada dendrograma, relacionando-as conforme seu percentual de similaridade. A Figura 21 ilustra um exemplo deste tipo de análise. 
Figura 21 - Dendrograma de HCA, onde os "ramos" da árvore indicam a similaridade entre as amostras.

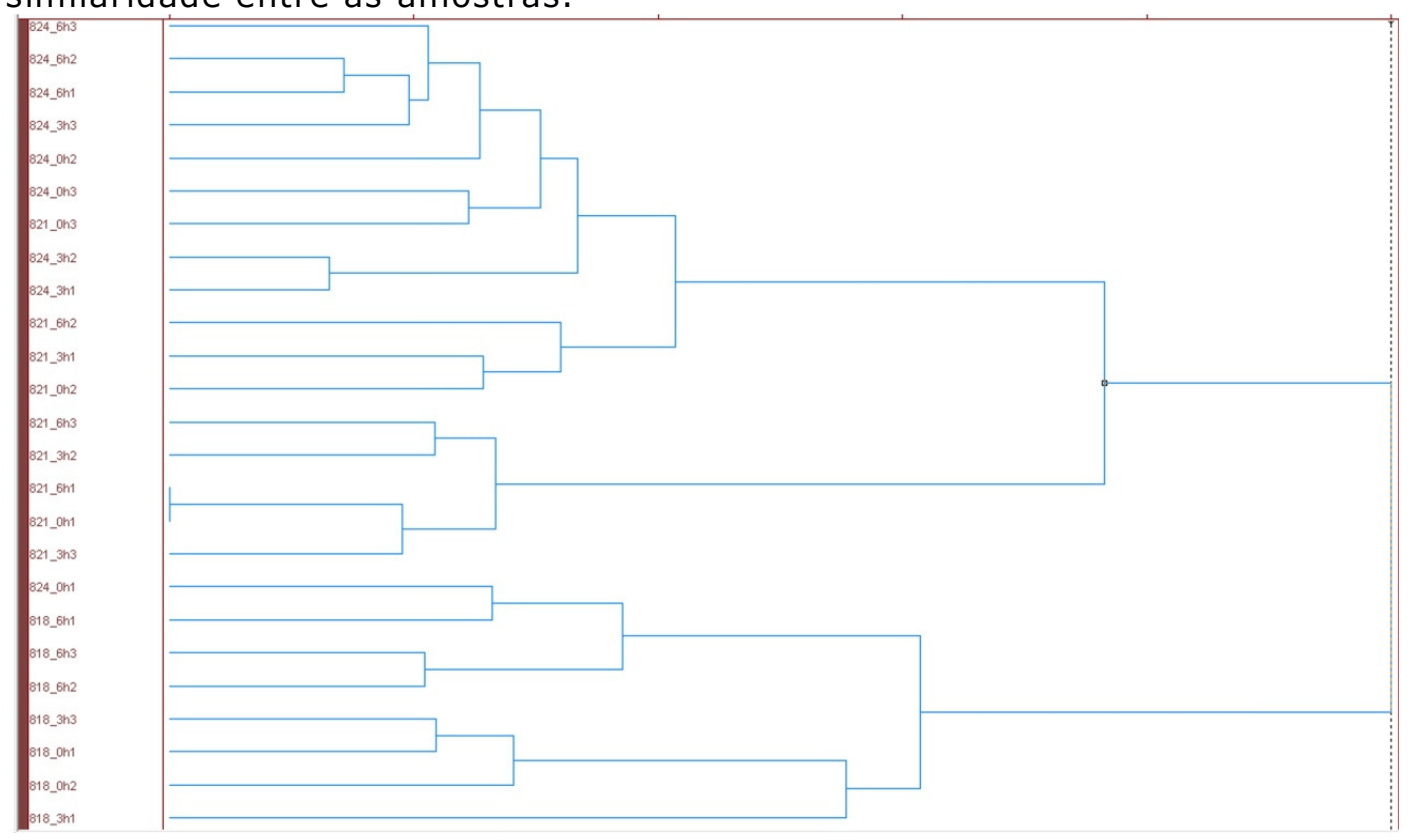

Vários animais foram inseridos no mesmo modelo, com o objetivo de se investigar a capacidade do modelo de apontar diferenças em amostras de diferentes animais, mas correlacionando as componentes responsáveis por essa distinção, procurando-se evidenciar se uma mesma variação metabólica acontece em animais distintos após a aplicação do medicamento. Neste caso, pode-se identificar esta alteração como sendo constante, e empregá-la, no futuro, como uma espécie de "impressão digital metabólica" para avaliação do uso desse fármaco.

\subsection{Experimento com Camundongos}

Adicionalmente aos estudos envolvendo amostras bovinas, foram realizados estudos de RMN e quimiometria em amostras provenientes de camundongos da linhagem Balb-C (Figura 22). Estes animais tem por característica a isogenia, ${ }^{70}$ além de possuírem um metabolismo altamente acelerado, o que permitiu se verificar em tempo mais curto os efeitos de uma dose tóxica de Ivermectina. 
Figura 22 - Camundongo Balb-C com 6 semanas de vida.

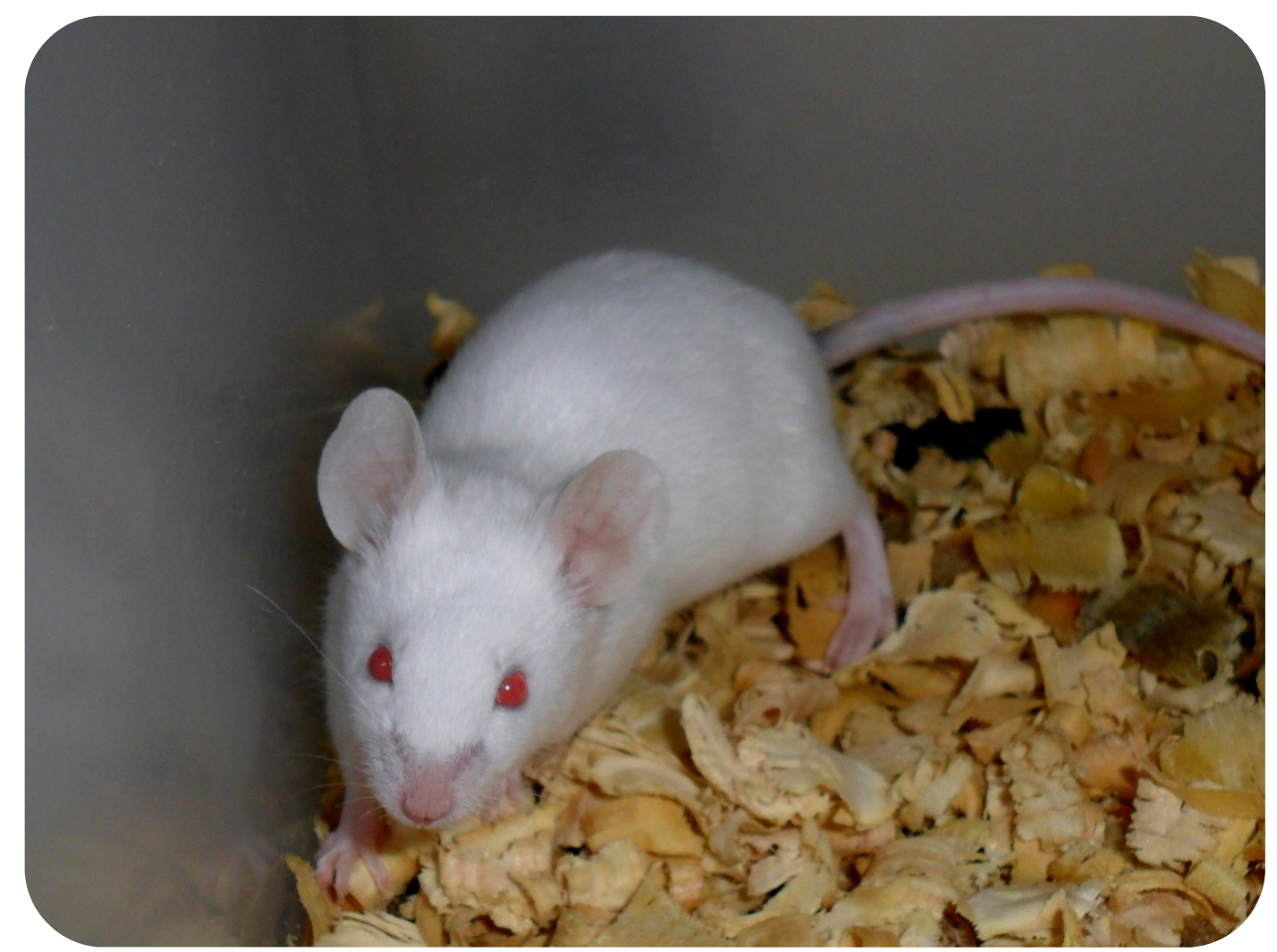

A fim de se produzir mudanças sensíveis no metabolismo destes animais, planejou-se um experimento com 30 camundongos machos saudáveis com 6 semanas de vida. Os experimentos foram conduzidos no biotério do Grupo de Cristalografia do Instituto de Física de São Carlos (IFSC-USP), que possui autorização da Comissão de Ética em Experimentação Animal da Universidade Federal de São Carlos (UFSCar).

Estes foram divididos em 6 grupos de 5 animais como mostra a Figura 23, sendo medicados ao longo de um único dia com doses de Ivermectina. A dose letal $\left(L_{50}\right)$ deste fármaco em camundongos é de 29 $\mathrm{mg} / \mathrm{kg}$ de massa corporal. ${ }^{71}$ Assim, planejou-se fazer uma aplicação sequencial de várias doses abaixo deste valor, mas que somadas ao final, superassem o valor de LD 50 para os indivíduos dos grupos 4 e 5 . O objetivo desta dosagem é procurar levar pelo menos um dos indivíduos estudados à morte por intoxicação, no intuito de se avaliar o metabolismo 
em todas as faixas possíveis, desde os indivíduos não medicados, àqueles cuja morte foi causada pela alta dose deste fármaco.

Figura 23 - Esquema do experimento com camundongos, divididos em 6 grupos, sendo um grupo basal e cinco grupos de tratamento. Os animais mostrados em cinza representam os indivíduos controle de cada grupo.

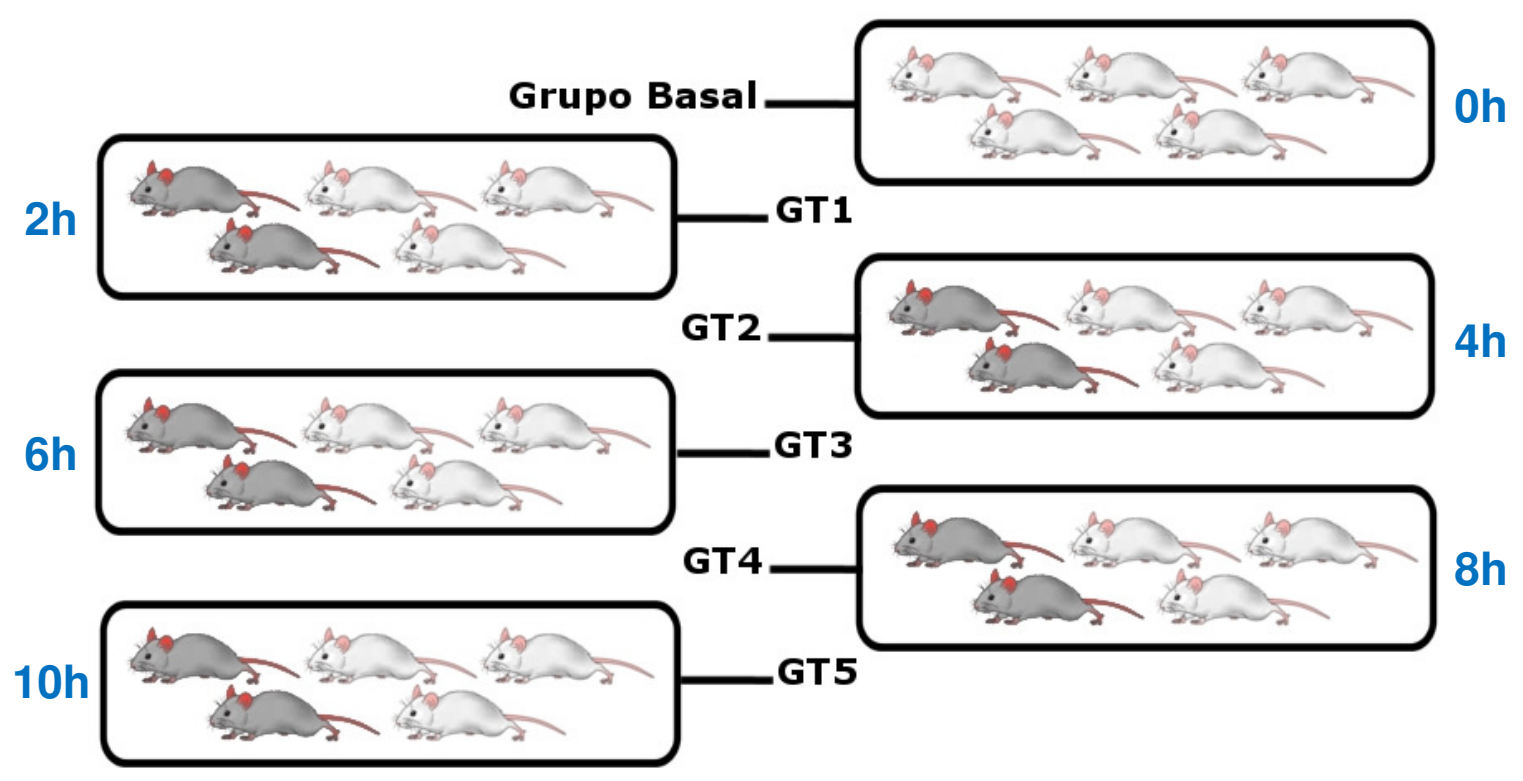

Inicialmente, um grupo de 5 animais foi sacrificado no início da manhã, tendo seu sangue coletado para extração do plasma, a fim de se estabelecer um ponto metabólico o mais próximo possível do basal. A seguir, todos os animais restantes receberam $10 \mathrm{mg} / \mathrm{kg}$ de ivermectina dispersa em PBS (Phosphate Buffered Saline), excetuando-se sempre dois indivíduos de cada grupo como controles. Estes indivíduos receberam somente injeção intraperitoneal de PBS, a fim de manter suas condições experimentais o mais próximas possível dos indivíduos medicados. Após decorridas $2 \mathrm{~h}$, um destes grupos foi sacrificado e teve seu sangue coletado, quando os animais restantes foram novamente medicados com a dose de $10 \mathrm{mg} / \mathrm{kg}$. Este procedimento foi repetido até que todos os animais tivessem suas amostras de sangue colhidas. Ao último grupo (GT5) foram administradas cerca de duas vezes a dose letal ao longo do dia (50 mg/Kg no total para o grupo 5). 
O plasma sanguíneo foi extraído em uma centrífuga de bancada Eppendorf modelo Centrifuge 5415D à temperatura ambiente e 10000 rpm (aproximadamente $8100 \times \mathrm{g}$ ) sendo coletado e a seguir concentrado em centrífuga a vácuo, analogamente ao plasma bovino, a fim de se obter a melhor resolução espectral possível.

Como se trata de animais isogênicos, o mínimo de tratamento foi aplicado às amostras, que foram analisadas imediatamente após o experimento de administração de Ivermectina. Por isso, não foi utilizada a azida sódica, e também não empregou-se o tampão fosfato, para que possíveis variações causadas por mudanças de $\mathrm{pH}$ pudessem ser observadas.

\subsection{Caracterização de Metabólitos}

Amostras biológicas são matrizes complexas, contendo inúmeros compostos inerentes ao metabolismo celular nos mais diversos compartimentos biológicos do organismo estudado. Esses níveis, como já abordado anteriormente podem variar, seja por processos naturais ou interferências de agentes externos como alimentação, medicamentos ou stress. Sendo assim, a variabilidade dos níveis de metabólitos, associada ao grande número de compostos, torna a análise de amostras biológicas uma etapa de grande dificuldade no estudo de Metaboloma/Metabonoma.

Neste projeto, fez-se uso de três grandes bases de dados para caracterização de metabólitos: a Human Metabolome Database (HMDB), ${ }^{72}$ desenvolvida pelo projeto Genome Alberta (Canadá), que compreende um banco de dados sobre metabólitos, contendo informações sobre estrutura química, massa molecular, espectros de massa, $\mathrm{RMN}-{ }^{1} \mathrm{H}$ e ${ }^{13} \mathrm{C}$, além de toxicidade, ocorrência nos mais diversos tecidos e funções bioquímicas no organismo, entre outros inúmeros dados. Mesmo em se tratando de uma base de dados para metabólitos humanos, pode-se empregar a mesma para mamíferos em geral, uma vez que o metabolismo dos mesmos mantém grande similaridade. Devido a isto estes animais são largamente 
empregados como modelos em pesquisas de doenças humanas. Exemplos disso são pesquisas empregando-se ratos, camundongos, coelhos e primatas, entre outras; a Madison Metabolomics Consortium Database, ${ }^{73}$ que permite a busca por deslocamentos químicos de RMN; e a Metabolomics, ${ }^{74}$ desenvolvida pelos pesquisadores Peter Lundberg (Suécia) e Alexandr Malusek (Rússia), cujo acesso foi concedido gentilmente pelos autores.

Suas principais ferramentas incluem simulações de espectro 1-D e 2-D de metabólitos, bem como uma poderosa ferramenta de busca, através da qual se pode identificar um metabólito através do deslocamento químico, escolhendo-se o núcleo desejado e a precisão desejada. Assim, empregando-se estas bases, pode-se fazer a caracterização dos metabólitos presentes nas amostras estudadas. 


\section{RESULTADOS E DISCUSSÃO}

\subsection{Bovinos}

\subsubsection{Preparo das amostras}

Inicialmente, foram realizados ensaios espectrométricos com as amostras in natura (sem tratamento), aplicando-se as sequências de pulsos previamente descritas, visando-se a máxima preservação do caráter das mesmas. Porém, para as amostras de urina, principalmente, os resultados obtidos não foram satisfatórios, gerando espectros de baixa qualidade e, sobretudo não reprodutíveis. Isso se deve ao fato de as amostras brutas conterem partículas sólidas em seu meio, bem como apresentarem variações significativas de $\mathrm{pH}$, quando colhidas em dois ou mais horários diferentes, ou de animais distintos, além da concentração. Logo, optou-se por fazer o tratamento padronizado destas amostras, a fim de se garantir maior reprodutibilidade e eficácia do método de análise.

Após a aplicação do tratamento descrito, a qualidade dos dados espectrais foi visivelmente melhor, optando-se assim por adotar o mesmo para todas as amostras envolvidas. Os resultados da mudança no protocolo de tratamento e análise serão mostrados nas Figuras 26 e 27, que mostram também as melhorias obtidas com a técnica PRESAT.

\subsubsection{Análises de Ressonância Magnética Nuclear}

\subsubsection{RMN de ${ }^{1} \mathrm{H}$}

Implementou-se o ensaio padrão de ressonância magnética para ${ }^{1} \mathrm{H}$ visando-se obter a melhor razão sinal-ruído no menor tempo de análise possível. Estipulou-se como ideal o acúmulo de 32 médias para cada amostra, empregando a sequência de supressão jump-return, previamente descrita. Como visto, a não utilização de uma sequência de 
supressão leva a um espectro dominado por um único sinal, correspondente ao núcleo de hidrogênio da espécie HDO, formada pelo equilíbrio químico entre $\mathrm{D}_{2} \mathrm{O}$ e hidrogênios intercambiáveis da amostra (Figura 14).

A técnica de jump-return mostrou-se eficiente para suprimir satisfatoriamente o sinal em questão, permitindo a análise de outros picos, anteriormente ocultos. Estes picos correspondem aos diversos metabólitos encontrados no organismo animal, e sua baixa concentração é um fator que deve ser levado em conta. A Figura 24 mostra o espectro de RMN para uma amostra de plasma sanguíneo, obtida com o auxilio da técnica de jump-return.

Figura 24 - Espectro de $\mathrm{RMN}-{ }^{1} \mathrm{H}$ para uma amostra de plasma sanguíneo bovino, empregando a técnica de supressão jump-return. O sinal marcado corresponde ao residual da água.

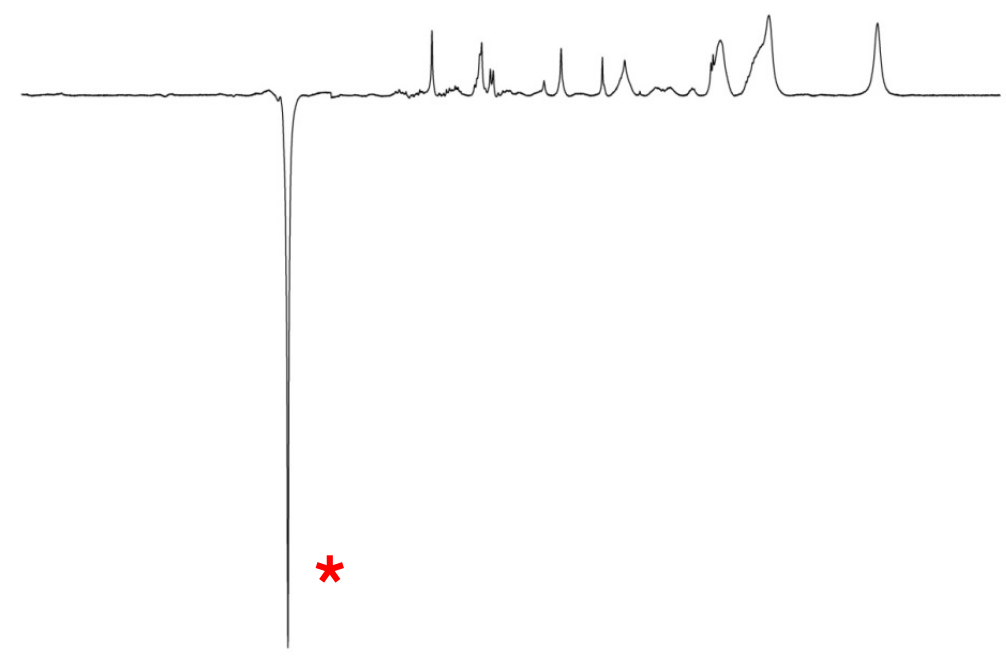

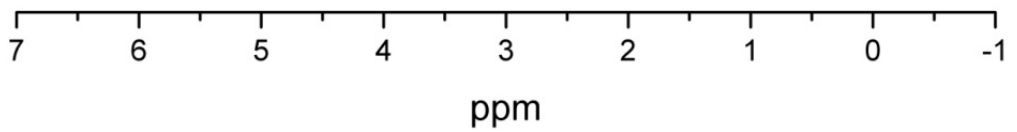

Como é possível notar, ocorre uma inversão do sinal correspondente à espécie HDO, bem como de todos os picos com deslocamento químico (e consequentemente frequência de ressonância) maiores que o mesmo. Isso 
se deve à distribuição vetorial resultante da aplicação da técnica, mostrada na Figura 15.

Este obstáculo foi contornado pela inversão dos valores de frequência (y) durante a construção do gráfico correspondente ao espectro da amostra. A Figura 25 ilustra a correção de fase do espectro da mesma amostra ilustrada anteriormente.

Figura 25 - Espectro de $\mathrm{RMN}-{ }^{1} \mathrm{H}$ para uma amostra de plasma sanguíneo, empregando a técnica de supressão jump-return, aplicando-se a correção de fase para sinais com deslocamento químico maiores ou iguais a 4,8 ppm. Neste caso, a supressão do sinal da água foi de cerca de 80 vezes.

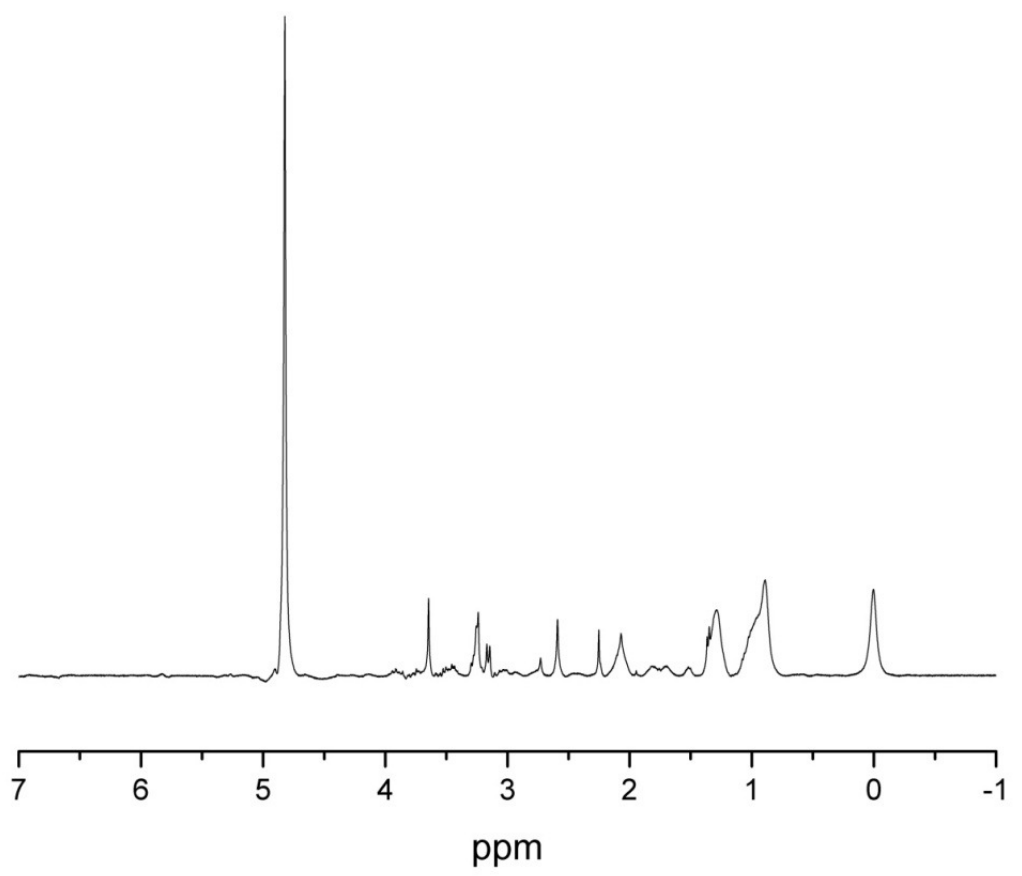

Apesar de mostrar-se eficiente na supressão do sinal da água, a técnica jump-return leva a espectros que necessitam de um tratamento manual para correção da inversão, fator este que pode tornar os dados menos confiáveis para análise exploratória quimiométrica. Com o uso da técnica PRESAT, os espectros já são obtidos com a fase desejada, mantendo os dados inalterados. As Figuras 26 e 27 mostram dados de RMN $-{ }^{1} \mathrm{H}$ obtidos com a técnica PRESAT, salientando as diferenças na qualidade dos dados obtidos. 
Figura 26 - Espectros de $\mathrm{RMN}-{ }^{1} \mathrm{H}$ de amostras de urina bovina, antes $(\mathrm{A})$ e após (B) a implementação dos novos protocolos de aquisição de dados. a qualidade dos dados obtidos, refletida sobretudo pela resolução espectral, pode ser notada nas regiões em destaque.

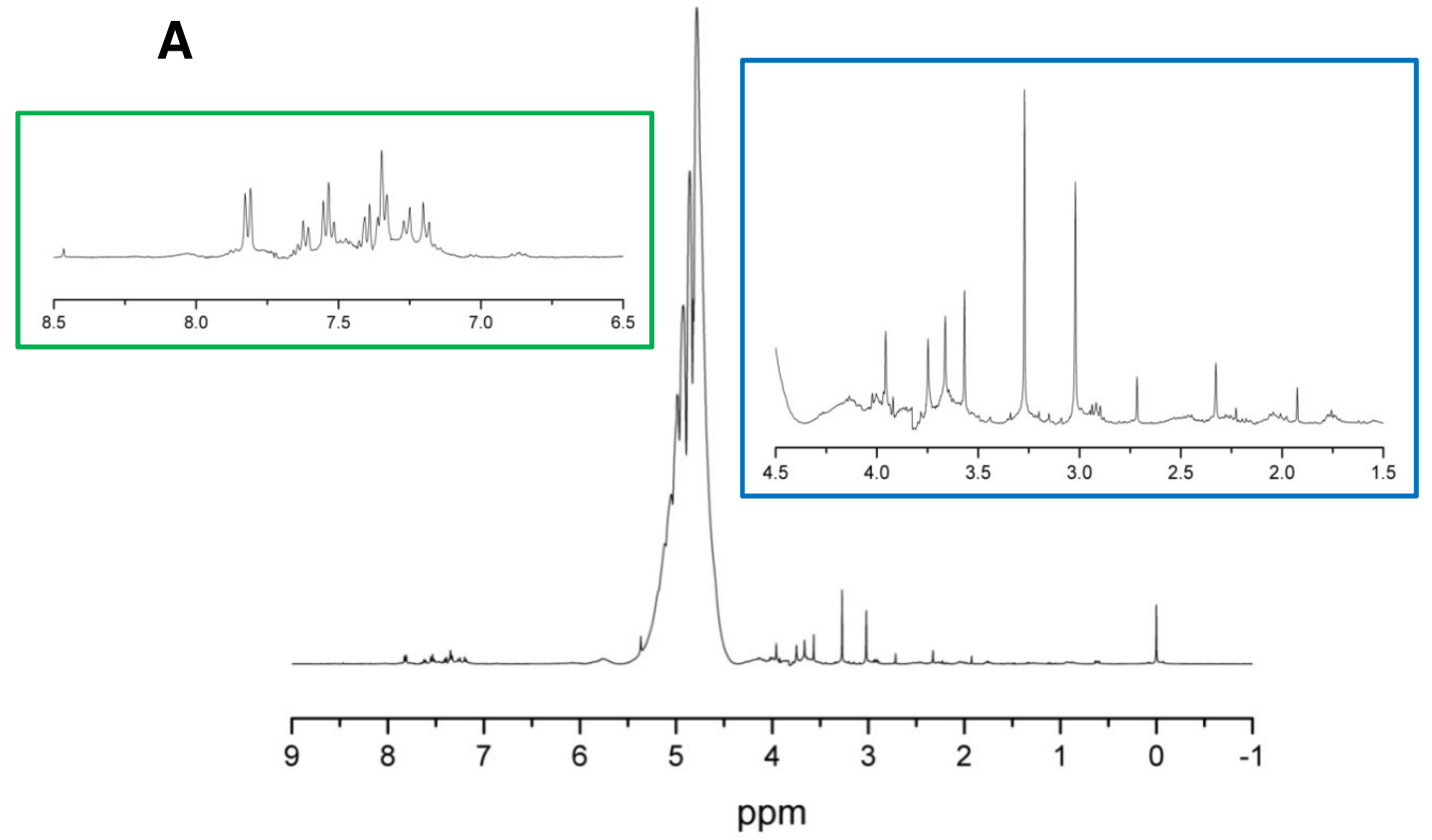

B
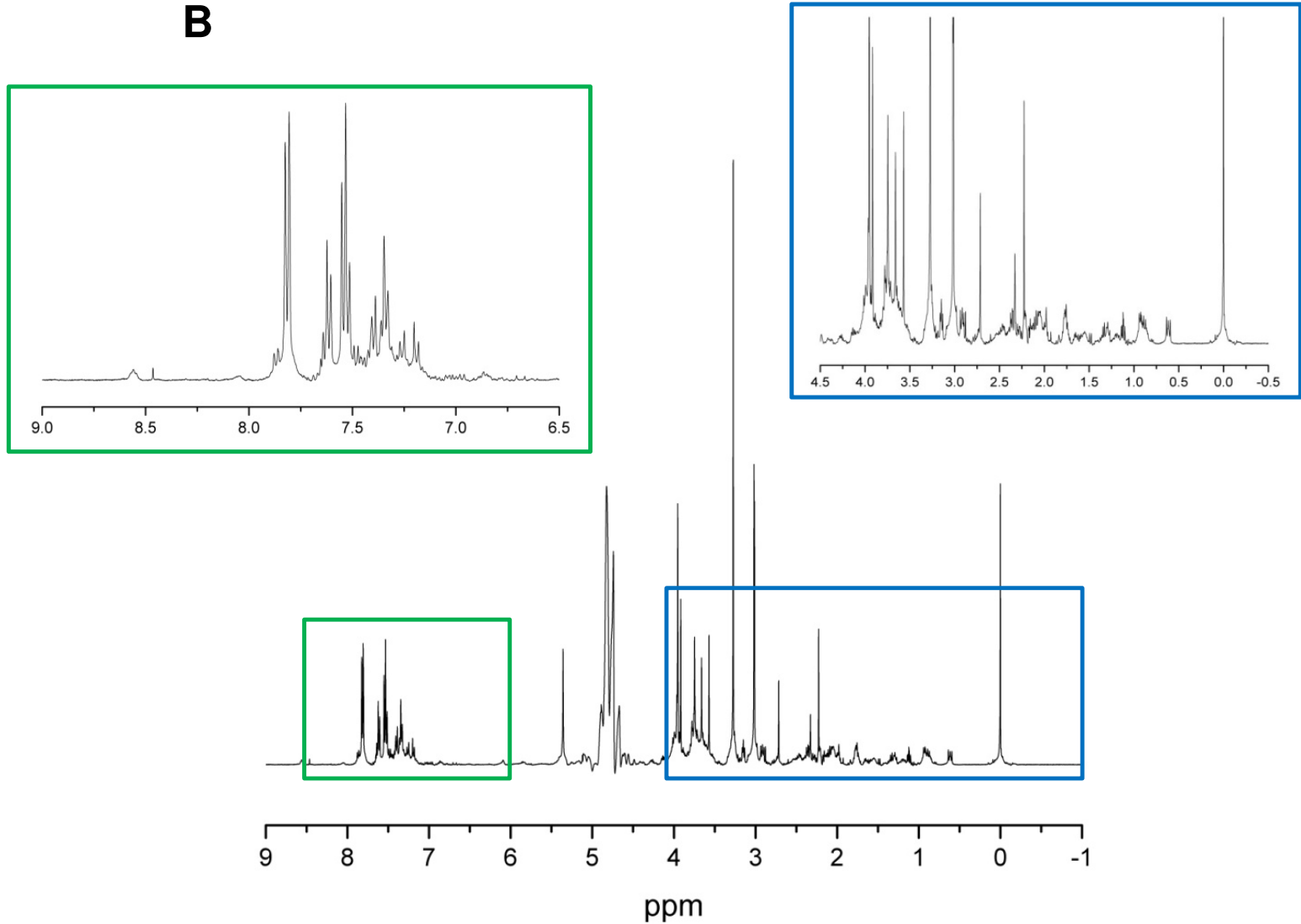
Figura 27 - Espectros de $\mathrm{RMN}-{ }^{1} \mathrm{H}$ de plasma sanguíneo bovino obtidos antes (A) e após (B) a implementação dos protocolos de tratamento e aquisição de dados.
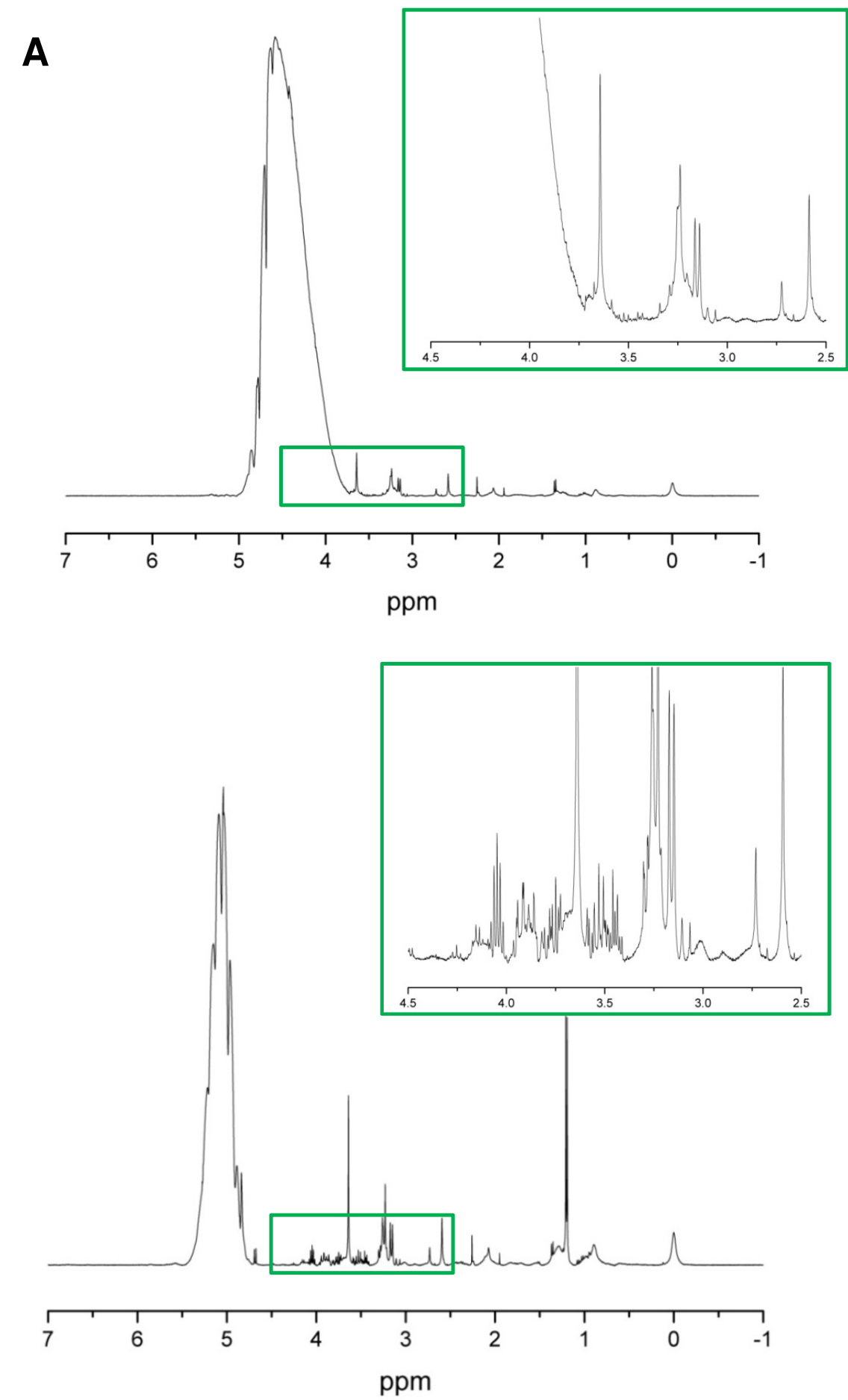

Dessa forma, optou-se pela utilização definitiva da técnica PRESAT. Através dos espectros obtidos, é possível encontrar uma grande quantidade de sinais correspondentes a pequenas moléculas presentes 
nos biofluidos. Estes sinais devem ser avaliados, em especial aqueles cuja intensidade é pouco expressiva. Nestes casos, o ruído presente no espectro pode dificultar a seleção destes sinais com segurança, afetando principalmente a reprodutibilidade dos dados avaliados. Para isso, optouse por considerar, neste estudo, apenas sinais cuja intensidade fosse igual ou maior que 5 vezes o ruído nas suas vizinhanças.

Devido à grande quantidade de sinais, bem como à impossibilidade de se identificar visualmente as variações ocorridas entre espectros de amostras distintas, a seleção dos picos de interesse para é feita através da Análise de Componentes Principais (PCA). Optou-se por este método já que muitos sinais não variam ou variam de forma pouco significativa, tornando a identificação manual dos sinais em um primeiro momento de pouca utilidade. Por outro lado, após a análise de componentes principais, as regiões espectrais destacadas mostram quais os picos responsáveis pela diferenciação entre espectros, revelando quais sinais devem ser prioritariamente avaliados, levando finalmente aos metabólitos que variam com a medicação dos animais.

\subsubsection{RMN de ${ }^{13} \mathrm{C}$ (Convencional e SSFP)}

Foram obtidos espectros de ressonância magnética para o núcleo de ${ }^{13} \mathrm{C}$ das amostras de plasma e urina com a sequência padrão. Espectros de ${ }^{13} \mathrm{C}$ são, via de regra, menos informativos que os de ${ }^{1} \mathrm{H}$, por conterem menos sinais, além do fato de possuírem uma baixa razão sinal-ruído. Contudo, são de grande utilidade para análises de metabólitos, uma vez que, sendo a matriz de composição complexa, e frequentemente variável (amostras obtidas em dias diferentes, de animais diferentes, em condições distintas) a análise feita exclusivamente por $\mathrm{RMN}$ de ${ }^{1} \mathrm{H}$ pode tornar-se ambígua em alguns casos pontuais, quando dois metabólitos apresentam sinais em deslocamentos químicos próximos, por exemplo. Neste ponto, a RMN de ${ }^{13} \mathrm{C}$ pode atuar como ferramenta complementar para os resultados obtidos. 
As Figuras 28 e 29 mostram espectros de RMN $-{ }^{13} \mathrm{C}$ para amostras de plasma sanguíneo e urina bovinos utilizando-se a técnica convencional de aquisição.

Figura 28 - Espectro de $\mathrm{RMN}-{ }^{13} \mathrm{C}$ obtido para amostra de urina bovina, a partir da técnica convencional.

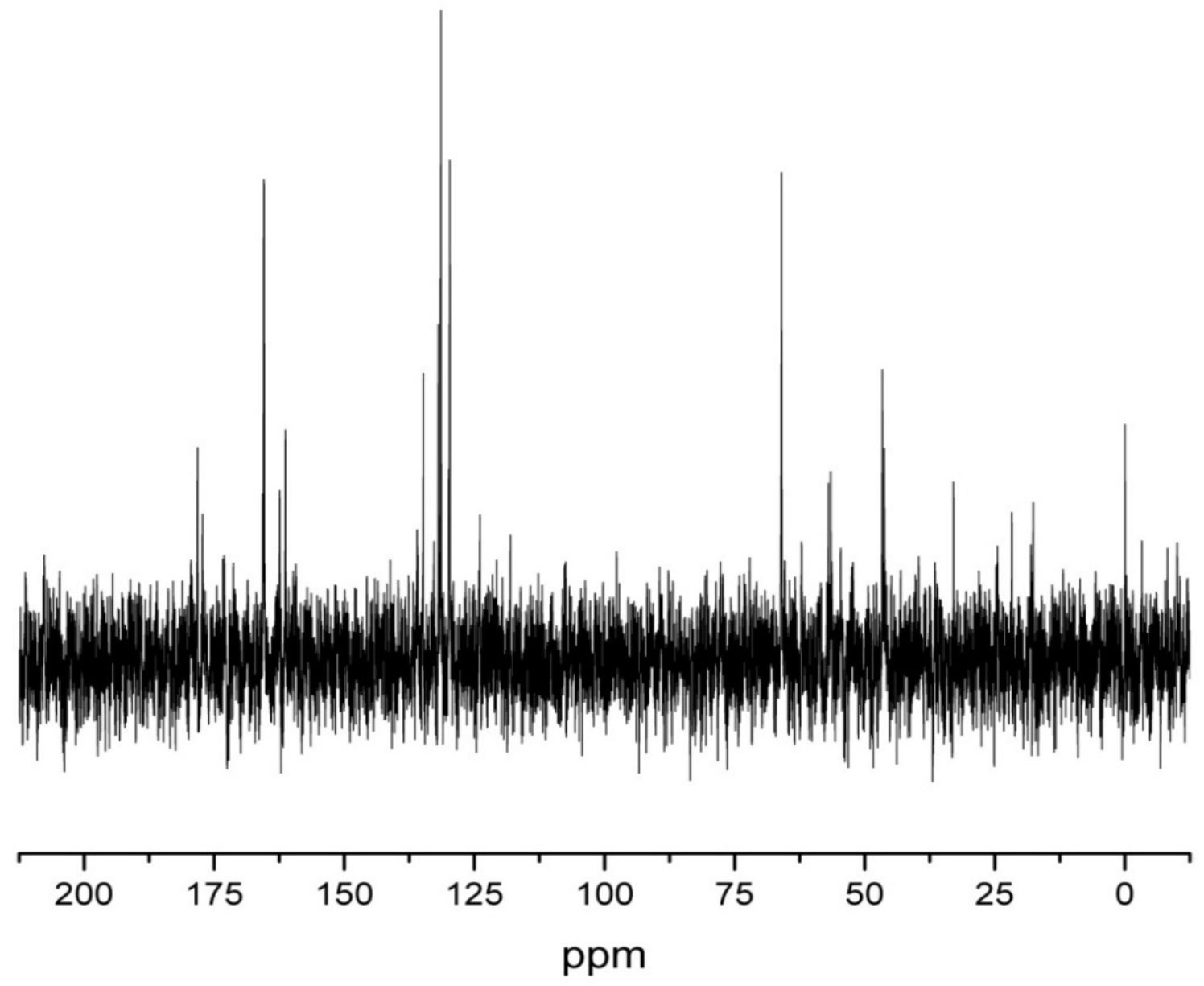


Figura 29 - Espectro de $\mathrm{RMN}-{ }^{13} \mathrm{C}$ obtido para amostra de plasma sanguíneo bovino, a partir da técnica convencional.

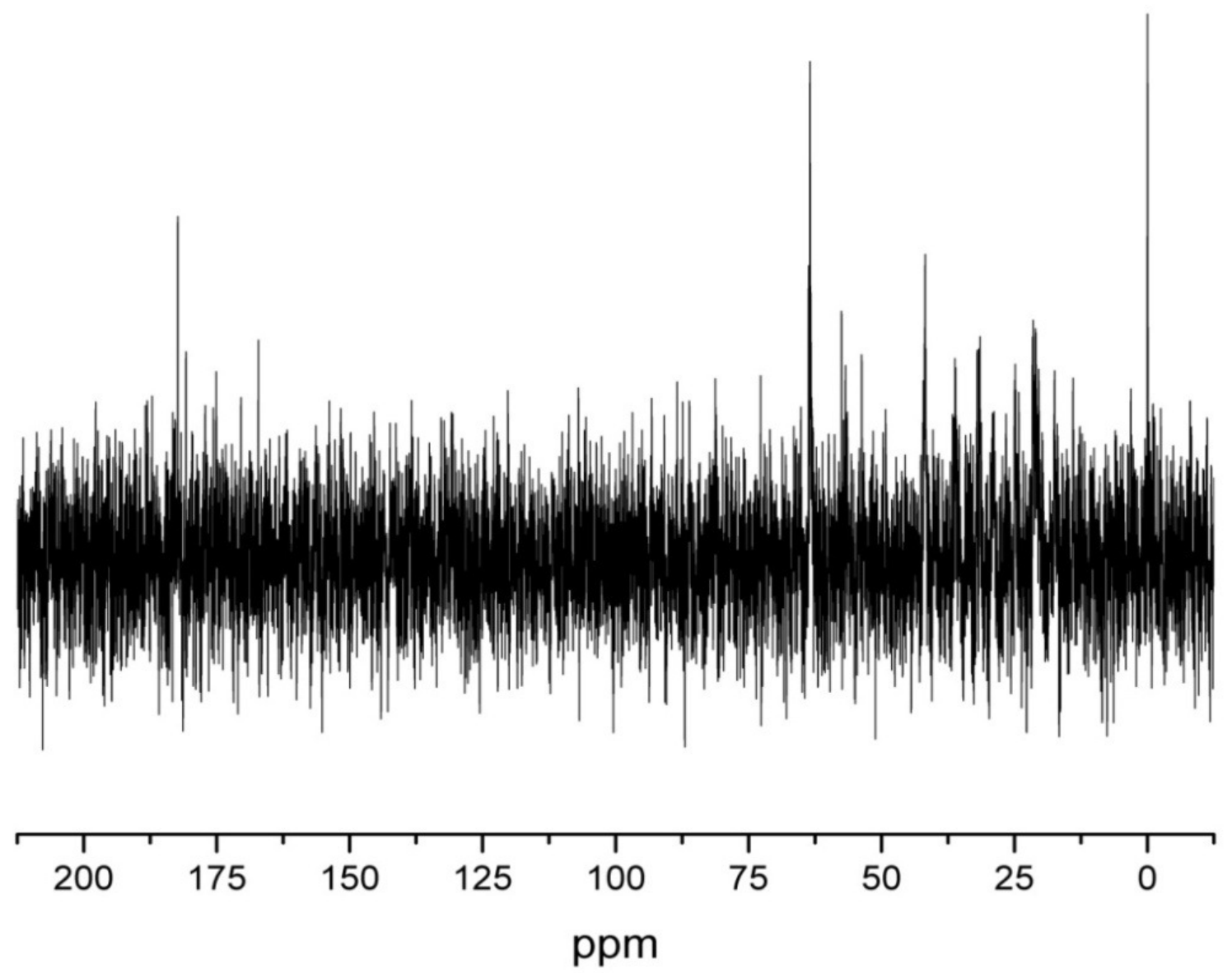

Como é possível notar, a técnica convencional para RMN de ${ }^{13} \mathrm{C}$ não apresenta resultados totalmente satisfatórios em se tratando de amostras de fluidos bovinos. A baixa concentração dos metabólitos associada às baixas sensibilidade e abundância do núcleo levam a um espectro com alto nível de ruído, mesmo com o acúmulo de muitas médias.

Apesar de uma das características da técnica de SSFP ser a formação de um eco como refocalização residual da magnetização transversal do sistema, os espectros obtidos neste trabalho não apresentaram este eco de spin. Isso se deve principalmente ao fato de não estar-se analisando amostras de caráter puro, e sim misturas complexas de componentes com forte presença de íons salinos e metálicos, o que provoca uma relaxação bem mais rápida do sistema. Por 
essa razão, os sinais FID mostrados na Figura 30 apresentam um rápido decaimento após o pulso.

Figura 30 - Sinal de $\mathrm{RMN}-{ }^{13} \mathrm{C}$ no domínio do tempo, obtido com a técnica SSFP para uma amostra de plasma sanguíneo.

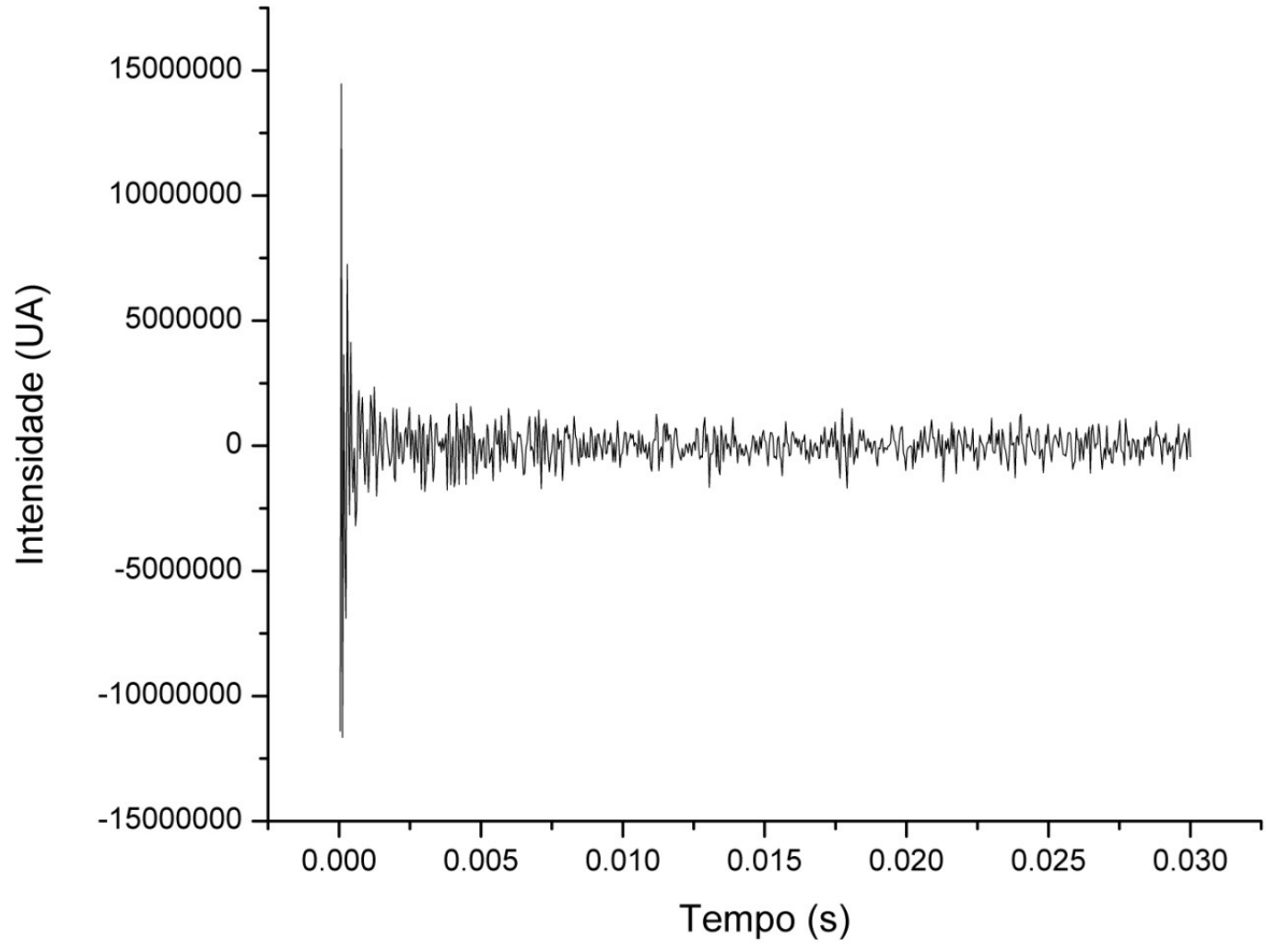

A transformada de Fourier deste sinal fornece o espectro de RMN de ${ }^{13} \mathrm{C}$, analogamente ao de ${ }^{1} \mathrm{H}$. Entretanto, uma vez que seu princípio não leva em conta o tempo de relaxação do ${ }^{13} \mathrm{C}$, os sinais obtidos têm distorções na fase, também característica da técnica de SSFP. ${ }^{21}$ A Figura 31 mostra a transformada de Fourier direta do sinal FID para um espectro de RMN-SSFP para ${ }^{13} \mathrm{C}$. 
Figura 31 - Espectro resultante da transformada de Fourier diretamente do sinal FID, sem qualquer tipo de tratamento.

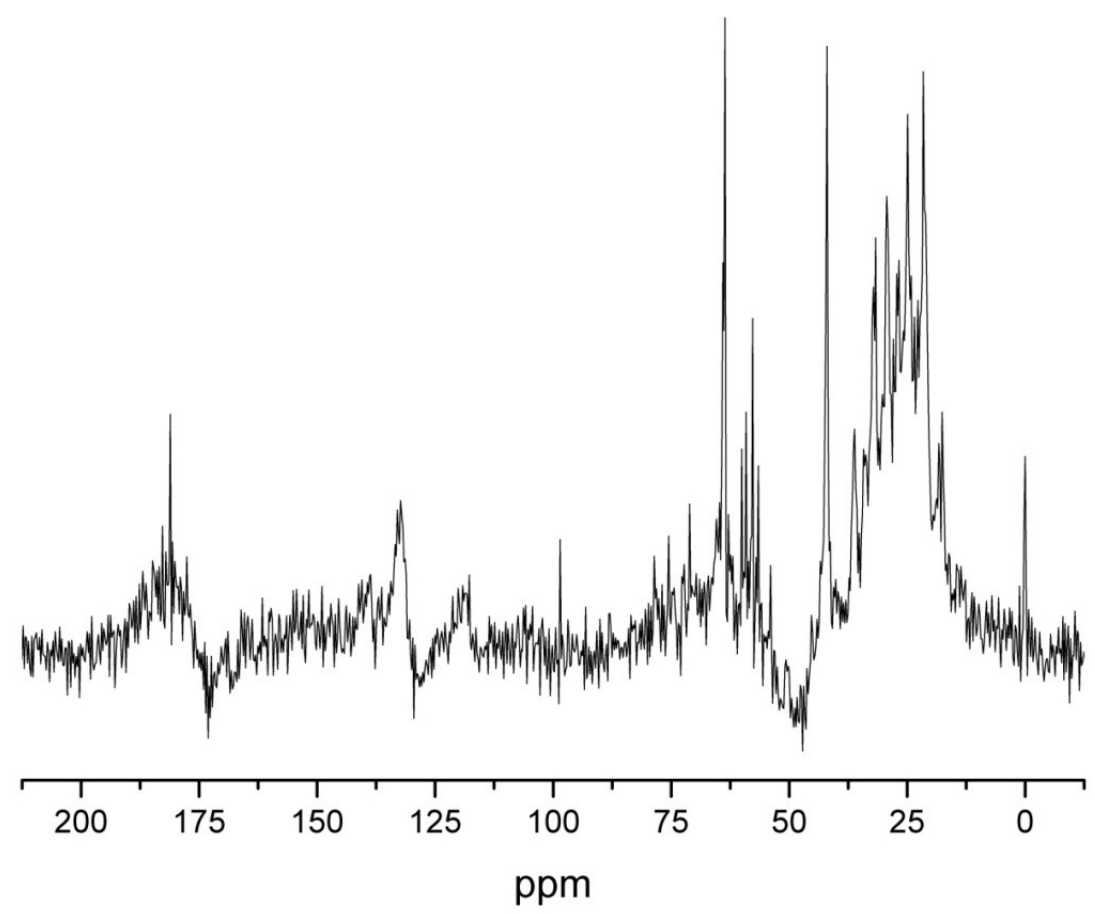

A fim de se contornar estas anomalias, antes da transformada de Fourier utilizou-se a função TRAFICANTE para apodização, ${ }^{75}$ além do recurso zero filling, que acrescenta zeros ao final do sinal FID, e não interfere no espectro resultante da transformada de Fourier, mas melhora a resolução digital, por "forçar" o decaimento a zero. A Figura 32 mostra o resultado destas ferramentas para um espectro SSFP. 
Figura 32 - Espectro de RMN-SSFP após a utilização de apodização e zero filling, para urina (A) e plasma sanguíneo (B). Apesar de ainda serem visíveis algumas distorções nos sinais encontrados, a qualidade dos dados finais é bastante melhor.
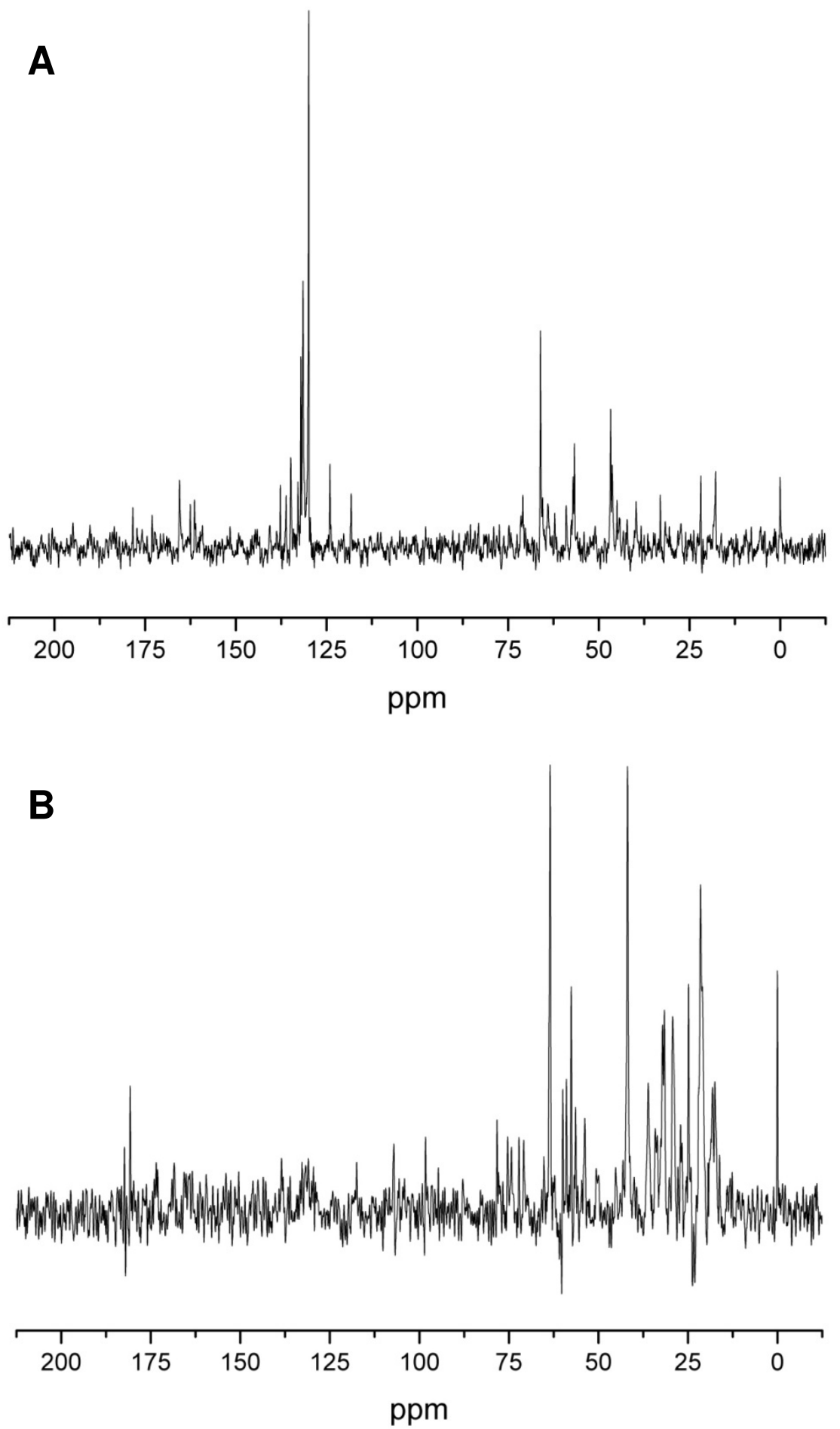

Claramente a técnica SSFP, após o tratamento adequado dos dados, leva a espectros resultantes mais satisfatórios, além de ser, em termos de 
quantidade de informação, superior à técnica convencional, por resultar em mais sinais. A Figura 33 e a Tabela 4 comparam um espectro de RMN${ }^{13} \mathrm{C}$ convencional e um espectro obtido para a mesma amostra através da técnica SSFP.

Figura 33 - Espectros de $\mathrm{RMN}^{13} \mathrm{C}$ de uma amostra de plasma bovino, empregando a sequência de pulsos convencional ( $A$ ) e a técnica SSFP (B).

A

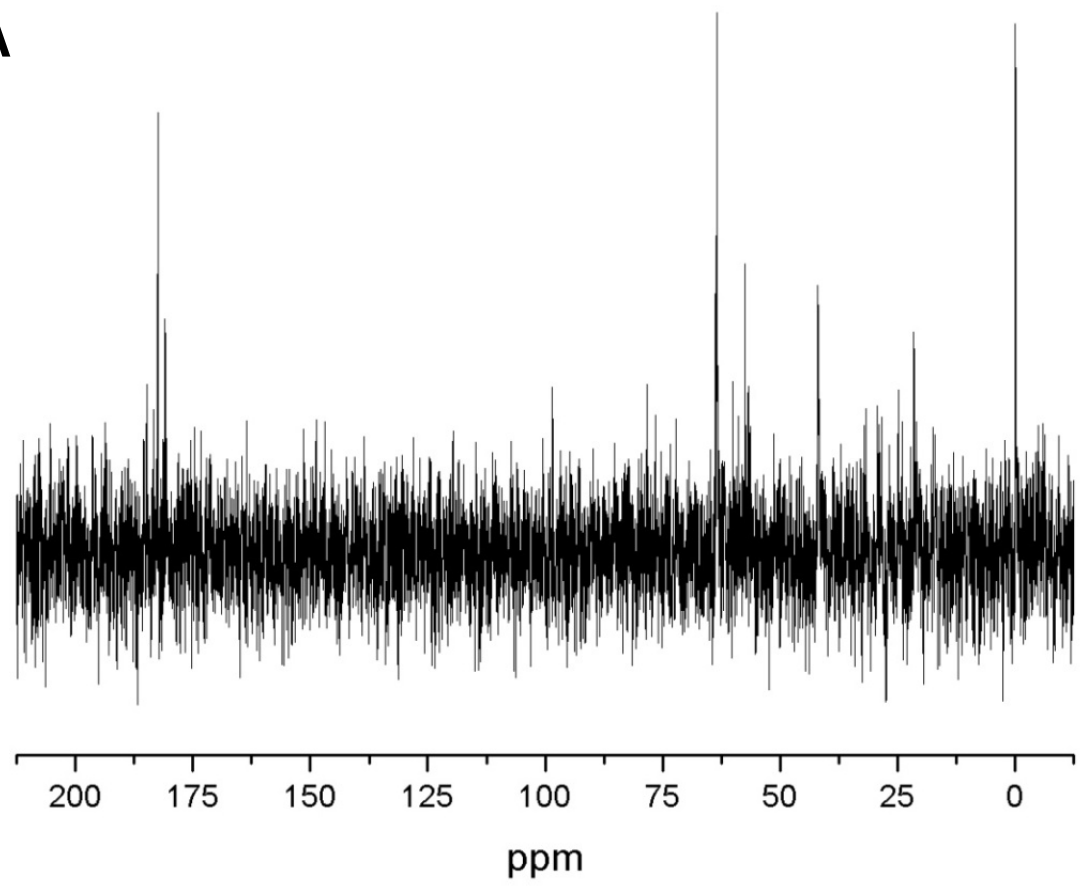

B

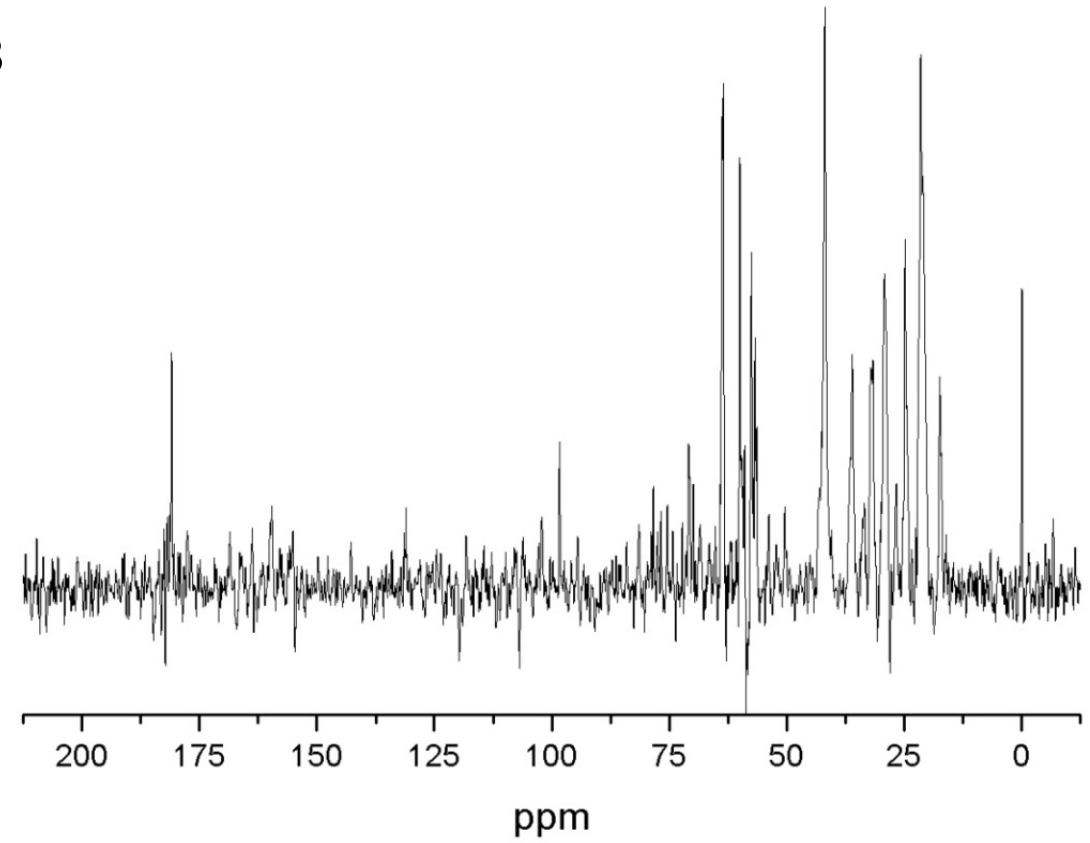


Tabela 4 - Sinais encontrados nos espectros de RMN $-{ }^{13} \mathrm{C}$ convencional e SSFP para uma mesma amostra de plasma bovino (Figura 33 ).

\begin{tabular}{cc|cccc}
\hline \multicolumn{2}{c|}{ Convencional } & \multicolumn{4}{c}{ SSFP } \\
\hline Sinal & $\mathbf{( p p m )}$ & Sinal & $\mathbf{( p p m )}$ & Sinal & $\mathbf{( p p m )}$ \\
\hline 1 & 0 & $\mathbf{1}$ & $\mathbf{0}$ & 20 & 69,92 \\
2 & 21,56 & 2 & 17,46 & 21 & 70,9 \\
3 & 24,92 & $\mathbf{3}$ & $\mathbf{2 1 , 5 2}$ & 22 & 72,25 \\
4 & 29,43 & 4 & 24,9 & 23 & 75,43 \\
5 & 31,82 & 5 & 26,73 & $\mathbf{2 4}$ & $\mathbf{7 6 , 7 9}$ \\
6 & 41,98 & $\mathbf{6}$ & $\mathbf{2 9 , 2 5}$ & $\mathbf{2 5}$ & $\mathbf{7 8 , 4 1}$ \\
7 & 56,85 & $\mathbf{7}$ & $\mathbf{3 1 , 6 9}$ & 26 & 81,51 \\
8 & 57,6 & 8 & 33,5 & 27 & 98,38 \\
9 & 60,15 & 9 & 36,11 & 28 & 102,16 \\
10 & 63,55 & $\mathbf{1 0}$ & $\mathbf{4 1 , 9 2}$ & 29 & 131,06 \\
$\mathbf{1 1}$ & $\mathbf{6 3 , 7 7}$ & 11 & 50,44 & 30 & 155,09 \\
12 & 76,51 & 12 & 53,86 & 31 & 159,57 \\
13 & 78,37 & $\mathbf{1 3}$ & $\mathbf{5 6 , 8 1}$ & 32 & 163,76 \\
14 & 98,45 & $\mathbf{1 4}$ & $\mathbf{5 7 , 5 7}$ & 33 & 168,56 \\
15 & 180,88 & 15 & 59 & 34 & 177,6 \\
16 & 182,43 & $\mathbf{1 6}$ & $\mathbf{6 0 , 0 4}$ & $\mathbf{3 5}$ & $\mathbf{1 8 0 , 9}$ \\
17 & 184,79 & $\mathbf{1 7}$ & $\mathbf{6 3 , 5 5}$ & $\mathbf{3 6}$ & $\mathbf{1 8 1 , 8 2}$ \\
& & 18 & 65,2 & $\mathbf{3 7}$ & $\mathbf{1 8 2 , 5 1}$ \\
& & 19 & 68,47 & 38 & 222,47 \\
\hline
\end{tabular}

Nota: Sinais obtidos automaticamente pelo software ACD 12, utilizando razão sinal-ruído maior que 2.

Como se pode notar, a técnica SSFP permite a obtenção de um espectro com menor ruído, em um menor tempo. Os sinais coloridos em vermelho correspondem aos sinais também encontrados no espectro convencional. Por outro lado, o sinal marcado em verde é o único que não figura entre os sinais SSFP. Porém, por se tratar de um sinal muito próximo de outro (em 63,55 ppm), a ligeira perda de resolução causada pelas distorções de fase na SSFP pode ser a responsável pelo não 
aparecimento do mesmo. Além disso, por se tratar de uma técnica não convencional, corre-se o risco de alguns sinais serem perdidos ou bastante reduzidos durante sua aplicação, devido a anomalias de fase, como é o caso de alguns núcleos de ${ }^{13} \mathrm{C}$ pertencentes a grupos carbonílicos (região de 180 ppm). Por outro lado, sinais em regiões alifáticas (região entre 0 e 100 ppm) aparecem em maior número e com maior intensidade quando comparados à técnica convencional.

Assim, tanto o ganho na razão sinal-ruído quanto o maior número de sinais encontrados tornam a técnica RMN-SSFP- ${ }^{13} \mathrm{C}$ uma interessante ferramenta complementar à $\mathrm{RMN}-{ }^{1} \mathrm{H}$ para análise de metabolomas.

\subsubsection{Análise de Exploratória dos Dados}

A fim de se compreender o comportamento das variações metabólicas ocorridas com a aplicação da Ivermectina, os dados de RMN${ }^{1} \mathrm{H}$ para bovinos foram inseridos no software Pirouette 4.0 , onde foram normalizados pela área unitária para a construção dos modelos PCA e HCA, sendo que dois modelos principais foram construídos, um para urina e outro para plasma sanguíneo, em várias configurações. Inicialmente, os espectros foram inseridos no modelo de forma integral, considerando-se todos os pontos. Como existem muitas regiões com baixa quantidade de informação, ou informação redundante, os resultados iniciais não mostraram qualquer tipo de separação para os espectros inseridos. Optou-se assim por um refinamento dos modelos, considerando-se apenas regiões com poder de modelagem mais elevado dentro do conjunto, selecionando-se assim a cada etapa, as variáveis responsáveis pela maior influência estatística dentro do conjunto de dados.

O modelo que se mostrou menos eficiente na distinção das amostras foi o construído para urina bovina, considerando a faixa de 0 a $9 \mathrm{ppm}$, excluindo-se a faixa 4,5 - 5,5 ppm (correspondente ao sinal residual da água), e onde mesmo após várias etapas de refinamento (resultando em um maior poder de descrição do modelo) não houve qualquer separação 
significativa. As Tabelas 5 e 6 mostram o aumento no poder descritivo do modelos, de acordo com suas componentes (PCs), antes e após o refinamento. Adicionalmente, a Figura 34 mostra o resultado da PCA para o modelo refinado.

Tabela 5 - Percentual do modelo descrito por cada uma das componentes do modelo gerado para urina bovina a partir de dados de $\mathrm{RMN}-{ }^{1} \mathrm{H}$ (todo o perfil do espectro).

\begin{tabular}{c|ccc}
\hline Componente & Variância & \% Descrito & \% Cumulativo \\
\hline 1 & 178080,02 & 10,18 & $\mathbf{1 0 , 1 8}$ \\
2 & 111791,24 & 6,39 & $\mathbf{1 6 , 5 7}$ \\
4 & 103262,48 & 5,90 & $\mathbf{2 2 , 4 7}$ \\
5 & 85451,50 & 4,89 & $\mathbf{2 7 , 3 6}$ \\
6 & 68921,49 & 3,94 & $\mathbf{3 1 , 3 0}$ \\
7 & 66164,51 & 3,78 & 35,08 \\
8 & 62206,77 & 3,56 & 38,64 \\
9 & 51832,75 & 2,96 & 41,60 \\
10 & 49670,41 & 2,84 & 44,44 \\
11 & 41319,17 & 2,36 & 46,80 \\
12 & 40180,72 & 2,30 & 49,10 \\
13 & 35559,16 & 2,03 & 51,13 \\
14 & 32483,43 & 1,86 & 52,99 \\
15 & 31587,51 & 1,81 & 54,80 \\
16 & 28822,03 & 1,65 & 56,44 \\
17 & 28694,04 & 1,64 & 58,08 \\
18 & 26725,89 & 1,53 & 59,61 \\
19 & 24978,72 & 1,43 & 61,04 \\
20 & 23825,48 & 1,36 & 62,40 \\
\hline & 21897,63 & 1,25 & 63,65 \\
\hline
\end{tabular}


Tabela 6 - Percentual do modelo descrito por cada uma das componentes do modelo gerado para urina bovina a partir de dados de $\mathrm{RMN}-{ }^{1} \mathrm{H}$ (pós refinamento).

\begin{tabular}{|c|c|c|c|}
\hline Componente & Variância & $\%$ Descrito & $\%$ Cumulativo \\
\hline 1 & 478288,69 & 38,22 & 38,22 \\
\hline 2 & 83548,92 & 6,68 & 44,89 \\
\hline 3 & 75088,62 & 6,00 & 50,89 \\
\hline 4 & 54250,50 & 4,33 & 55,23 \\
\hline 5 & 47839,97 & 3,82 & 59,05 \\
\hline 6 & 40014,34 & 3,20 & 62,25 \\
\hline 7 & 34497,17 & 2,76 & 65,00 \\
\hline 8 & 27761,02 & 2,22 & 67,22 \\
\hline 9 & 24963,67 & 1,99 & 69,22 \\
\hline 10 & 21023,68 & 1,68 & 70,90 \\
\hline 11 & 18193,91 & 1,45 & 72,35 \\
\hline 12 & 16252,03 & 1,30 & 73,65 \\
\hline 13 & 15513,71 & 1,24 & 74,89 \\
\hline 14 & 14674,57 & 1,17 & 76,06 \\
\hline 15 & 13975,76 & 1,12 & 77,18 \\
\hline 16 & 12470,42 & 1,00 & 78,18 \\
\hline 17 & 11103,34 & 0,89 & 79,06 \\
\hline 18 & 10944,10 & 0,87 & 79,94 \\
\hline 19 & 10407,41 & 0,83 & 80,77 \\
\hline 20 & 10019,91 & 0,80 & 81,57 \\
\hline
\end{tabular}


Figura 34 - Análise de componentes principais para urina bovina a partir de dados de $\mathrm{RMN}-{ }^{1} \mathrm{H}$, modelo contendo 17 animais. Mesmo considerando-se as componentes de maior peso estatístico, não há uma separação clara das amostras.

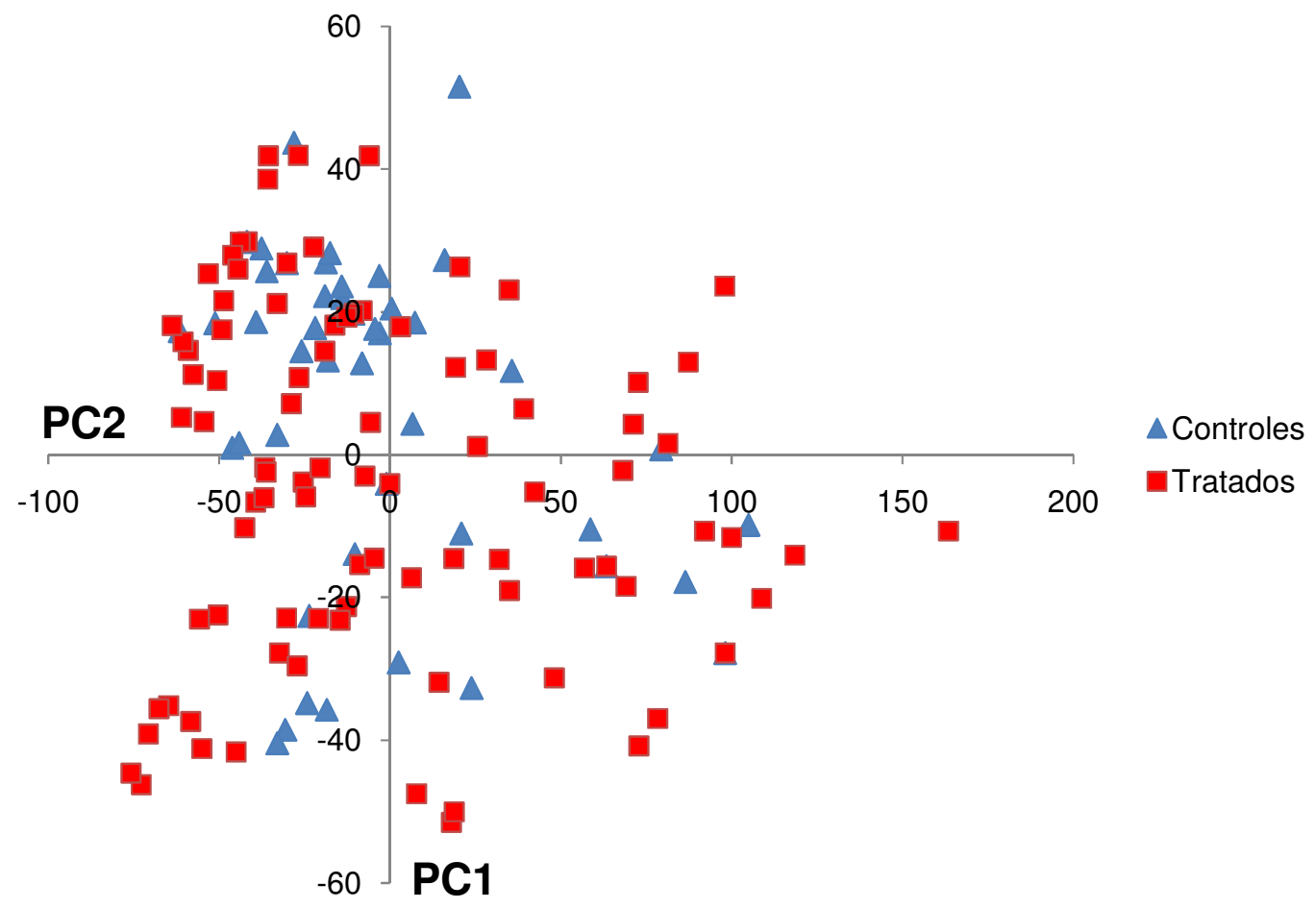

Como mostra a PCA (Figura 34), mesmo após o modelo atingir um percentual descrito satisfatório, o que significa uma maior capacidade descritiva por parte das componentes, não existe uma mudança suficientemente forte na composição da urina para que haja distinção das amostras. Uma vez que para o refinamento seleciona-se apenas as regiões do espectro com maior poder de modelagem, a repetição deste processo pode levar a perda de informações espectrais.

Assim, aplicou-se os mesmos passos no processamento dos dados obtidos de plasma sanguíneo, realizando-se uma análise dos dados na íntegra antes do refinamento. Para as amostras de plasma, foram considerados os pontos do espectro entre 0 e 4,5 ppm, por ser a única região contendo informações apreciáveis. As Tabelas 7 e 8 e as Figuras 35 e 36 mostram os resultados iniciais e finais da PCA. 
Tabela 7 - Percentual do modelo descrito por cada uma das componentes do modelo gerado para plasma sanguíneo bovino (todo o perfil do espectro).

\begin{tabular}{c|ccc}
\hline Componente & Variância & \% Descrito & \% Cumulativo \\
\hline 1 & 29195,68 & 20,55 & $\mathbf{2 0 , 5 5}$ \\
2 & 25178,37 & 17,72 & $\mathbf{3 8 , 2 7}$ \\
3 & 19848,54 & 13,97 & $\mathbf{5 2 , 2 5}$ \\
4 & 8723,38 & 6,14 & $\mathbf{5 8 , 3 9}$ \\
5 & 8168,80 & 5,75 & $\mathbf{6 4 , 1 4}$ \\
6 & 7062,77 & 4,97 & 69,11 \\
7 & 6118,01 & 4,31 & 73,41 \\
8 & 5092,49 & 3,58 & 77,00 \\
9 & 4676,06 & 3,29 & 80,29 \\
10 & 4187,75 & 2,95 & 83,24 \\
11 & 3879,16 & 2,73 & 85,97 \\
12 & 3240,63 & 2,28 & 88,25 \\
13 & 2554,53 & 1,80 & 90,05 \\
14 & 2227,96 & 1,57 & 91,62 \\
15 & 1880,94 & 1,32 & 92,94 \\
16 & 1638,03 & 1,15 & 94,09 \\
17 & 1415,05 & 1,00 & 95,09 \\
18 & 1287,01 & 0,91 & 96,00 \\
19 & 1119,72 & 0,79 & 96,78 \\
20 & 888,40 & 0,63 & 97,41 \\
\hline
\end{tabular}


Figura 35 - Gráfico de scores para PCA de um modelo para plasma sanguíneo bovino contendo 8 animais a partir de dados de $\mathrm{RMN}-{ }^{1} \mathrm{H}$. Mesmo considerando-se as componentes de maior peso estatístico, não há uma separação clara das amostras.

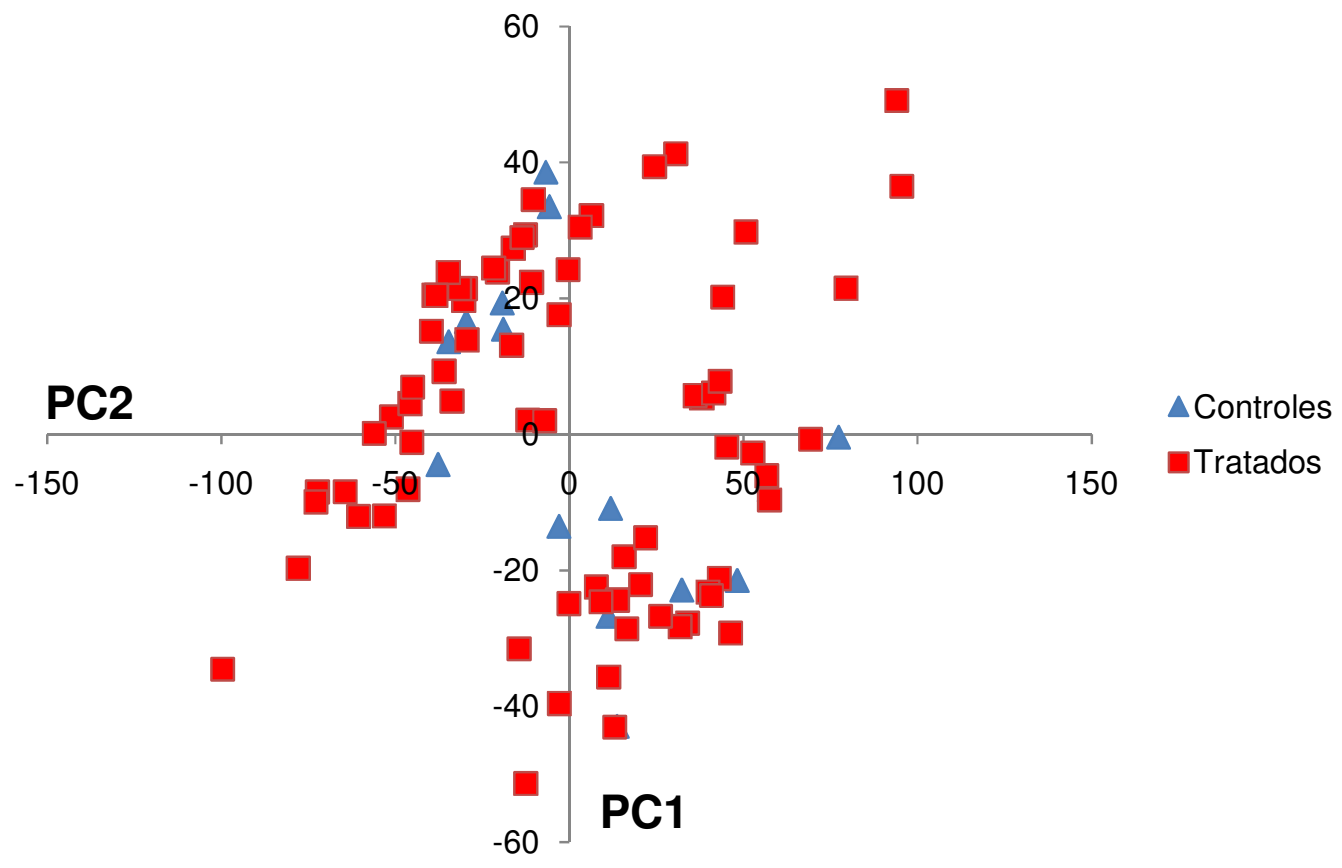

Tabela 8 - Percentual do modelo descrito por cada uma das componentes do modelo gerado para plasma sanguíneo bovino (pós refinamento).

\begin{tabular}{c|ccc}
\hline Componente & Variância & \% Descrito & \% Cumulativo \\
\hline 1 & 7537,90 & 35,84 & 35,84 \\
2 & 6535,54 & 31,07 & 66,91 \\
3 & 2023,35 & 9,62 & 76,53 \\
4 & 1713,92 & 8,15 & $\mathbf{8 4 , 6 8}$ \\
5 & 871,92 & 4,15 & $\mathbf{8 8 , 8 2}$ \\
6 & 677,68 & 3,22 & 92,04 \\
7 & 424,98 & 2,02 & 94,06 \\
8 & 298,64 & 1,42 & 95,48 \\
9 & 225,11 & 1,07 & 96,55 \\
10 & 150,66 & 0,72 & 97,27 \\
11 & 129,42 & 0,62 & 97,88 \\
12 & 109,43 & 0,52 & 98,41 \\
13 & 67,39 & 0,32 & 98,73
\end{tabular}


Tabela 8 - Percentual do modelo descrito por cada uma das componentes do modelo gerado para plasma sanguíneo bovino (pós refinamento).

(conclusão)

\begin{tabular}{c|ccc}
\hline Componente & Variância & \% Descrito & \% Cumulativo \\
\hline 14 & 50,92 & 0,24 & 98,97 \\
15 & 34,89 & 0,17 & 99,13 \\
16 & 33,72 & 0,16 & 99,29 \\
17 & 26,72 & 0,13 & 99,42 \\
18 & 23,82 & 0,11 & 99,53 \\
19 & 21,30 & 0,10 & 99,64 \\
20 & 18,66 & 0,09 & 99,72 \\
\hline
\end{tabular}

Figura 36 - Gráfico de Scores para PCA a partir de dados de $\mathrm{RMN}-{ }^{1} \mathrm{H}$ resultante da seleção de regiões com melhor poder de modelagem.

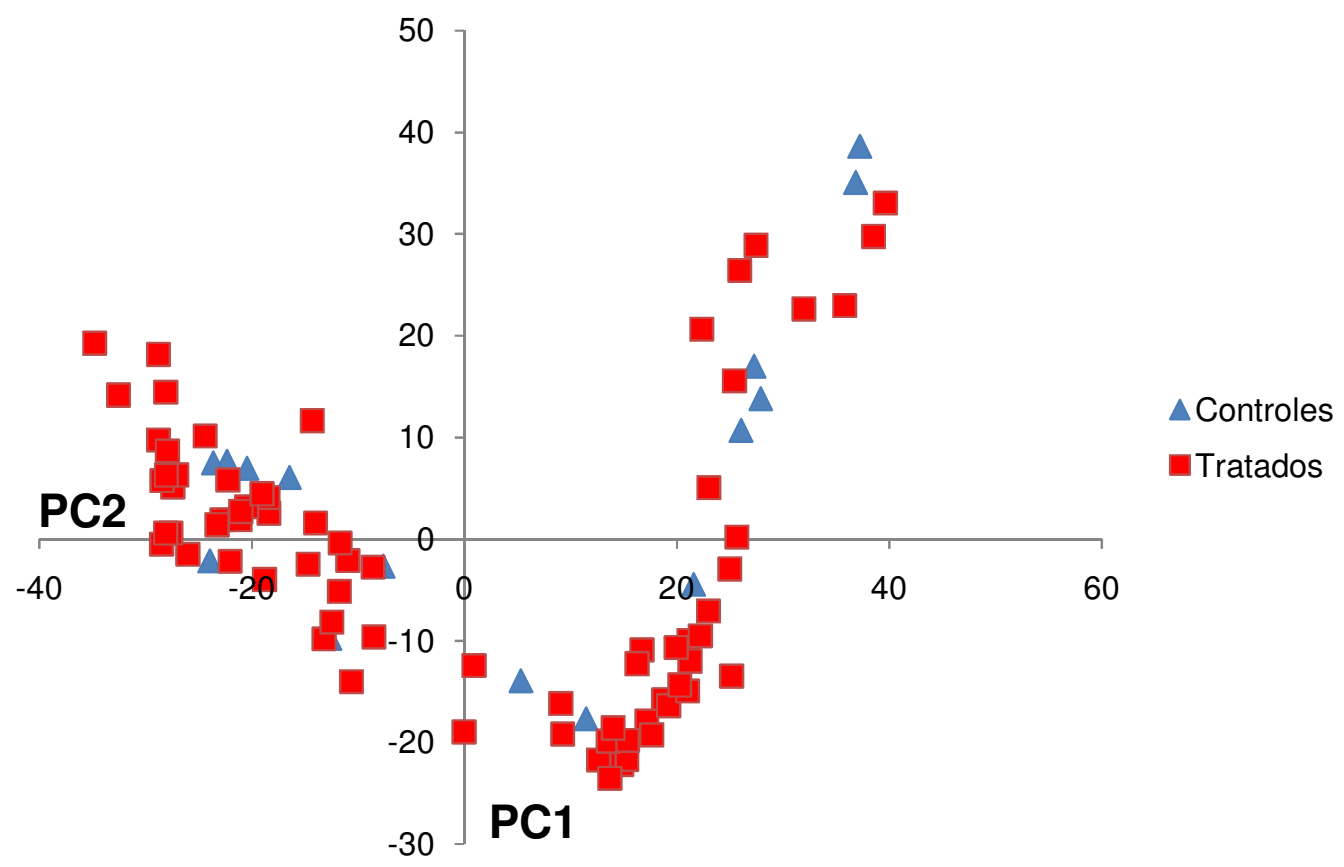

Como é notável, o refinamento por poder de modelagem tornou o modelo mais robusto, sendo capaz de descrever um percentual maior dos dados utilizando menos componentes. Contudo, mesmo com este incremento, a informação obtida a partir do modelo tem pouca precisão no que diz respeito a distinguir os animais antes e após a administração 
de Ivermectina, levando as amostras apenas a uma separação modesta na Análise de Componentes Principais.

Um fator importante de ser ressaltado é um outro tipo de separação obtida para os modelos refinados. Quando se solicita ao programa que mostre as amostras por animais, obtém-se o resultado mostrado na Figura 37.

Figura 37 - Separação das amostras na PCA por animais. Amostras de um mesmo animal tendem a se agrupar com o refinamento do modelo.

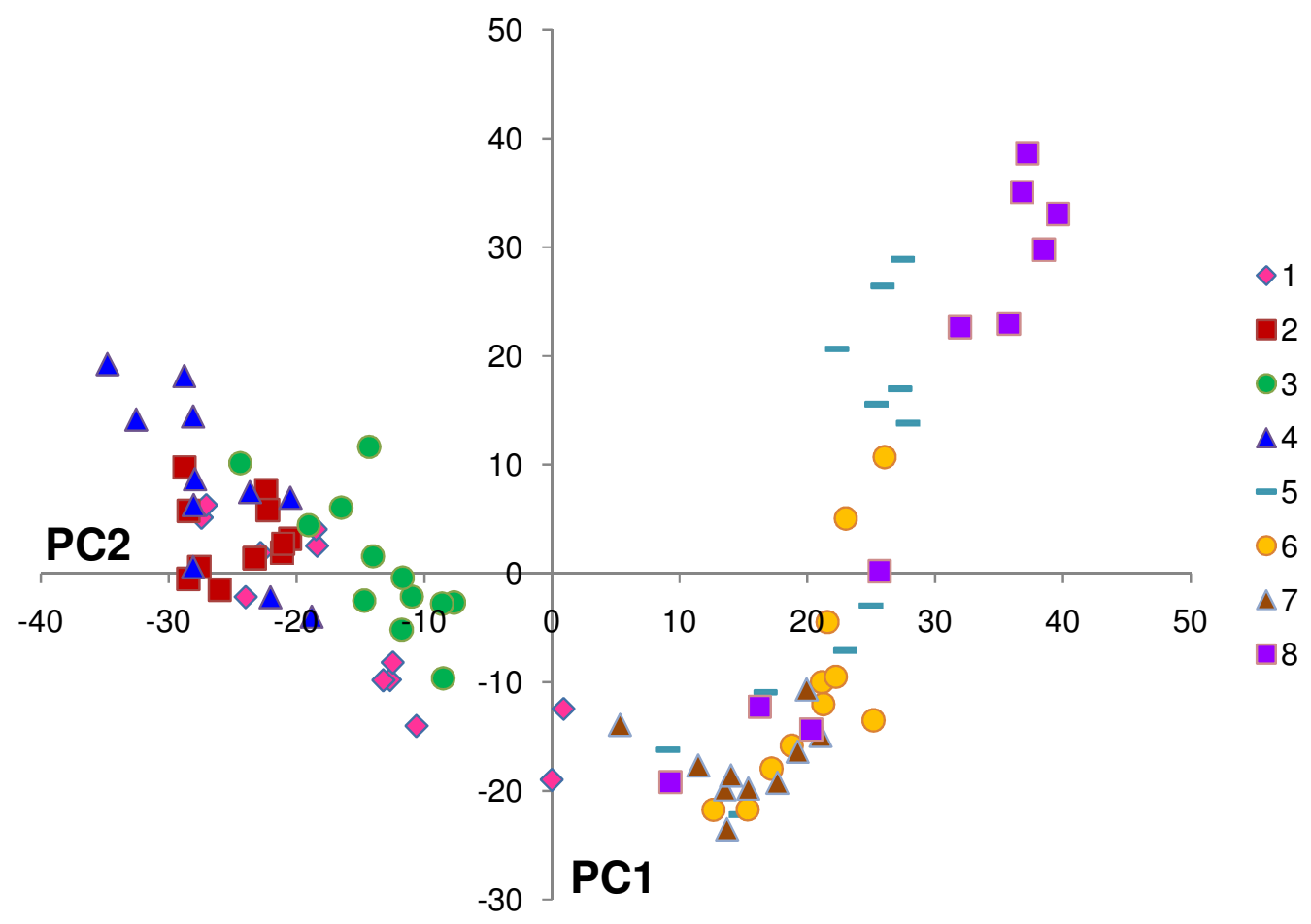

Este agrupamento das amostras por animais sugere que a composição metabólica de um conjunto proveniente do mesmo animal possui caráter único, definido pelo somatório de inúmeros fatores com influência sobre o metabolismo animal, tais como idade, alimentação, presença de doenças ou pragas no organismo, entre outros. Vale ressaltar que mesmo se tratando de animais de mesma espécie, como o gado holandês preto-e-branco, existe um conjunto de pequenas diferenças entre os indivíduos que é estabelecido desde o nascimento dos mesmos, sendo o metabolismo constantemente modificado de acordo com as 
necessidades individuais, no sentido de adaptar o organismo ao ambiente em que vive. De certa forma, as diferenças inerentes ao metabolismo de cada animal estudado são de certa forma mais influentes sobre o modelo quimiométrico do que aquelas provocadas pela administração de Ivermectina. Logo, os dados de $\mathrm{RMN}-{ }^{1} \mathrm{H}$ obtidos para bovinos, apesar de fornecerem informações importantes para o desenvolvimento da técnica e levantamento do perfil metabólico, mostraram-se pouco úteis para a criação de um modelo capaz de distinguir animais tratados e não tratados.

Assim, a técnica de RMN associada a ferramentas quimiométricas simples constitui um promissor método para análise de metabólitos, uma vez que os protocolos de tratamento de amostras permitem a aquisição de dados com boa resolução espectral, e que inseridos em um modelo exploratório, permitem uma leve distinção das amostras, porém não conforme o desejado para este projeto. Após os estudos mostrados, constatou-se que a falta de similaridade entre os organismos estudados, bem como a pequena mudança metabólica induzida por doses terapêuticas de Ivermectina, levam a uma limitação no uso da técnica com o objetivo inicialmente proposto: a utilização destas técnicas para identificação de uso de Ivermectina em animais de corte.

Contudo, no intuito de se verificar a robustez de um modelo como este, propôs-se um experimento envolvendo camundongos da linhagem Balb-C, conforme descrito anteriormente.

\subsection{Camundongos}

\subsubsection{RMN de ${ }^{1} \mathrm{H}$ e ${ }^{13} \mathrm{C}$}

A curva de administração de Ivermectina nos camundongos foi bastante satisfatória para acompanhar todas as etapas da intoxicação. De fato, quatro indivíduos morreram por intoxicação, sendo um do grupo de tratamento 3, um do grupo 4 e dois do grupo 5. 
Os dados de $\mathrm{RMN}-{ }^{1} \mathrm{H}$ foram de boa qualidade, apesar da baixa concentração dos metabólitos. Os camundongos analisados, com então 6 semanas de vida, possuíam massa média de $25 \mathrm{~g}$, e contavam com cerca de apenas $1 \mathrm{~mL}$ de sangue, o que resultava em cerca de $500 \mu \mathrm{L}$ de plasma sanguíneo para análise. Este volume é muito próximo do mínimo necessário para a obtenção dos espectros, o que impediu uma préconcentração satisfatória das amostras. Um dos espectros obtidos é ilustrado na Figura 38.

Figura 38 - Espectro de $\mathrm{RMN}-{ }^{1} \mathrm{H}$ obtido para plasma sanguíneo de um camundongo Balb-C. Analogamente aos espectros para bovinos, é possível observar uma quantidade satisfatória de sinais.

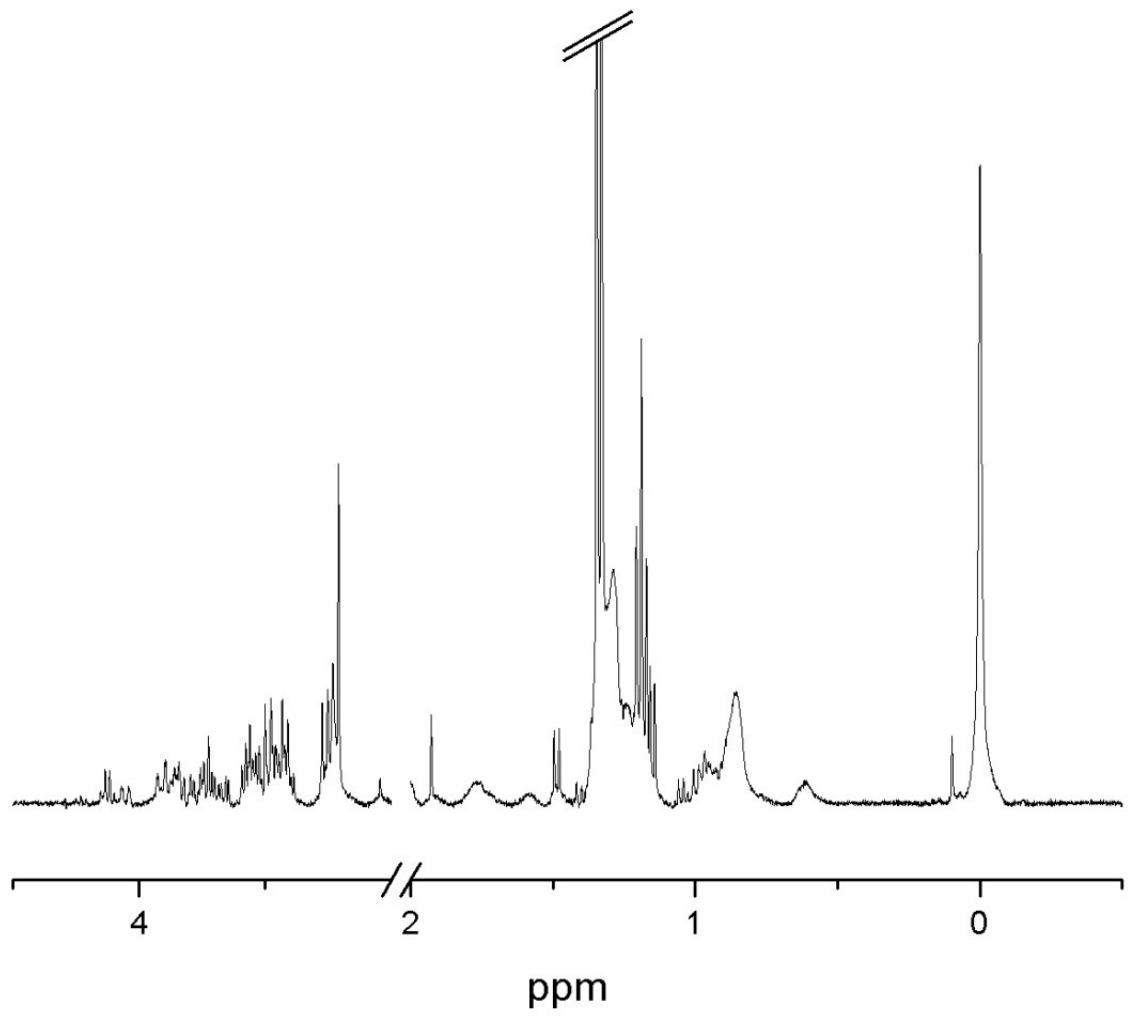

Conforme visto, a qualidade espectral é alta o suficiente para a visualização até mesmo de sinais menores, garantindo assim uma boa matriz de informações para a análise exploratória.

Adicionalmente, foram obtidos espectros de $\mathrm{RMN}-{ }^{13} \mathrm{C}$ para estas amostras, empregando-se tanto a sequência convencional quanto a técnica SSFP, mostrados na Figura 39 e na Tabela 9. 
Figura 39 - Comparativo entre espectros obtidos para plasma sanguíneo de camundongo através das sequência convencional (A) e SSFP (B).
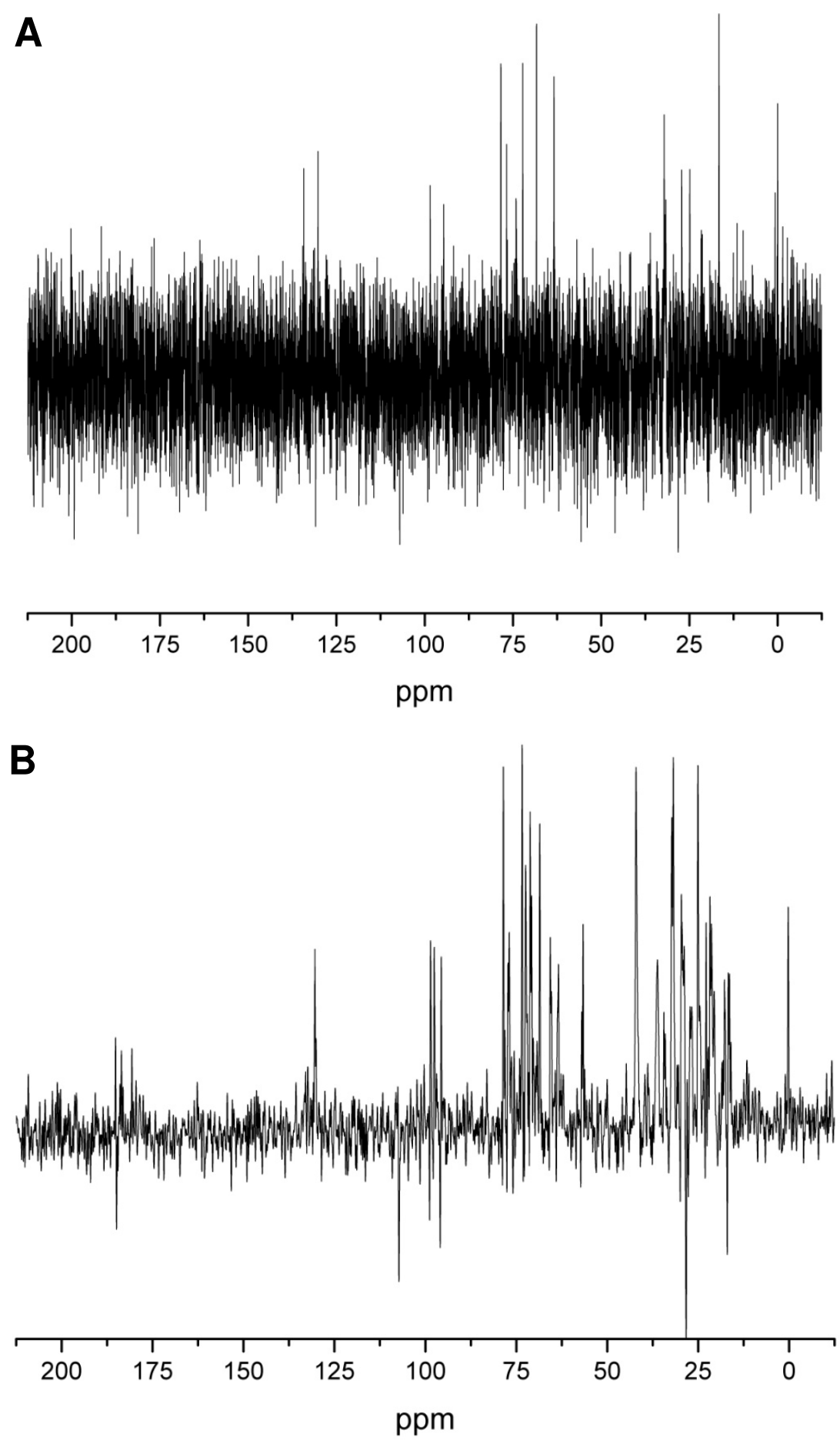
Tabela 9 - Assinalamento de picos para os espectros mostrados na Figura 39.

\begin{tabular}{cc|cccc}
\hline \multicolumn{2}{c|}{ Convencional } & \multicolumn{4}{c}{ SSFP } \\
\hline Sinal & $\mathbf{( p p m )}$ & Sinal & $\mathbf{( p p m )}$ & Sinal & $\mathbf{( p p m )}$ \\
\hline 1 & 0 & $\mathbf{1}$ & $\mathbf{0}$ & 16 & 56,4 \\
2 & 16,63 & $\mathbf{2}$ & $\mathbf{1 6 , 4 4}$ & $\mathbf{1 7}$ & $\mathbf{6 3 , 1 8}$ \\
3 & 24,89 & 3 & 17,45 & 18 & 65,14 \\
4 & 27,17 & 4 & 20,96 & $\mathbf{1 9}$ & $\mathbf{6 8 , 3 1}$ \\
5 & 32,14 & 5 & 21,5 & 20 & 70,94 \\
6 & 63,37 & 6 & 22,57 & $\mathbf{2 1}$ & $\mathbf{7 2 , 1 7}$ \\
7 & 68,31 & $\mathbf{7}$ & $\mathbf{2 4 , 8 4}$ & $\mathbf{2 2}$ & $\mathbf{7 3 , 8 1}$ \\
8 & 72,23 & $\mathbf{8}$ & $\mathbf{2 7 , 7 4}$ & 23 & $\mathbf{7 5 , 3 7}$ \\
9 & 76,79 & 9 & 29,33 & $\mathbf{2 4}$ & $\mathbf{7 6 , 7}$ \\
10 & 78,44 & 10 & 30,18 & $\mathbf{2 5}$ & $\mathbf{7 8 , 3}$ \\
11 & 98,45 & 11 & 31,58 & $\mathbf{2 6}$ & $\mathbf{9 8 , 2 8}$ \\
12 & 130,23 & $\mathbf{1 2}$ & $\mathbf{3 2 , 1 2}$ & 27 & 107,11 \\
13 & 134,27 & 13 & 34,15 & $\mathbf{2 8}$ & $\mathbf{1 3 0 , 1 2}$ \\
& & 14 & 36,04 & 29 & 132 \\
& & 15 & 41,84 & 30 & 184,92 \\
\hline
\end{tabular}

Analogamente aos dados obtidos para as amostras provenientes de bovinos, a técnica SSFP leva à obtenção de um número maior de sinais quando comparada à técnica convencional, mostrando que a grande maioria dos sinais obtidos por esta é visível nos espectros SSFP, com o aparecimento de outros antes não observados. O sinal tarjado em verde para a técnica convencional é o único sem correspondente no espectro SSFP, ao passo que este possui uma quantidade significativamente maior de picos, sendo os sinais em vermelho aqueles observados no espectro obtido com a técnica convencional.

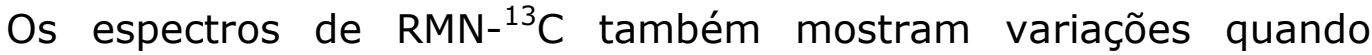
comparados para animais controle e tratados. Contudo, conforme anteriormente mencionado, a aplicabilidade ainda limitada da técnica, associada ao longo tempo de análise, não permitem o uso destes dados 
para análises exploratórias, devendo ser utilizado unicamente com o propósito de complementar os dados de ${ }^{1} \mathrm{H}$ obtidos.

\subsubsection{Análise de Exploratória dos Dados}

Os dados de $\mathrm{RMN}-{ }^{1} \mathrm{H}$ foram também estudados através de ferramentas exploratórias, como PCA e HCA, gerando modelos capazes de distinguir os animais através do tratamento, separando-os dos demais conforme a dose de Ivermectina aumenta durante o experimento. Dos 30 animais estudados, utilizou-se as amostras de plasma de 29, sendo 1 das amostras (um dos animais do grupo basal) descartada por ter-se mostrado inadequada para aquisição de espectros de qualidade. Analogamente aos modelos gerados para bovinos, inicialmente foi realizada uma análise exploratória dos dados integrais, considerando-se para isso a região entre 0 e 4,5 ppm. Como esperado, o refinamento do modelo através das regiões com melhor poder de modelagem mostrou-se eficiente no aumento do poder de separação, mesmo o modelo inicial já mostrando uma promissora capacidade de distinguir as amostras. As Tabelas 10 e 11, juntamente com as Figuras 40e 41 ilustram o resultado da PCA antes e após o refinamento.

Tabela 10 - Percentual descrito pelas componentes do modelo gerado para dados de $\mathrm{RMN}-{ }^{1} \mathrm{H}$ de plasma sanguíneo de camundongo (todo o perfil do espectro).

(continua)

\begin{tabular}{c|ccc}
\hline Componente & Variância & \% Descrito & \% Cumulativo \\
\hline 1 & 43428,74 & 10,97 & $\mathbf{1 0 , 9 7}$ \\
2 & 40307,95 & 10,18 & $\mathbf{2 1 , 1 5}$ \\
3 & 32212,12 & 8,13 & $\mathbf{2 9 , 2 8}$ \\
4 & 23542,06 & 5,95 & $\mathbf{3 5 , 2 3}$ \\
5 & 22024,91 & 5,56 & $\mathbf{4 0 , 7 9}$ \\
7 & 19762,48 & 4,99 & 45,78 \\
& 18884,90 & 4,77 & 50,55
\end{tabular}


Tabela 11 - Percentual descrito pelas componentes do modelo gerado para dados de $\mathrm{RMN}-{ }^{1} \mathrm{H}$ de plasma sanguíneo de camundongo (todo o perfil do espectro).

(conclusão)

\begin{tabular}{c|ccc}
\hline Componente & Variância & \% Descrito & \% Cumulativo \\
\hline 8 & 17526,77 & 4,43 & 54,97 \\
9 & 16255,69 & 4,11 & 59,08 \\
10 & 15116,35 & 3,82 & 62,90 \\
11 & 14223,14 & 3,59 & 66,49 \\
12 & 11409,18 & 2,88 & 69,37 \\
13 & 11485,82 & 2,90 & 72,27 \\
14 & 11000,79 & 2,78 & 75,05 \\
15 & 10097,13 & 2,55 & 77,60 \\
16 & 9498,01 & 2,40 & 79,99 \\
17 & 9066,22 & 2,29 & 82,28 \\
18 & 8317,24 & 2,10 & 84,38 \\
19 & 7875,07 & 1,99 & 86,37 \\
20 & 7581,64 & 1,91 & 88,29 \\
\hline
\end{tabular}

Figura 40 - Gráfico de scores da PCA para o modelo gerado com as amostras de camundongos a partir de dados de $\mathrm{RMN}-{ }^{1} \mathrm{H}$, mostrando animais controle e grupo basal (azul) e tratados (vermelho). Análise realizada com todo o perfil do espectro.

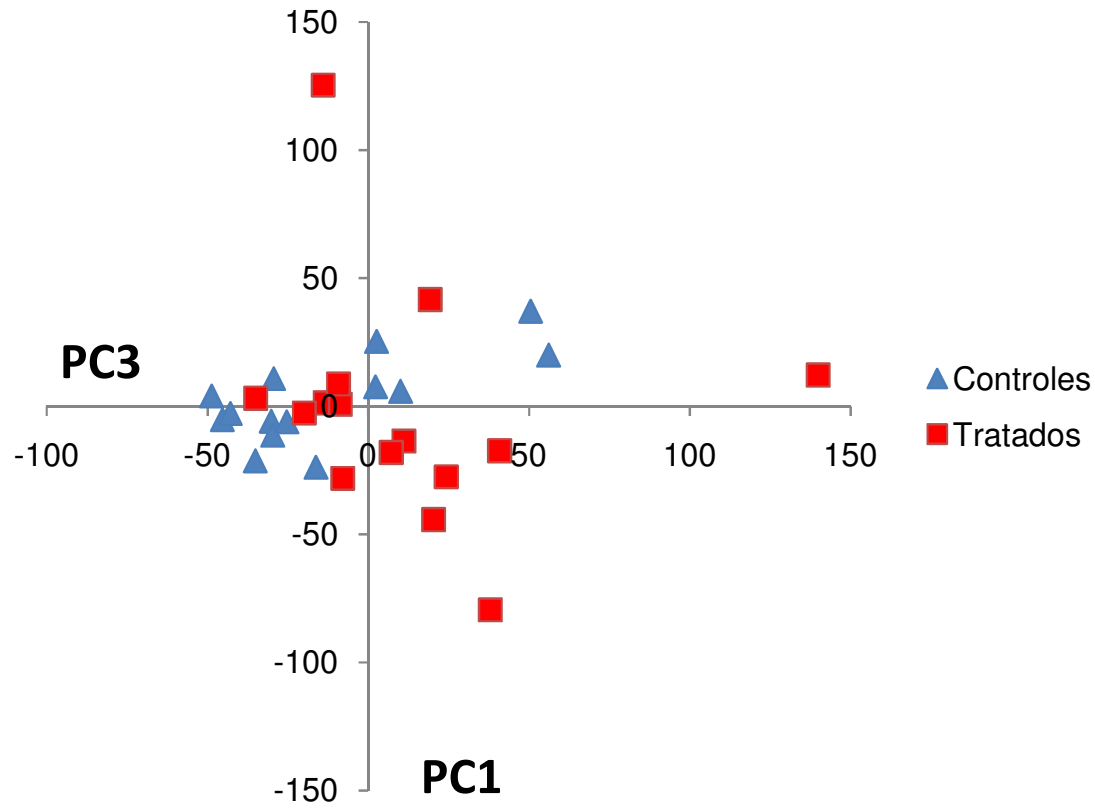


Tabela 12 - Percentual descrito pelas componentes do modelo gerado para dados de $\mathrm{RMN}-{ }^{1} \mathrm{H}$ de plasma sanguíneo de camundongo (pós refinamento).

\begin{tabular}{c|ccc}
\hline Componente & Variância & \% Descrito & \% Cumulativo \\
\hline 1 & 13622,03 & 37,02 & 37,02 \\
2 & 5746,73 & 15,62 & $\mathbf{5 2 , 6 4}$ \\
3 & 3006,82 & 8,17 & $\mathbf{6 0 , 8 2}$ \\
4 & 2134,90 & 5,80 & $\mathbf{6 6 , 6 2}$ \\
5 & 1762,76 & 4,79 & $\mathbf{7 1 , 4 1}$ \\
6 & 1620,73 & 4,41 & 75,82 \\
7 & 1432,47 & 3,89 & 79,71 \\
8 & 1220,49 & 3,32 & 83,03 \\
9 & 1002,84 & 2,73 & 85,75 \\
10 & 762,82 & 2,07 & 87,83 \\
11 & 742,29 & 2,02 & 89,84 \\
12 & 580,84 & 1,58 & 91,42 \\
13 & 471,82 & 1,28 & 92,70 \\
14 & 423,69 & 1,15 & 93,86 \\
15 & 382,05 & 1,04 & 94,89 \\
16 & 352,66 & 0,96 & 95,85 \\
17 & 261,51 & 0,71 & 96,56 \\
18 & 247,66 & 0,67 & 97,24 \\
19 & 197,35 & 0,54 & 97,77 \\
20 & 159,94 & 0,43 & 98,21 \\
\hline
\end{tabular}


Figura 41 - Gráfico de scores da PCA para o modelo gerado com as amostras de camundongos a partir de dados de $\mathrm{RMN}-{ }^{1} \mathrm{H}$, mostrando animais controle e grupo basal (azul) e tratados (vermelho). Análise conduzida após refinamento por regiões de alto poder de modelagem.

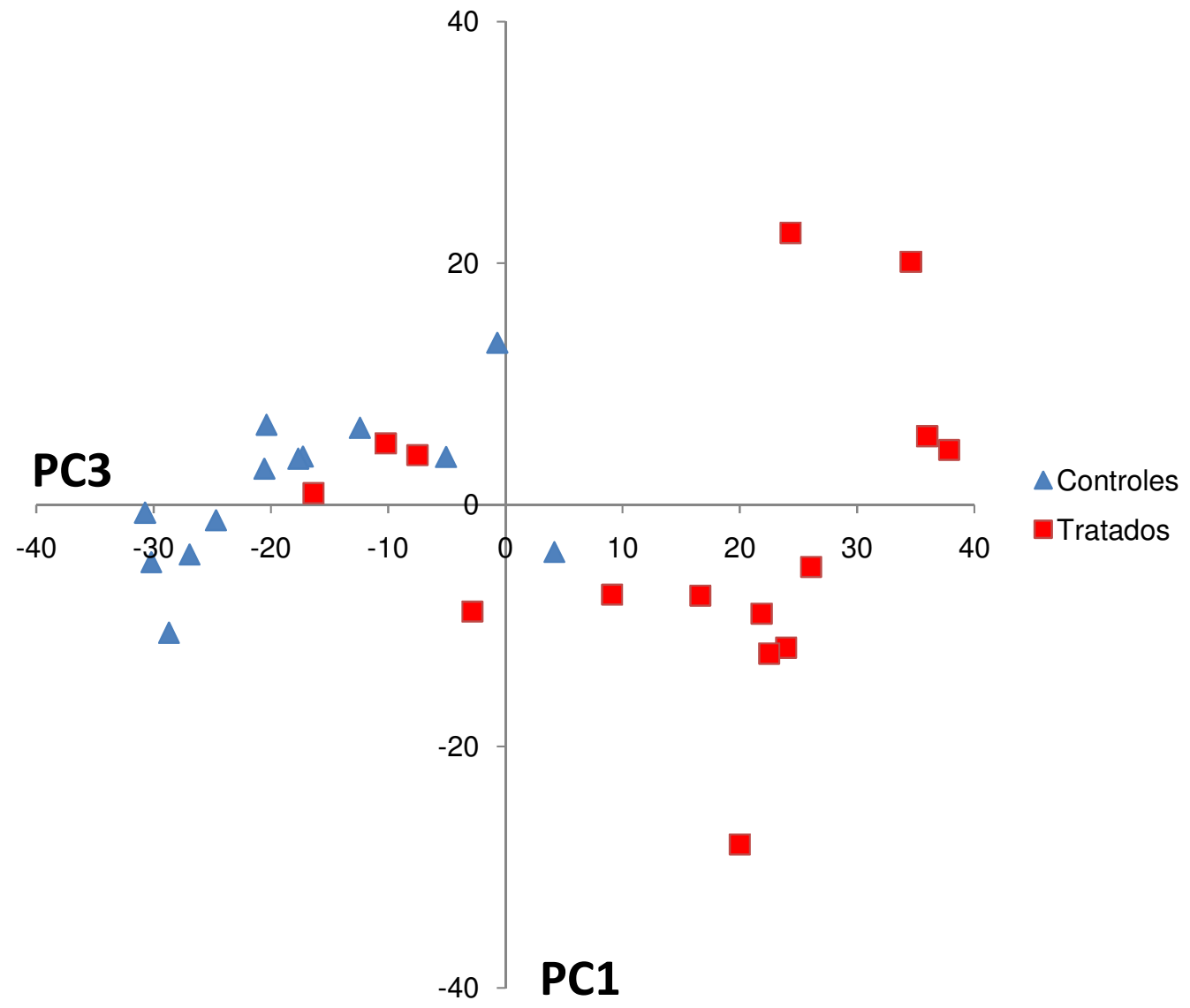

Como se nota, o modelo foi capaz de diferenciar as amostras de animais tratados e controle, separando-as em torno da PC-1. Ao analisarse as 3 amostras de animais tratados que encontram-se entre as amostras de animais controle, notou-se que estas pertencem ao primeiro grupo de tratamento, sugerindo maior similaridade com os animais controle. Isso se deve provavelmente ao fato de que com apenas a primeira dose programada, o metabolismo não foi ainda significativamente alterado. A fim de se investigar como os grupos se comportam na PCA, foi criada uma nova classificação das amostras, através dos grupos de maneira independente, como mostra a Figura 42. 
Figura 42 - PCA ilustrada na figura 20, utilizando classificação por grupos.

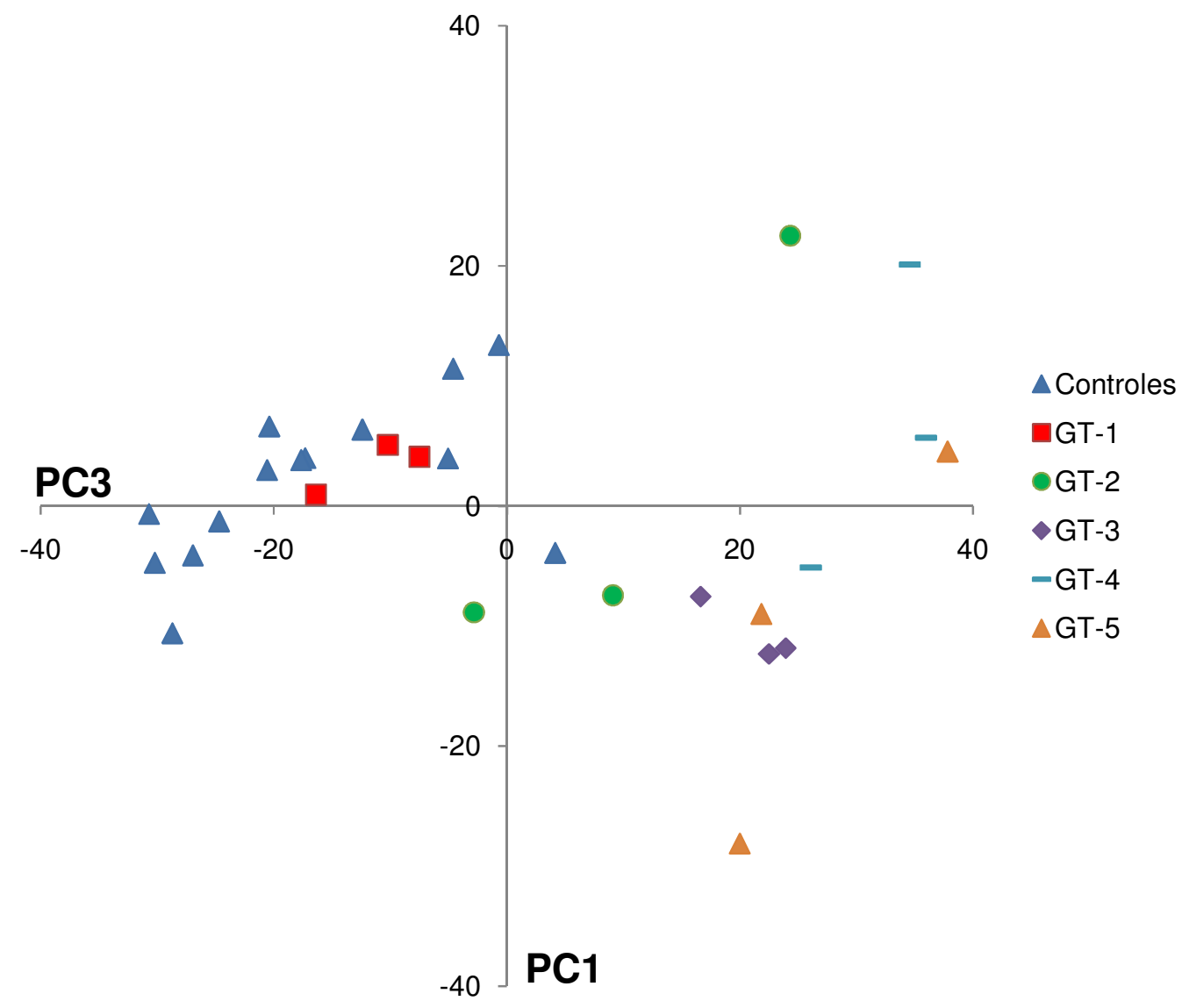

Através da PCA, os dados de RMN são capazes de distinguir alterações metabólicas ocorridas, quando compara-se aqueles obtidos para os animais controle e do grupo basal àqueles obtidos para os animais medicados com Ivermectina, mostrando que o sistema depende da indução de uma mudança drástica na composição do plasma, levando a espectros sensivelmente diferentes entre si.

Uma ferramenta de grande utilidade durante as análises exploratórias é a possibilidade de se selecionar as variáveis (inputs, pontos do espectro) responsáveis pela distinção das amostras. Para isso, elege-se no gráfico de scores as componentes responsáveis pela maior distinção do modelo. Em seguida, utilizando-se as mesmas componentes no gráfico de loadings, seleciona-se as entradas com maior peso estatístico em torno desta componente, tecnicamente responsáveis pela maior influência no modelo. Finalmente, as variáveis selecionadas são 
simultaneamente destacadas nos dados originais, revelando-se assim as regiões espectrais onde o modelo identificou as variações. No caso do modelo gerado para as amostras de plasma de camundongos, após o refinamento contínuo do modelo, as amostras passaram a concentrar-se em duas regiões do gráfico de loadings, mostrando que este procedimento, quando executado corretamente, tende a selecionar as amostras de maior influência sobre o modelo de maneira natural.

As Figuras 43, 44 e 45 ilustram o passo a passo da análise exploratória utilizando PCA para os dados de RMN de camundongos.

Figura 43 - Gráfico de loadings da PCA. Utilizando-se as melhores componentes da PCA para gerar o gráfico, é possível selecionar as variáveis mais provavelmente responsáveis pela distinção do modelo. As imagens referem-se aos loadings antes (A) e após (B) o refinamento.

(continua)

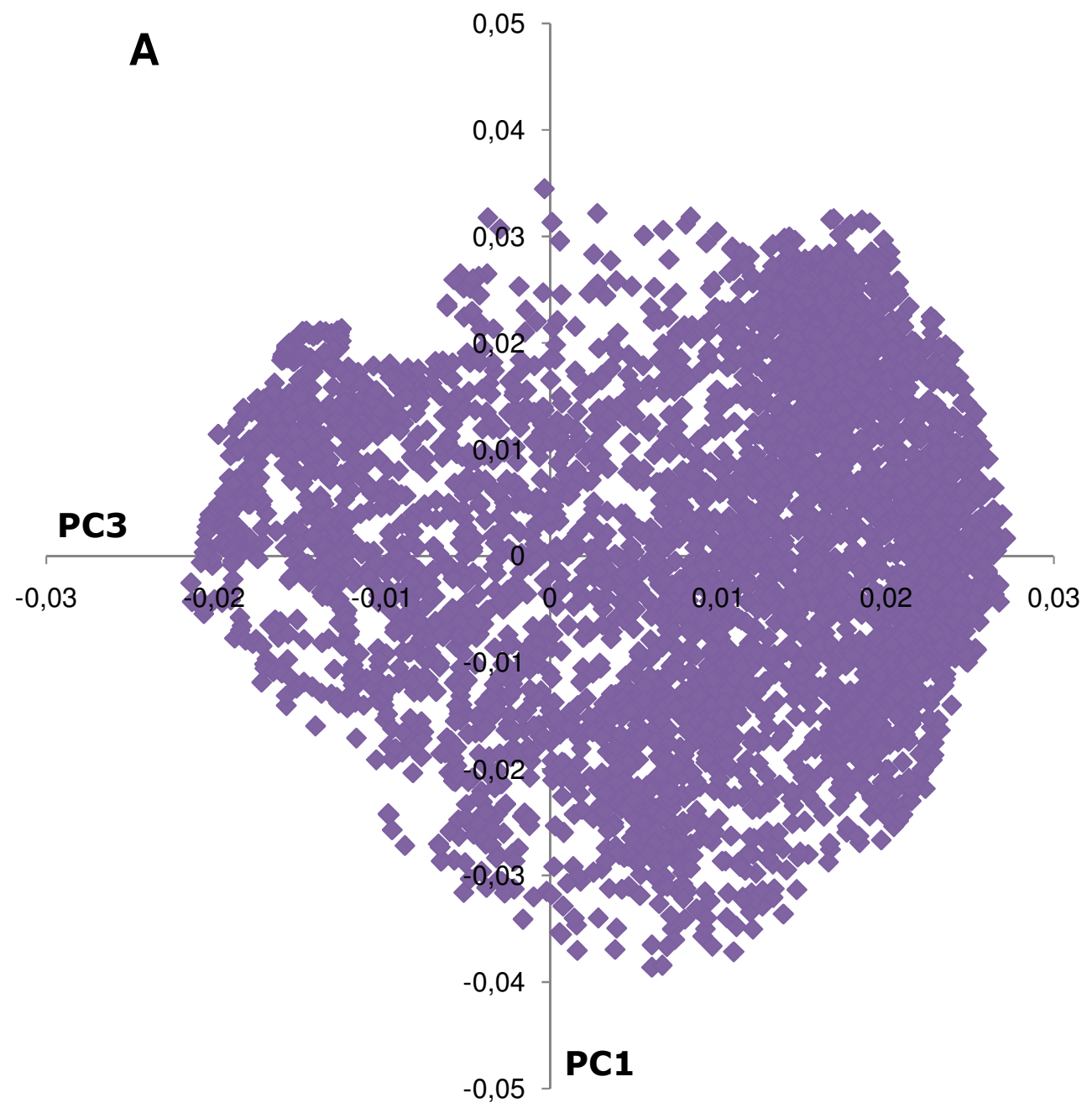


Figura 43 - Gráfico de loadings da PCA. Utilizando-se as melhores componentes da PCA para gerar o gráfico, é possível selecionar as variáveis mais provavelmente responsáveis pela distinção do modelo. As imagens referem-se aos loadings antes (A) e após (B) o refinamento.

(conclusão)

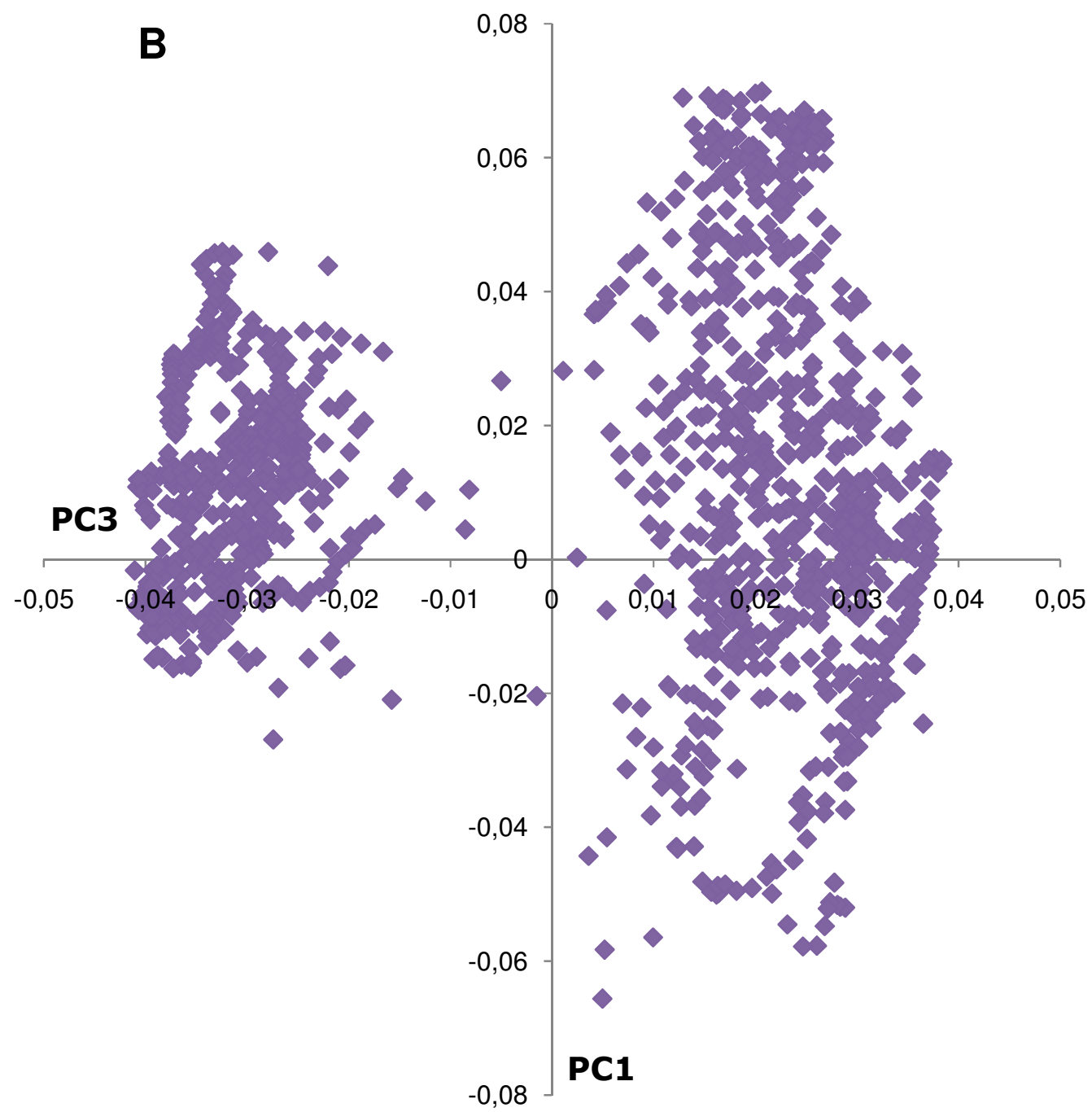


Figura 44 - Através da seleção das variáveis desejadas, as mesmas são destacadas em todo o modelo, inclusive nos dados originais, mostrando as regiões de interesse no espectro.
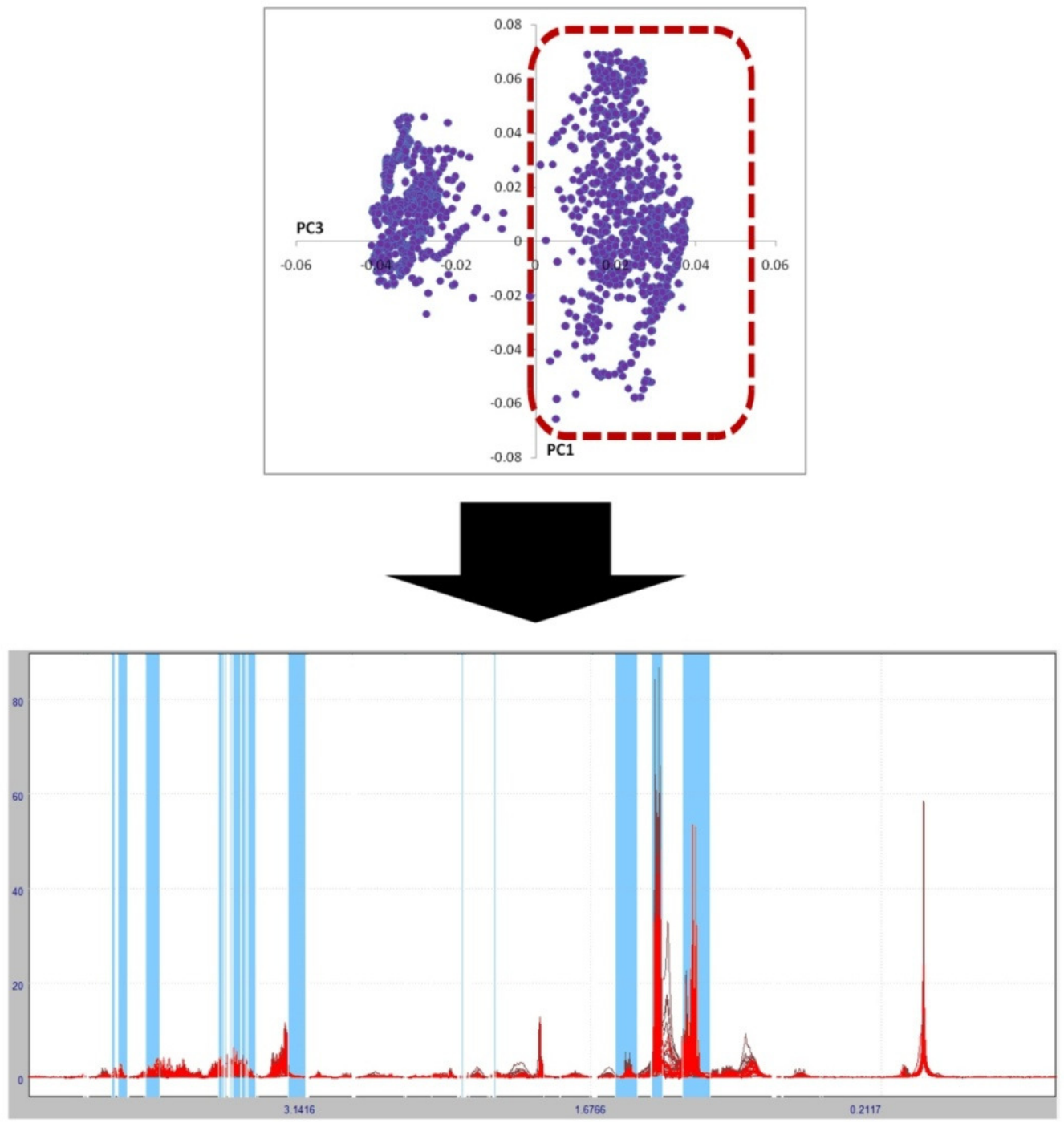
Figura 45 - Sobreposição espectral de dados de $\mathrm{RMN}-{ }^{1} \mathrm{H}$ das regiões indicadas pela PCA.
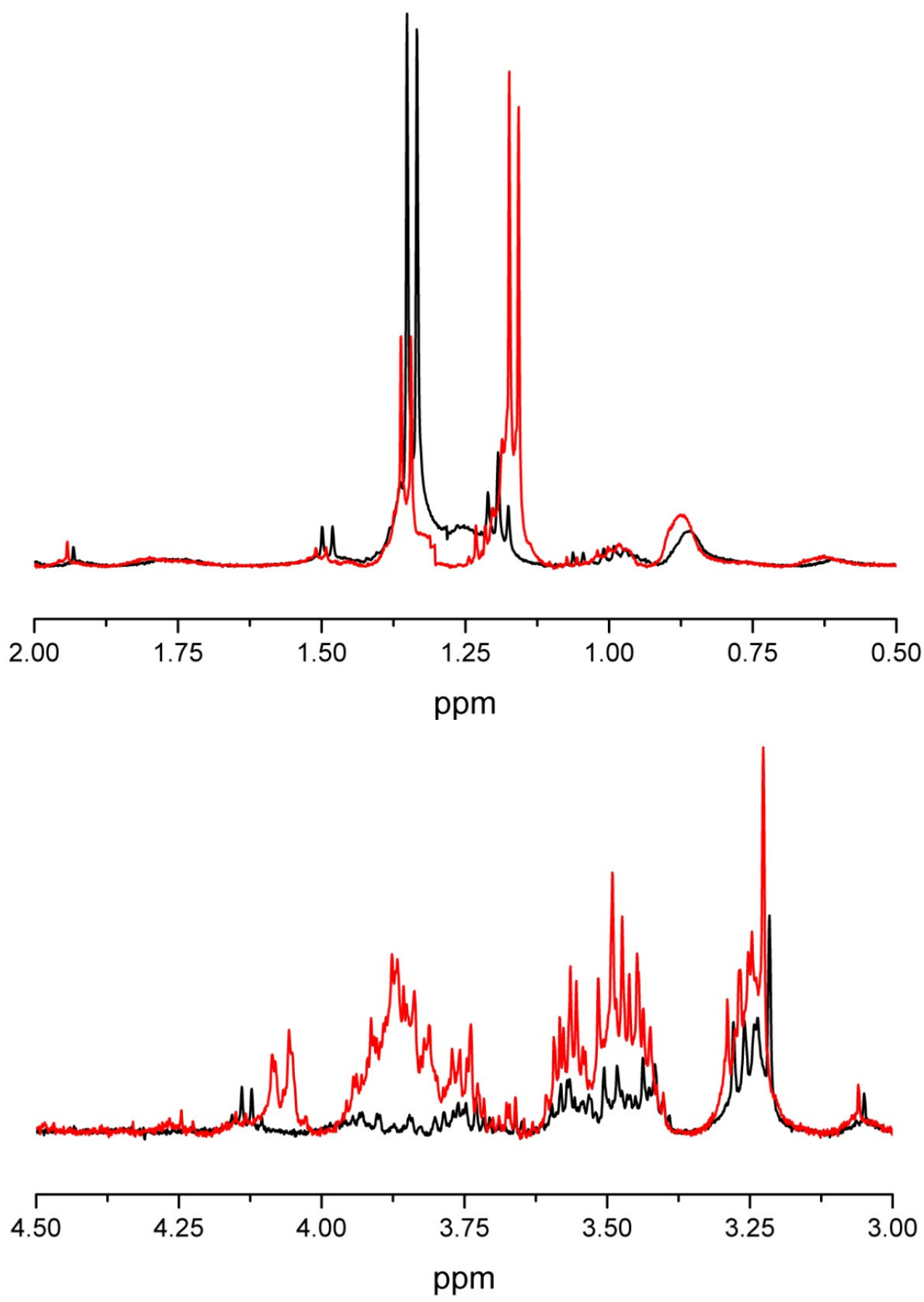

Como forma de corroborar os dados de PCA, modelos de HCA foram gerados também para os camundongos estudados. Os dados de HCA são mostrados na Figura 46. 
Figura 46 - Dendrograma de HCA para amostras de plasma sanguíneo de camundongos a partir de dados de RMN- ${ }^{1} \mathrm{H} . \mathrm{A}$ linha pontilhada mostra a divisão das amostras em dois grandes grupos.

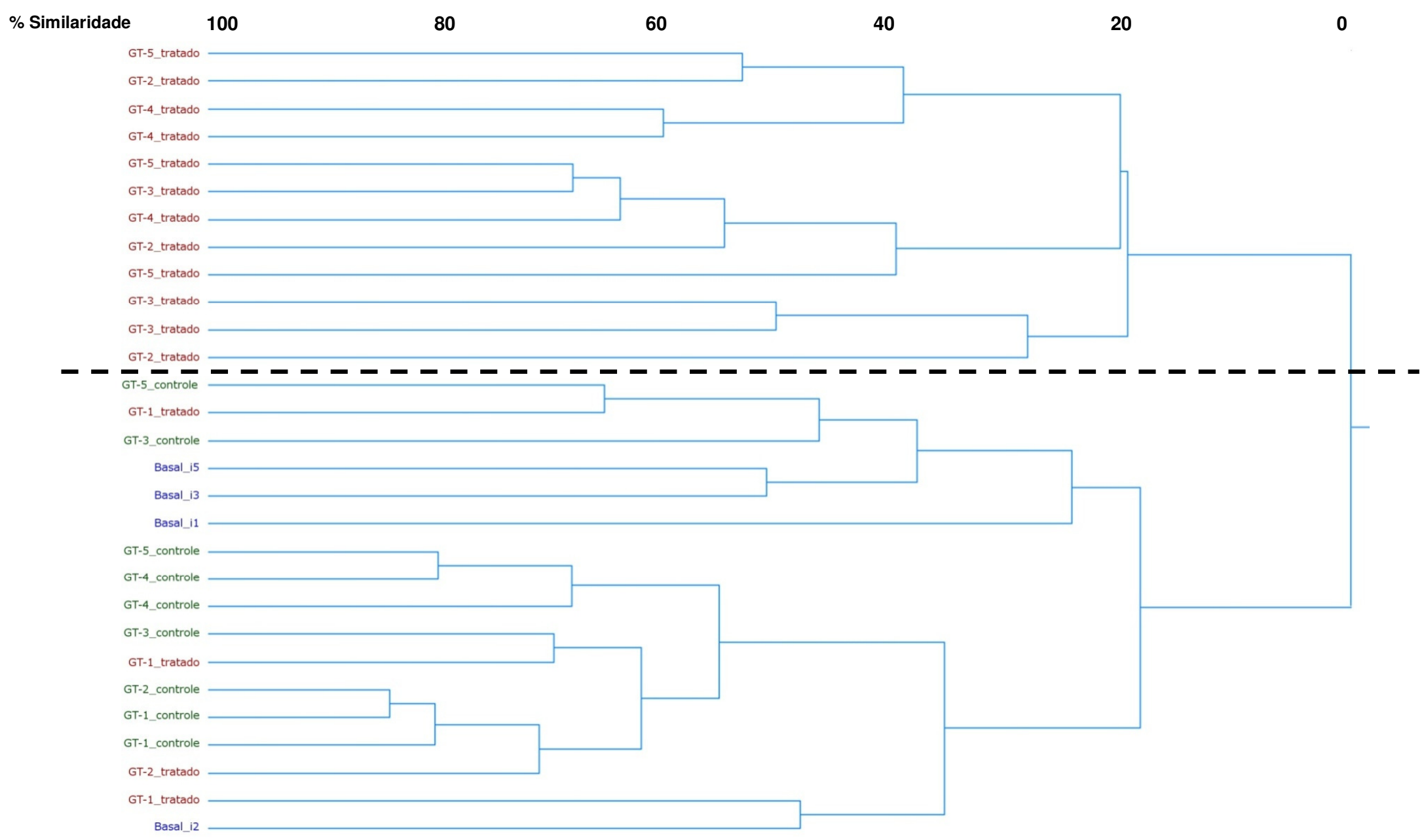


Conforme mostra o dendrograma, as amostras são distinguidas logo no início do gráfico (à direita), sendo separadas em dois grupos. A HCA considera o percentual de similaridade entre as amostras, e compara a informação conservada entre as mesmas para correlacioná-las, estabelecendo esta similaridade em percentagem. Quando duas amostras possuem um certo percentual de similaridade, abaixo daquele valor há somente um braço do dendrograma para ambas, sendo que acima daquele a ramificação ilustra as amostras separadamente, até que aos $100 \%$ as amostras são todas individuais. A separação em dois grupos mostra que o sistema foi capaz de identificar as amostras dos animais que receberam Ivermectina, diferindo-as das demais. Enquanto o grupo abaixo da linha pontilhada é composto pelos animais do grupo basal, além dos animais controle de cada grupo e alguns indivíduos tratados dos grupos iniciais (GT-1 e GT-2) o grupo acima é composto unicamente por indivíduos tratados dos grupos finais (GT-3 a GT-5), com uma similaridade entre os dois grupos de cerca de apenas $20 \%$. Este resultado mostra que através da $\mathrm{RMN}^{1} \mathrm{H}$ é possível fazer a leitura da composição plasmática sanguínea para estes animais, e que através de um experimento que induza uma variação sensível no metabolismo é torna-se praticável a detecção de variações através do uso de ferramentas quimiométricas.

\subsection{Caracterização de Metabólitos}

Utilizando-se os espectros mono e bidimensionais, com o auxílio das bases de dados mencionadas, fez-se a caracterização de alguns dos sinais encontrados, relacionando-os aos metabólitos correspondentes.

Inicialmente, através de uma inspeção visual, é possível notar uma mudança gradual nos espectros obtidos para os animais 
estudados. A Figura 47 detalha a região espectral entre 0,9 e 1,7 ppm ao longo do experimento.

Figura 47 - Espectros de $\mathrm{RMN}-{ }^{1} \mathrm{H}$ para um camundongo do grupo basal (preto) e tratados: GT-3 (azul) e GT-5 (vermelho). A região ilustrada mostra alterações na composição do plasma sanguíneo destes animais ao longo do experimento. As linhas pontilhadas unem sinais equivalentes nos diferentes espectros.

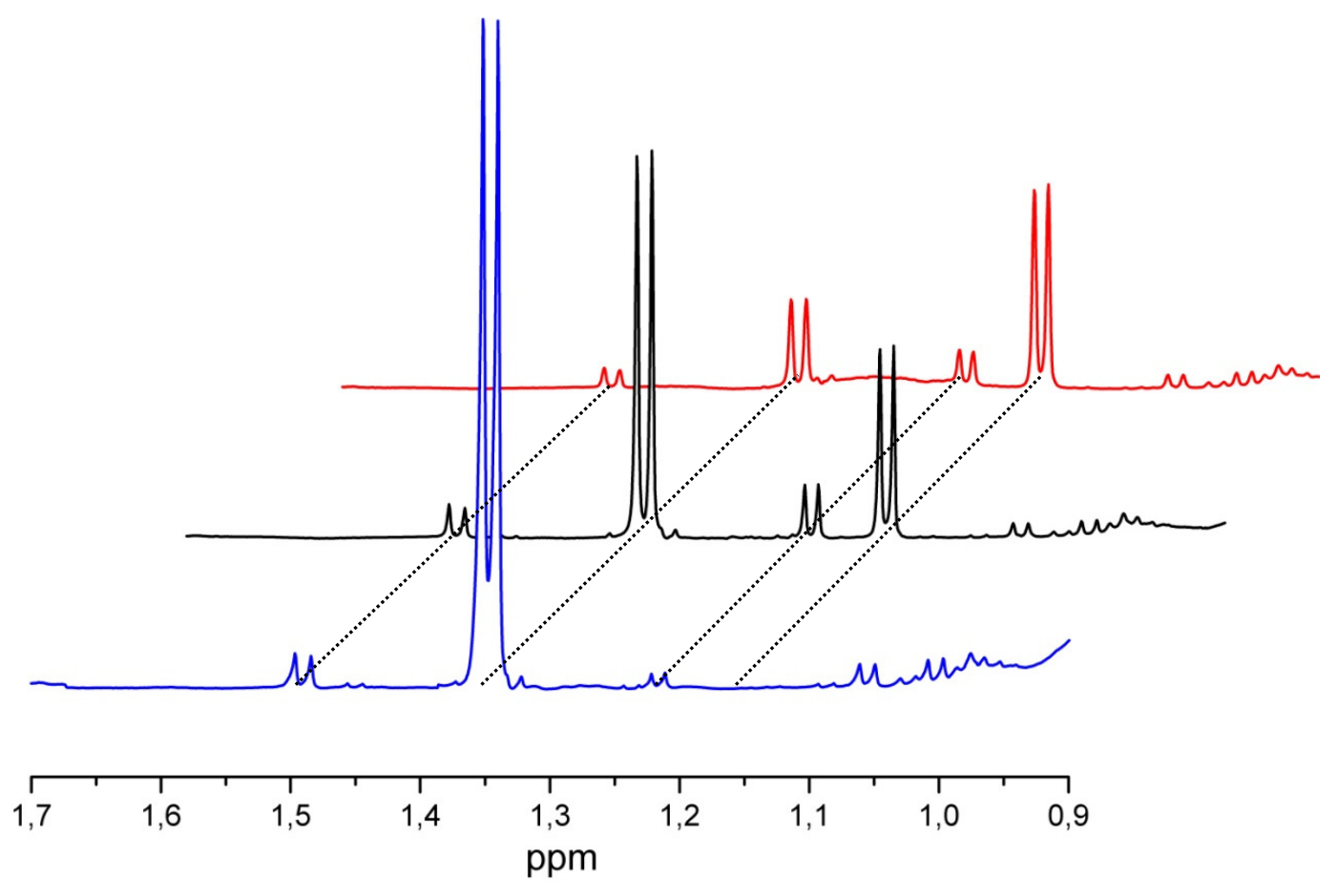

A interpretação dos dados 2D foi feita primeiramente através dos dados de COSY, onde as correlações de hidrogênios vizinhos é visível. A Figura 48 ilustra a região em torno de 1,3 ppm em um espectro monodimensional, onde destaca-se um dubleto com constante de acoplamento (J) de 6,97 Hz. 
Figura 48 - Região espectral em torno de 1,3 ppm, mostrando o dubleto com constante de acoplamento de $6,97 \mathrm{~Hz}$.

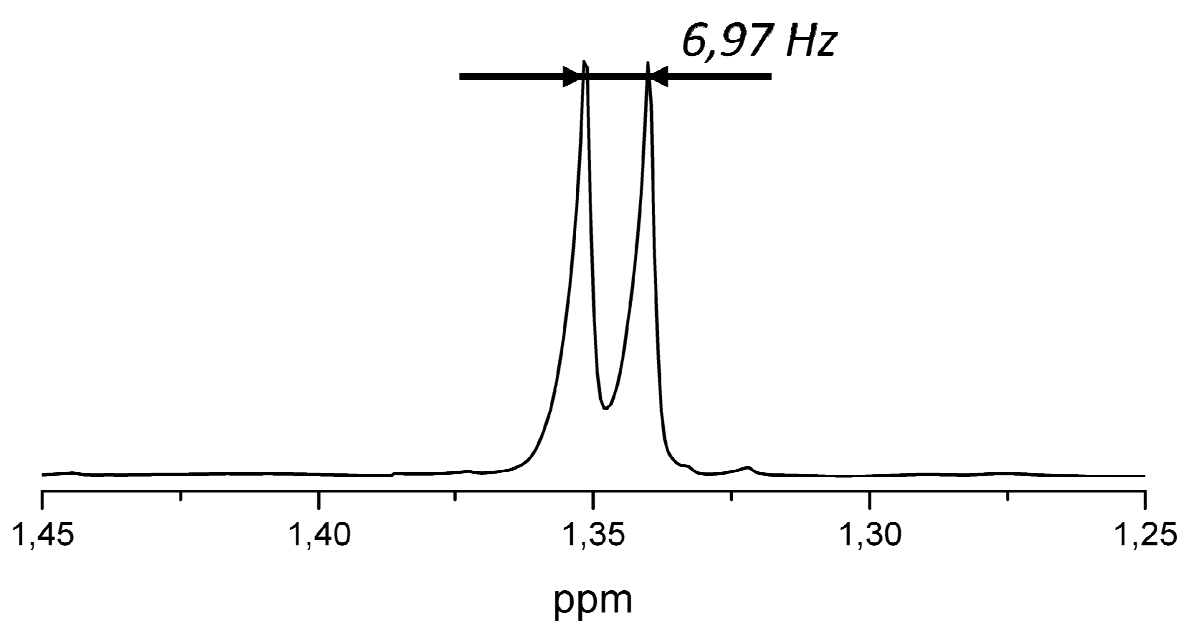

Ao analisar-se o mesmo sinal no espectro COSY, nota-se que o mesmo possui correlação com outro grupo (quarteto), cujo deslocamento químico é 4,13 ppm, e que apresenta a mesma constante de acoplamento de $6,97 \mathrm{~Hz}$, como mostra a Figura 49. A correlação entre dubleto e quarteto sugere a presença de um grupo metil vizinho a um $\mathrm{CH}$, bem como a ausência de outras correlações expressivas destes sinais com outros presentes no espectro sugere que trata-se de uma molécula pequena, desprovida de outros hidrogênios. 
Figura 49 - Espectro COSY para amostra de plasma sanguíneo de camundongo. Mostrando as correlações entre átomos de hidrogênio em grupos imediatamente vizinhos.

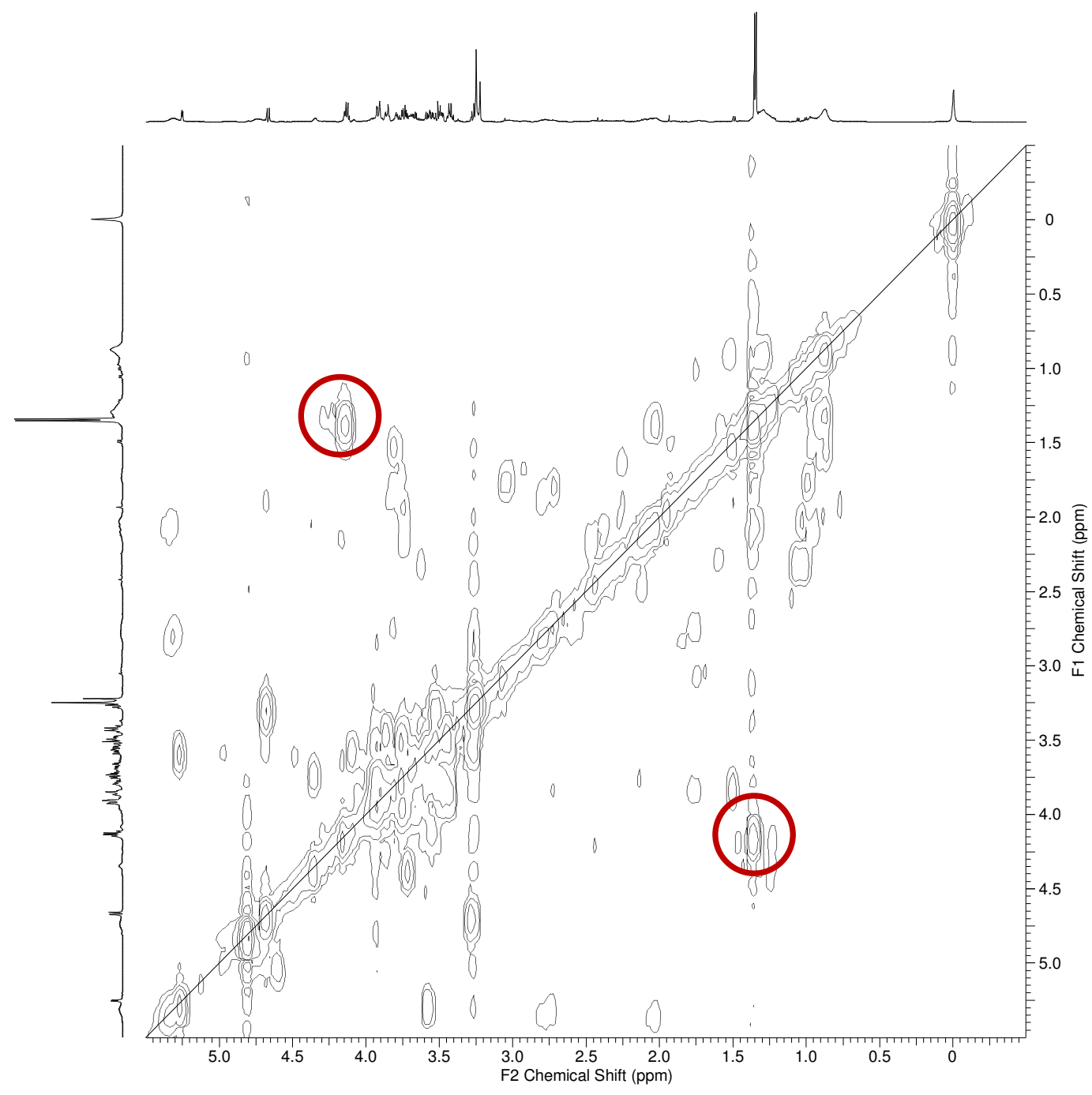

O passo seguinte na caracterização 2D é procurar correlações entre hidrogênios e carbonos ligados diretamente entre si através dos espectros HSQC, que mostra em uma das dimensões o espectro de ${ }^{1} \mathrm{H}$ e na outra, ${ }^{13} \mathrm{C}$, revelando assim quais ligações existem entre os átomos presentes. Na figura 50 , é mostrado o espectro HQSC para a mesma amostra, com destaque para as regiões onde encontram-se as correlações de hidrogênio mostradas na figura anterior. 
Figura 50 - Espectro HQSC para amostra de plasma sanguíneo de camundongo (somente regiões contendo correlações são mostradas). As regiões destacadas mostram correlações $\mathrm{C}-\mathrm{H}$ para os sinais levantados no COSY.

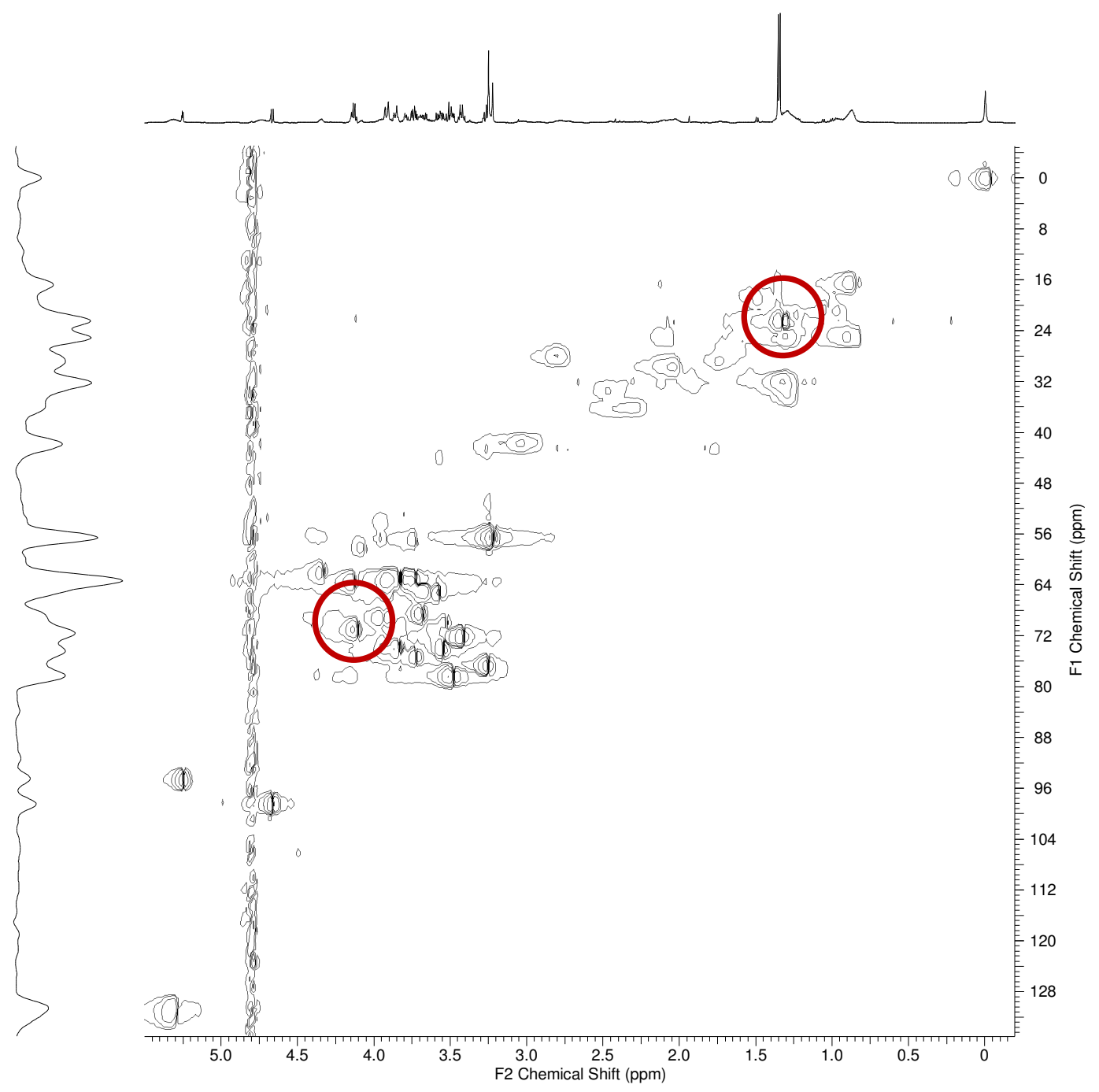

Como é mostrado, para o dubleto em 1,35 ppm, há uma correlação com um átomo de carbono com deslocamento químico aproximado de $22,2 \mathrm{ppm}$, ao passo que para o quarteto em 4,13 ppm, a correlação aparece em 70,5 ppm. Finalmente, o espectro HMBC mostra as correlações restantes, ocorrentes entre átomos de carbono e hidrogênio a longa distância (mais de uma ligação entre os mesmos). A Figura 51 mostra o resultado do espectro HMBC para a mesma amostra. 
Figura 51 - Espectro HMBC para amostra de plasma sanguíneo de camundongo. As regiões destacadas mostram as correlações a longa distância para os sinais encontrados no COSY.

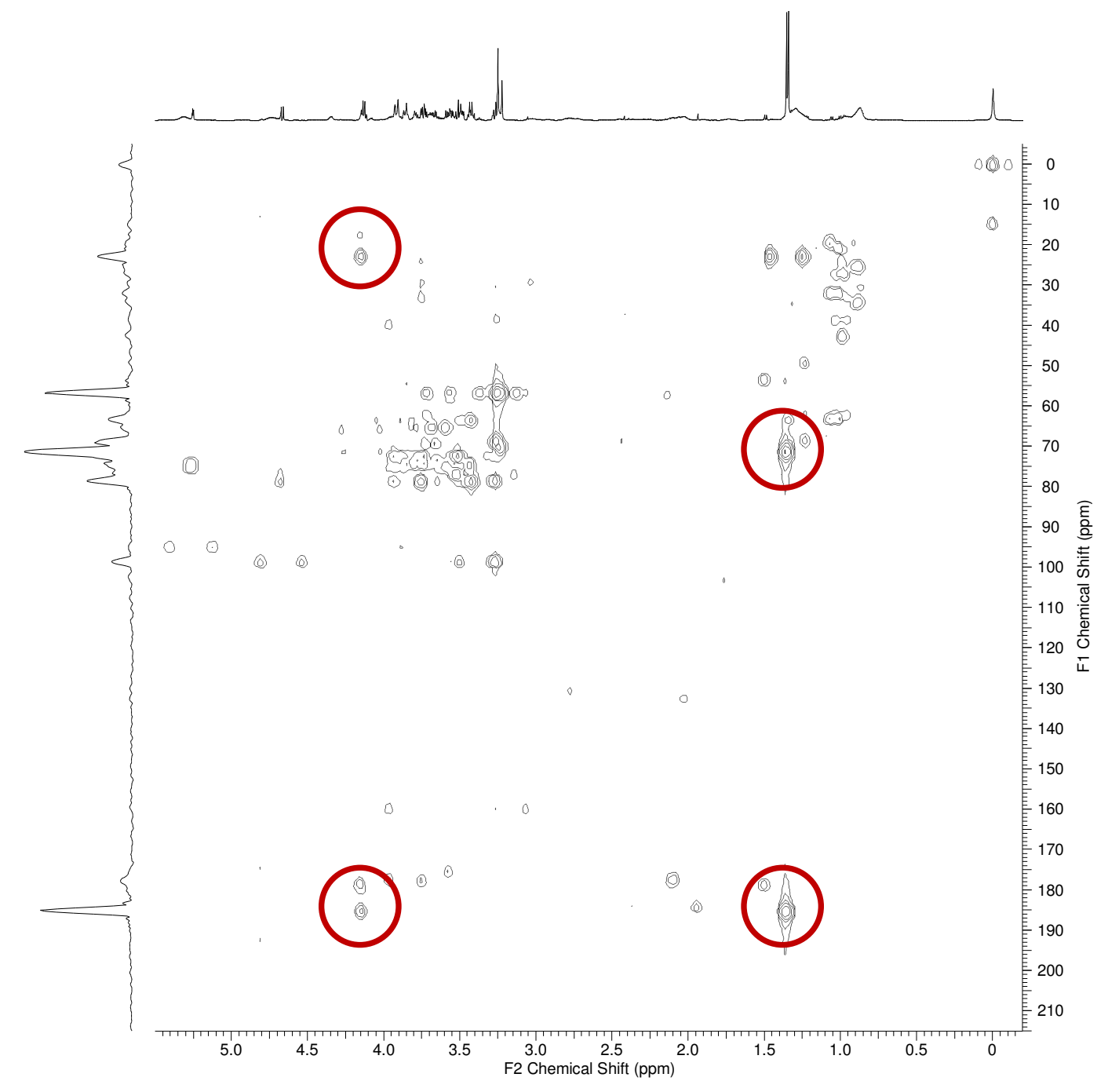

Como mostra o espectro HMBC, os sinais de hidrogênio em 1,35 ppm possuem correlação a longa distância com carbonos em 70,5 e 183,9 ppm, ao passo que os sinais em 4,13 ppm mostram correlações em 22,2 e 183,9 ppm. Através destes dados, as bases HMDB e Metabolomics permitem que informações entre deslocamento químico e multiplicidade sejam cruzadas, e neste caso, o metabólito em questão é o lactato, cuja estrutura é mostrada na Figura 52, juntamente com seus deslocamentos químicos. 
Figura 52 - Estrutura química do lactato, deslocamentos químicos $\left({ }^{1} \mathrm{H}\right.$ e ${ }^{13} \mathrm{C}$ ) e multiplicidades.

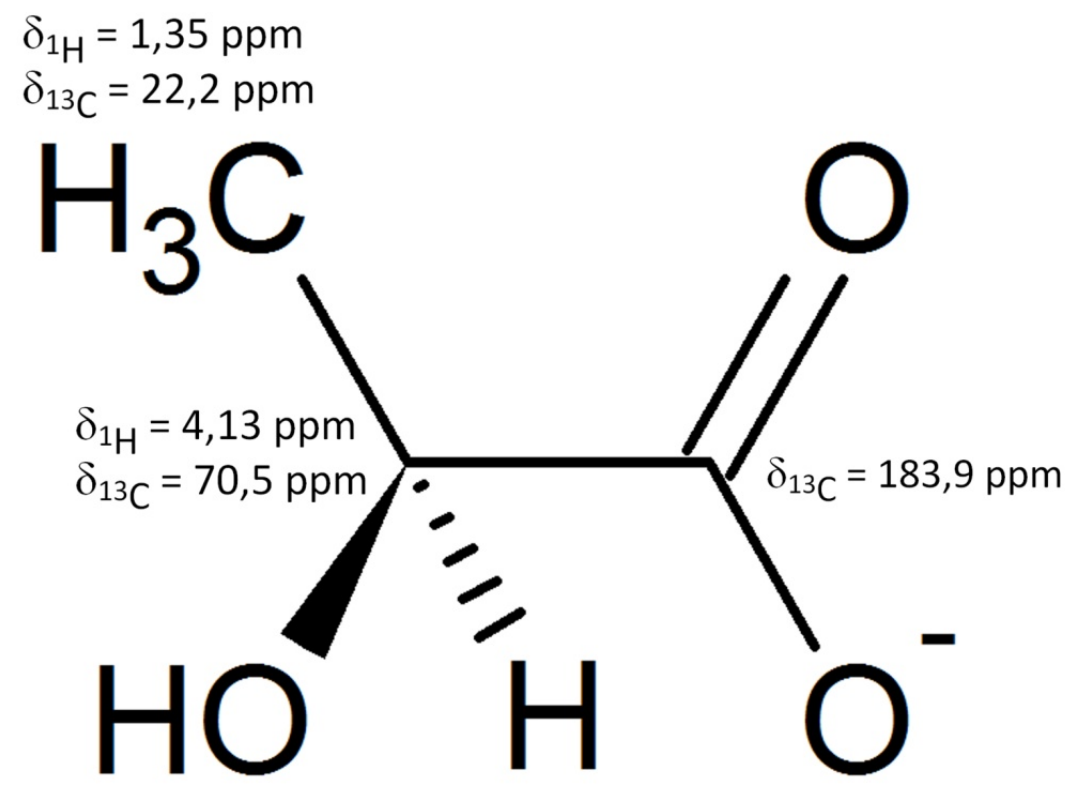

Seguindo os mesmos procedimentos descritos para a caracterização dos sinais do lactato, este tipo de análise foi feito para as outras correlações encontradas nos espectros COSY, HSQC e HMBC, permitindo que vários outros metabólitos fossem identificados nos espectros, como mostram as Figuras 53 e 54, onde os mesmos são assinalados em um espectro monodimensional. A Tabela 12 mostra suas estruturas, com os respectivos deslocamentos químicos para ${ }^{1} \mathrm{H}$ e ${ }^{13} \mathrm{C}$. 
Figura 53 - Assinalamento dos metabólitos encontrados no plasma sanguíneo de camundongos controle (A) e tratado (B). Região de 0,5 a 2,5 ppm.

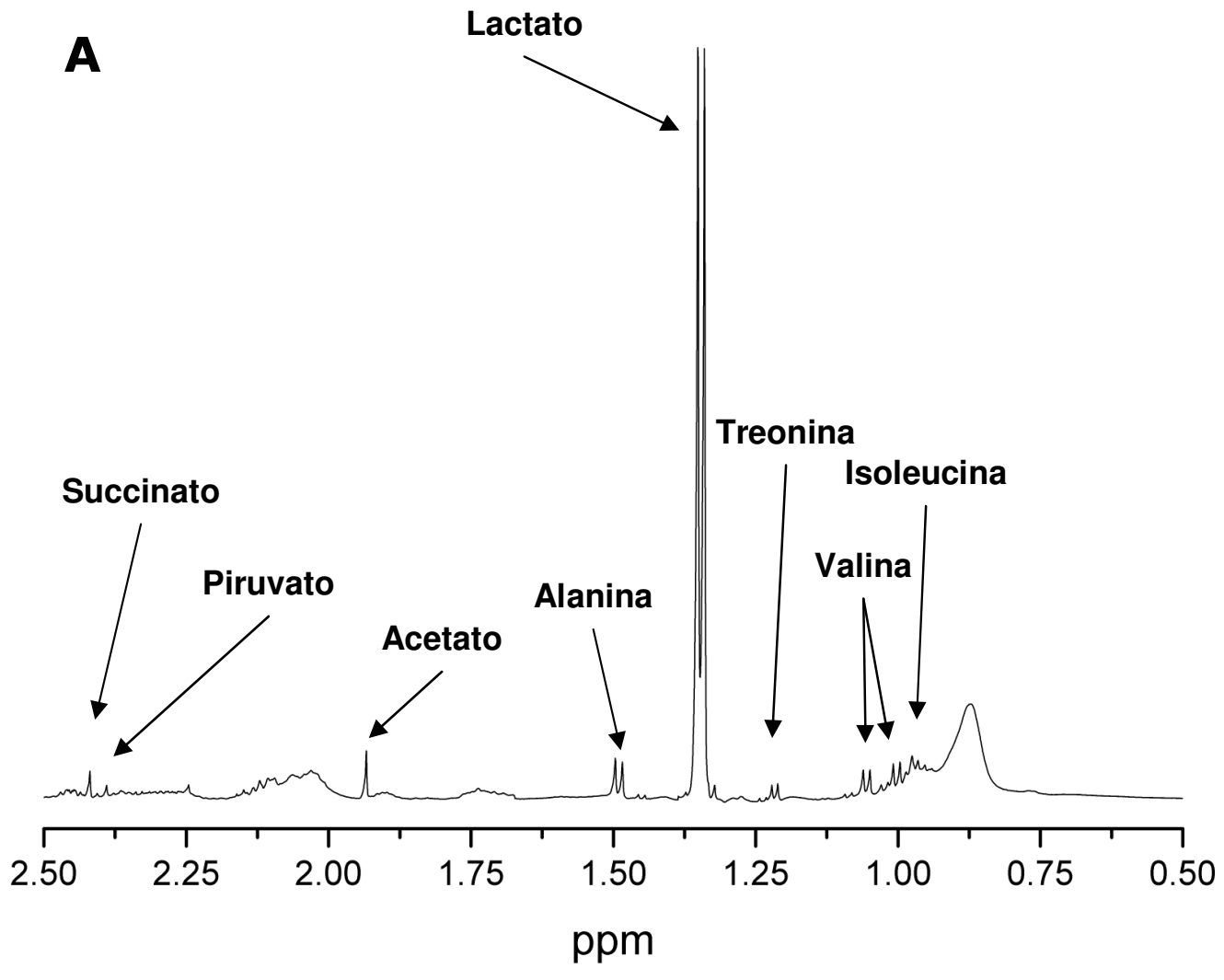

B

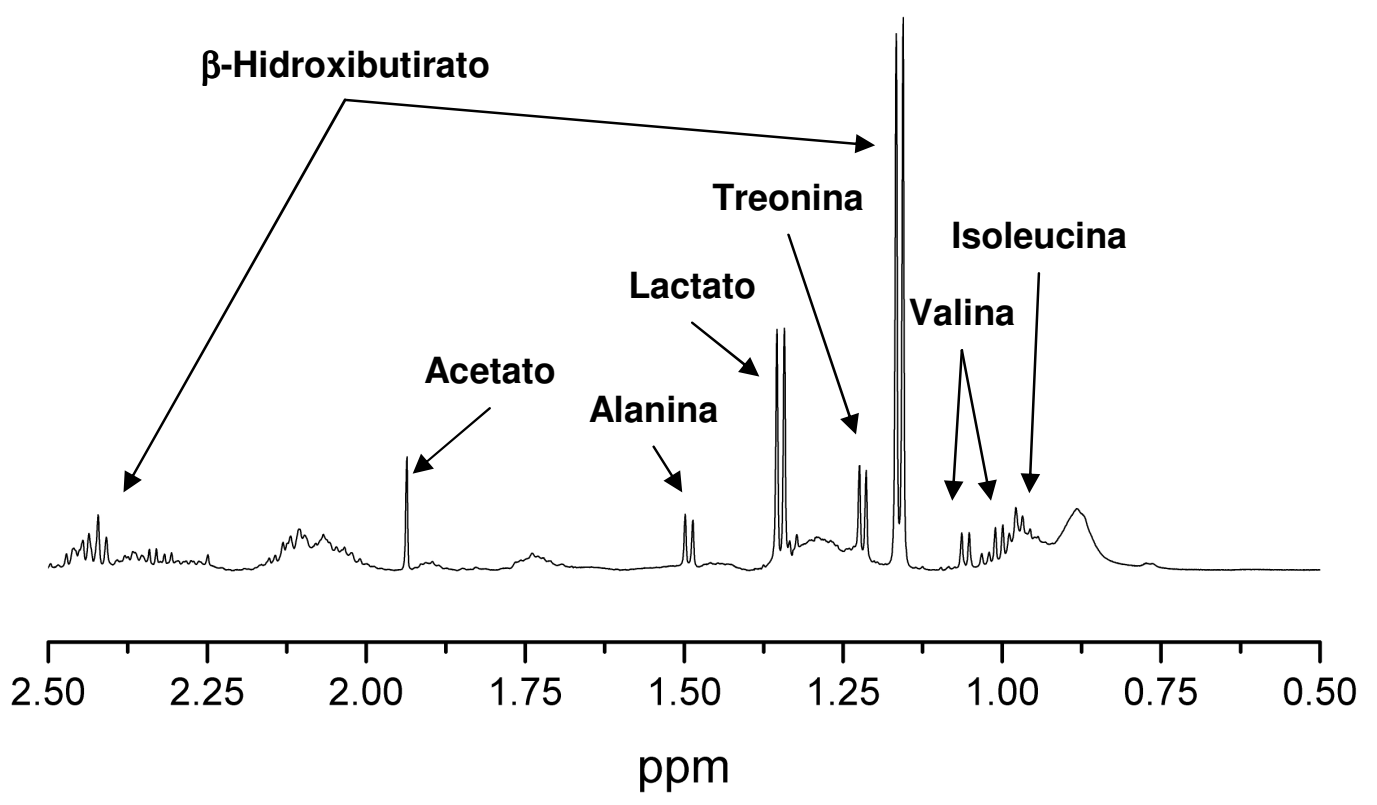


Figura 54 - Assinalamento dos metabólitos encontrados no plasma sanguíneo de camundongos controle (A) e tratado (B). Região de 2,5 a 5,5 ppm.

A
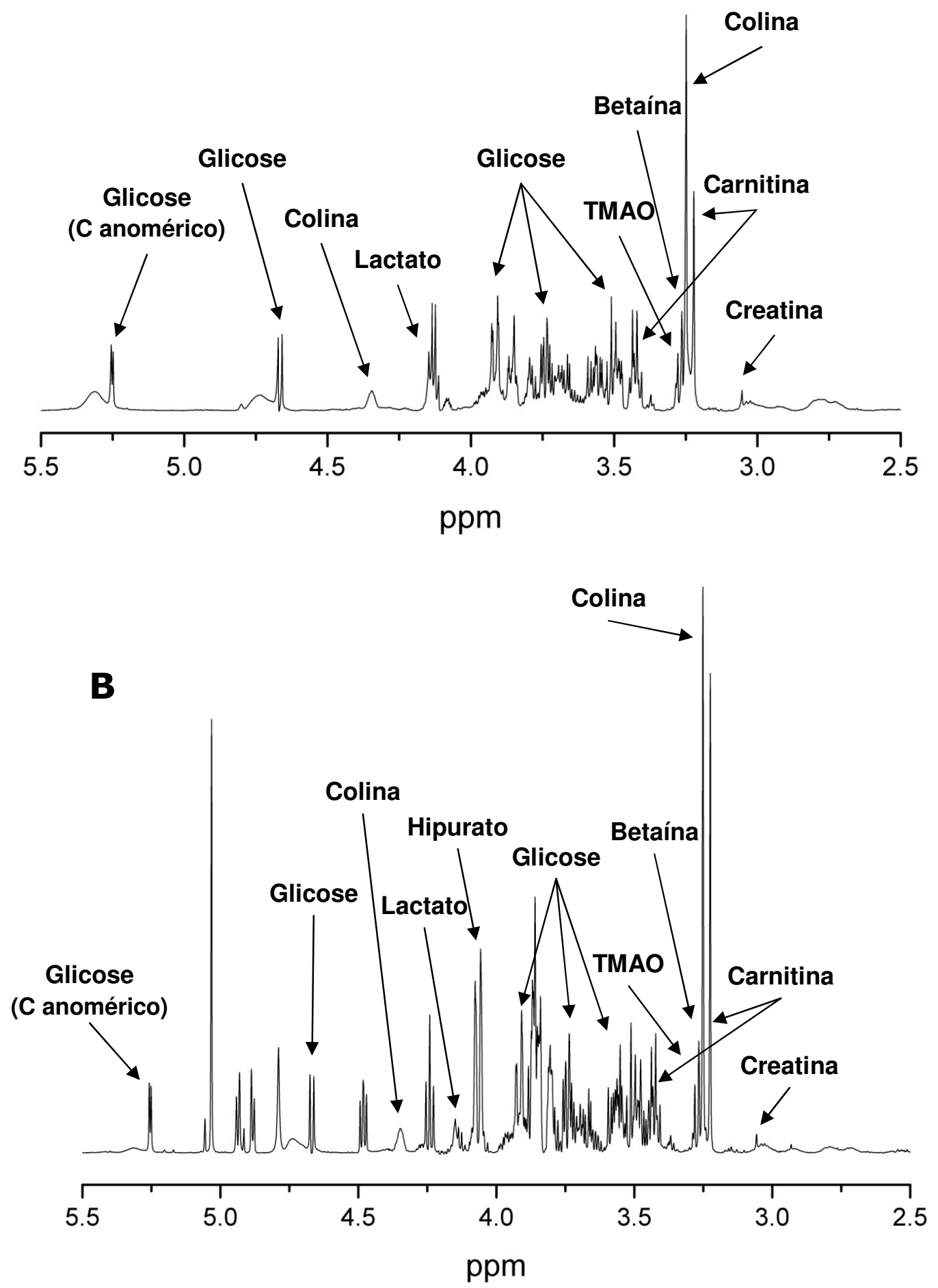
Tabela 13 - Estruturas químicas, deslocamentos químicos $\left({ }^{1} \mathrm{H}\right.$ e $\left.{ }^{13} \mathrm{C}\right)$ e multiplicidade $\left({ }^{1} \mathrm{H}\right)$ para os sinais assinalados na figura 54. (Multiplicidades: $\mathrm{s}=$ singleto; $\mathrm{d}=$ dubleto; $\mathrm{dd}=$ duplo dubleto; $\mathrm{t}=$ tripleto; $\mathrm{q}$ quarteto; $\mathrm{m}=$ multipleto).

(continua)

\begin{tabular}{|c|c|c|c|}
\hline Metabólito & Estrutura & $\delta^{1} H(p p m)$ & $\delta^{13} C(p p m)$ \\
\hline$\beta$-Hidroxibutirato & & $\begin{array}{l}\gamma \mathrm{CH}_{3}=1,17(\mathrm{~d}) \\
\alpha \mathrm{CH}_{2}=2,3(\mathrm{~m}) \\
\beta \mathrm{CH}=4,16(\mathrm{~m})\end{array}$ & $\begin{aligned} \mathrm{CH}_{3} & =22,4 \\
\mathrm{CH}_{2} & =43,8 \\
\mathrm{CH} & =65,3 \\
\mathrm{C}=\mathrm{O} & =180,3\end{aligned}$ \\
\hline Acetato & & $\mathrm{CH}_{3}=1,93(\mathrm{~s})$ & $\begin{aligned} \mathrm{CH}_{3} & =21,1 \\
\mathrm{C}=\mathrm{O} & =177,2\end{aligned}$ \\
\hline Alanina & & $\begin{array}{c}\beta \mathrm{CH}_{3}=1,49(\mathrm{~d}) \\
\alpha \mathrm{CH}=3,76(\mathrm{q})\end{array}$ & $\begin{array}{c}\mathrm{CH}_{3}=17,5 \\
\mathrm{CH}=51,5 \\
\mathrm{C}=\mathrm{O}=177,2\end{array}$ \\
\hline Betaína & & $\begin{array}{c}\mathrm{N}-\mathrm{CH}_{3}=3,26(\mathrm{~s}) \\
\alpha \mathrm{CH}_{2}=3,85(\mathrm{~s})\end{array}$ & $\begin{array}{c}\mathrm{N}-\mathrm{CH}_{3}=54,6 \\
\alpha \mathrm{CH}=67,7 \\
\mathrm{C}=\mathrm{O}=172,2\end{array}$ \\
\hline Carnitina & & $\begin{array}{l}\alpha \mathrm{CH}_{2}=2,41(\mathrm{~m}) \\
\mathrm{N}-\mathrm{CH}_{3}=3,22(\mathrm{~s}) \\
\gamma \mathrm{CH}_{2}=3,42(\mathrm{~m}) \\
\beta \mathrm{CH}=4,48(\mathrm{~m})\end{array}$ & $\begin{array}{c}\alpha \mathrm{CH}_{2}=43,8 \\
\mathrm{~N}-\mathrm{CH}_{3}=54,6 \\
\mathrm{CH}=64,9 \\
\mathrm{CH}_{2}=70,9 \\
\mathrm{C}=\mathrm{O}=178,9\end{array}$ \\
\hline
\end{tabular}


Tabela 12 - Estruturas químicas, deslocamentos químicos $\left({ }^{1} \mathrm{H}\right.$ e $\left.{ }^{13} \mathrm{C}\right)$ e multiplicidade $\left({ }^{1} \mathrm{H}\right)$ para os sinais assinalados na figura 54. (Multiplicidades: $\mathrm{s}=$ singleto; $\mathrm{d}=$ dubleto; $\mathrm{dd}=$ duplo dubleto; $\mathrm{t}=$ tripleto; $\mathrm{q}$ quarteto; $\mathrm{m}=$ multipleto).

(continuação)

\begin{tabular}{|c|c|c|c|}
\hline Metabólito & Estrutura & $\delta^{1} H(p p m)$ & $\delta^{13} \mathrm{C}(\mathrm{ppm})$ \\
\hline Creatina & & $\begin{array}{c}\mathrm{N}-\mathrm{CH}_{3}=3,05(\mathrm{~s}) \\
\alpha \mathrm{CH}_{2}=3,93(\mathrm{~s})\end{array}$ & $\begin{array}{c}\mathrm{N}-\mathrm{CH}_{3}=34,1 \\
\alpha \mathrm{CH}_{2}=49,4 \\
\mathrm{C}=\mathrm{N}=160,9 \\
\mathrm{C}=\mathrm{O}=168,8\end{array}$ \\
\hline Colina & $\mathrm{CH}_{3}$ & $\begin{array}{l}\mathrm{N}-\mathrm{CH}_{3}=3,25(\mathrm{~s}) \\
\mathrm{\beta CH}_{2}=3,41(\mathrm{~m}) \\
\alpha \mathrm{CH}_{2}=4,05(\mathrm{~m})\end{array}$ & $\begin{array}{c}\mathrm{N}-\mathrm{CH}_{3}=55,1 \\
\alpha \mathrm{CH}_{2}=57,4 \\
\beta \mathrm{CH}_{2}=74,8\end{array}$ \\
\hline Glicose & & $\begin{array}{c}3,39(\mathrm{dd}) \\
3,47(\mathrm{dd}) \\
3,72(\mathrm{~m}) \\
3,88(\mathrm{~m}) \\
4,67(\mathrm{~d}) \\
5,25(\mathrm{~d})-\text { anomérico }\end{array}$ & $\begin{array}{c}\beta \mathrm{Gli} \mathrm{C}_{1}=98,6 \\
\alpha \mathrm{Gli}_{1}=94,8 \\
\beta \mathrm{GliC}_{3} / \beta \mathrm{GliC}_{5}=78,6 \\
\beta \mathrm{Gli}_{2}=76,9 \\
\alpha \mathrm{Gli} \mathrm{C}_{3}=75,4 \\
\alpha \mathrm{GliC}_{2} / \alpha \mathrm{GliC}_{5}=74,1 \\
\alpha \mathrm{GliC}_{4} / \beta \mathrm{GliC}_{4}=72,3 \\
\alpha \mathrm{GliC}_{6} / \beta \mathrm{GliC}_{6}=63,4\end{array}$ \\
\hline Hipurato & & $\begin{array}{l}\alpha \mathrm{CH}_{2}=4,05(\mathrm{~d}) \\
\mathrm{CH}_{\text {(ar) }} \approx 7,5-7,8\end{array}$ & $\begin{array}{c}\alpha \mathrm{CH}_{2}=43,6 \\
\mathrm{C}_{(\mathrm{ar})} \approx 130 \\
\mathrm{C}=\mathrm{O}=170,7 \\
\mathrm{C}=\mathrm{O}=173,6\end{array}$ \\
\hline
\end{tabular}


Tabela 12 - Estruturas químicas, deslocamentos químicos $\left({ }^{1} \mathrm{H}\right.$ e $\left.{ }^{13} \mathrm{C}\right)$ e multiplicidade $\left({ }^{1} \mathrm{H}\right)$ para os sinais assinalados na figura 54. (Multiplicidades: $\mathrm{s}=$ singleto; $\mathrm{d}=$ dubleto; $\mathrm{dd}=$ duplo dubleto $\mathrm{t}=$ tripleto; $\mathrm{q}$ quarteto; $\mathrm{m}=$ multipleto).

(continuação)

\begin{tabular}{|c|c|c|c|}
\hline Metabólito & Estrutura & $\delta^{1} H(p p m)$ & $\delta^{13} \mathrm{C}(\mathrm{ppm})$ \\
\hline Isoleucina & $\mathrm{CH}_{3}$ & $\begin{aligned} \delta \mathrm{CH}_{3} & =0,97(\mathrm{t}) \\
\gamma_{2} \mathrm{CH}_{3} & =1,03(\mathrm{~d}) \\
\gamma_{1} \mathrm{CH}_{2} & =1,3(\mathrm{~m}) \\
\beta \mathrm{CH} & =2,05(\mathrm{~m}) \\
\alpha \mathrm{CH} & =3,66(\mathrm{~d})\end{aligned}$ & $\begin{array}{c}\gamma_{2} \mathrm{CH}_{3}=12,5 \\
\delta \mathrm{CH}_{3}=15,9 \\
\gamma_{1} \mathrm{CH}_{2}=25,7 \\
\beta \mathrm{CH}=39,7 \\
\alpha \mathrm{CH}=60,9 \\
\mathrm{C}=\mathrm{O}=175,2\end{array}$ \\
\hline Lactato & & $\begin{array}{c}\beta \mathrm{CH}_{3}=1,35(\mathrm{~d}) \\
\alpha \mathrm{CH}=4,13(\mathrm{q})\end{array}$ & $\begin{array}{c}\beta \mathrm{CH}_{3}=22,2 \\
\alpha \mathrm{CH}=70,5 \\
\mathrm{C}=\mathrm{O}=183,9\end{array}$ \\
\hline Piruvato & & $\beta \mathrm{CH}_{3}=2,39(\mathrm{~s})$ & $\begin{array}{c}\beta \mathrm{CH}_{3}=29,1 \\
\alpha \mathrm{C}=\mathrm{O}=176,1 \\
\mathrm{C}=\mathrm{O}=188,5\end{array}$ \\
\hline Succinato & & $\alpha \mathrm{CH}_{2}=2,42(\mathrm{~s})$ & $\begin{array}{l}\alpha \mathrm{CH}_{2}=36,4 \\
\mathrm{C}=\mathrm{O}=183,9\end{array}$ \\
\hline
\end{tabular}


Tabela 12 - Estruturas químicas, deslocamentos químicos $\left({ }^{1} \mathrm{H}\right.$ e $\left.{ }^{13} \mathrm{C}\right)$ e multiplicidade $\left({ }^{1} \mathrm{H}\right)$ para os sinais assinalados na figura 54. (Multiplicidades: $\mathrm{s}=$ singleto; $\mathrm{d}=$ dubleto; $\mathrm{dd}=$ duplo dubleto $\mathrm{t}=$ tripleto; q quarteto; $\mathrm{m}=$ multipleto).

(conclusão)

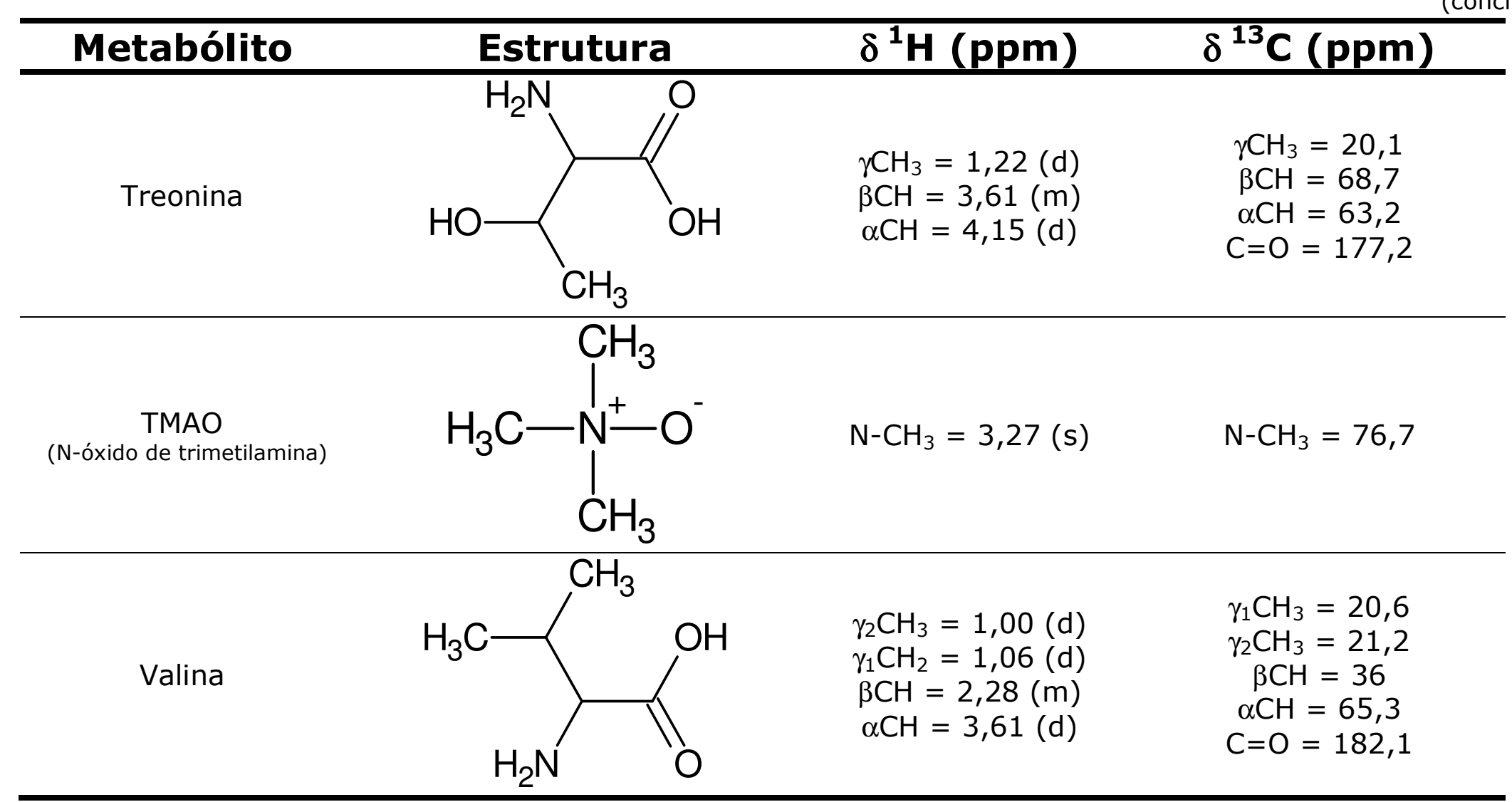


Adicionalmente, após a caracterização dos sinais encontrados nos espectros de $\mathrm{RMN}^{1}{ }^{1} \mathrm{H}$ (1D e 2D), utilizou-se os dados monodimensionais de ${ }^{13} \mathrm{C}$ para a comparação entre os espectros obtidos através das técnicas convencional e SSFP, que contém um número de sinais consideravelmente maior em relação àquela, sendo possível dessa forma, correlacionar também os sinais encontrados para os metabólitos através dos dados de carbono. Nas Figuras 55 e 56 são mostrados os espectros de $\mathrm{RMN}^{13} \mathrm{C}$ já apresentados, com o devido assinalamento dos sinais.

Figura 55 - Assinalamento de sinais de metabólitos para espectro de RMN${ }^{13} \mathrm{C}$ (técnica convencional). No detalhe, a região de carbonilas. (pir. = piruvato; succ. = succinato $)$.

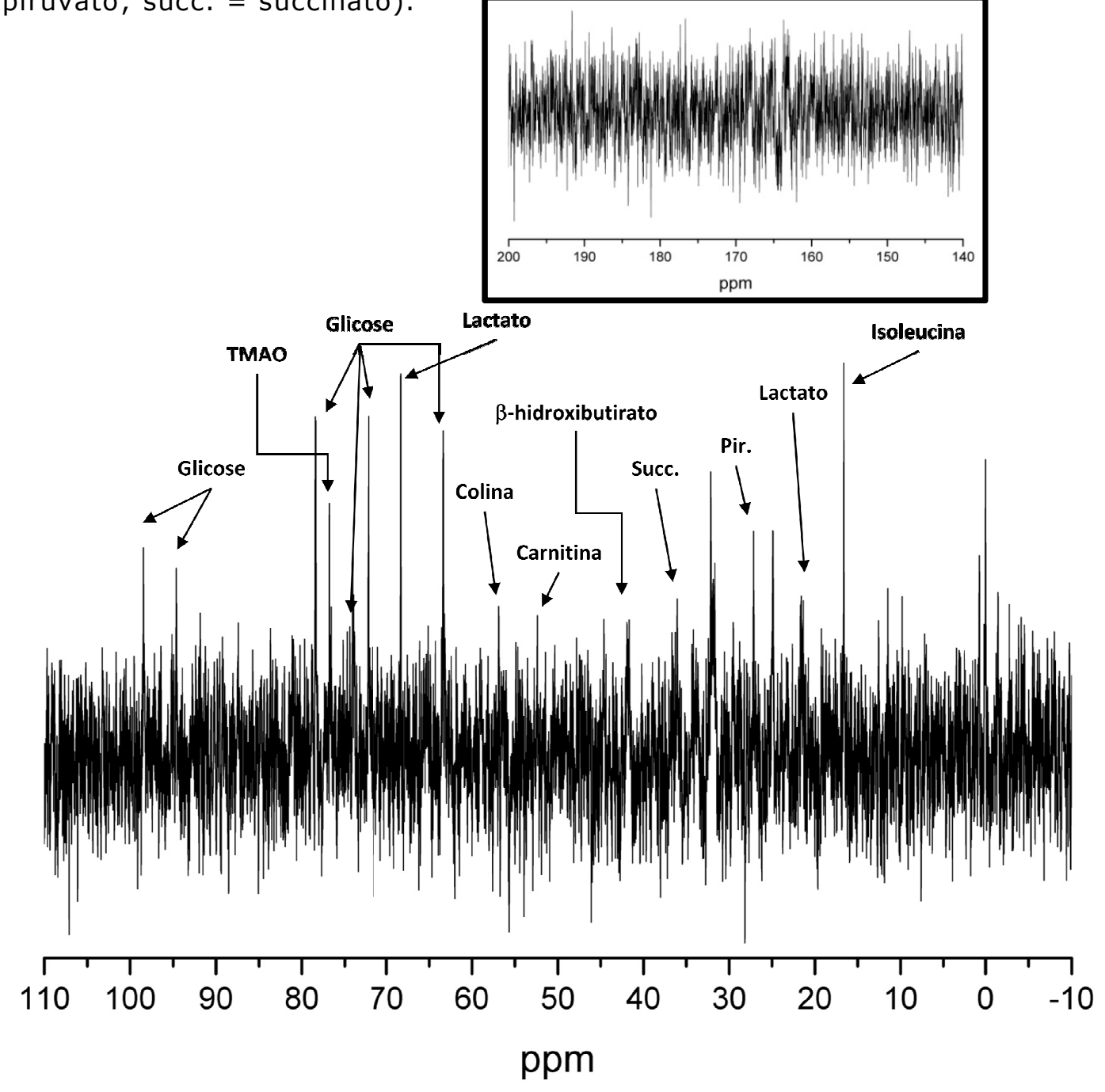


Figura 56 - Assinalamento de sinais de metabólitos para espectro de RMN${ }^{13} \mathrm{C}$ (SSFP). No detalhe, a região de carbonilas. (glic. = glicose; pir. = piruvato; succ. $=$ succinato $)$.

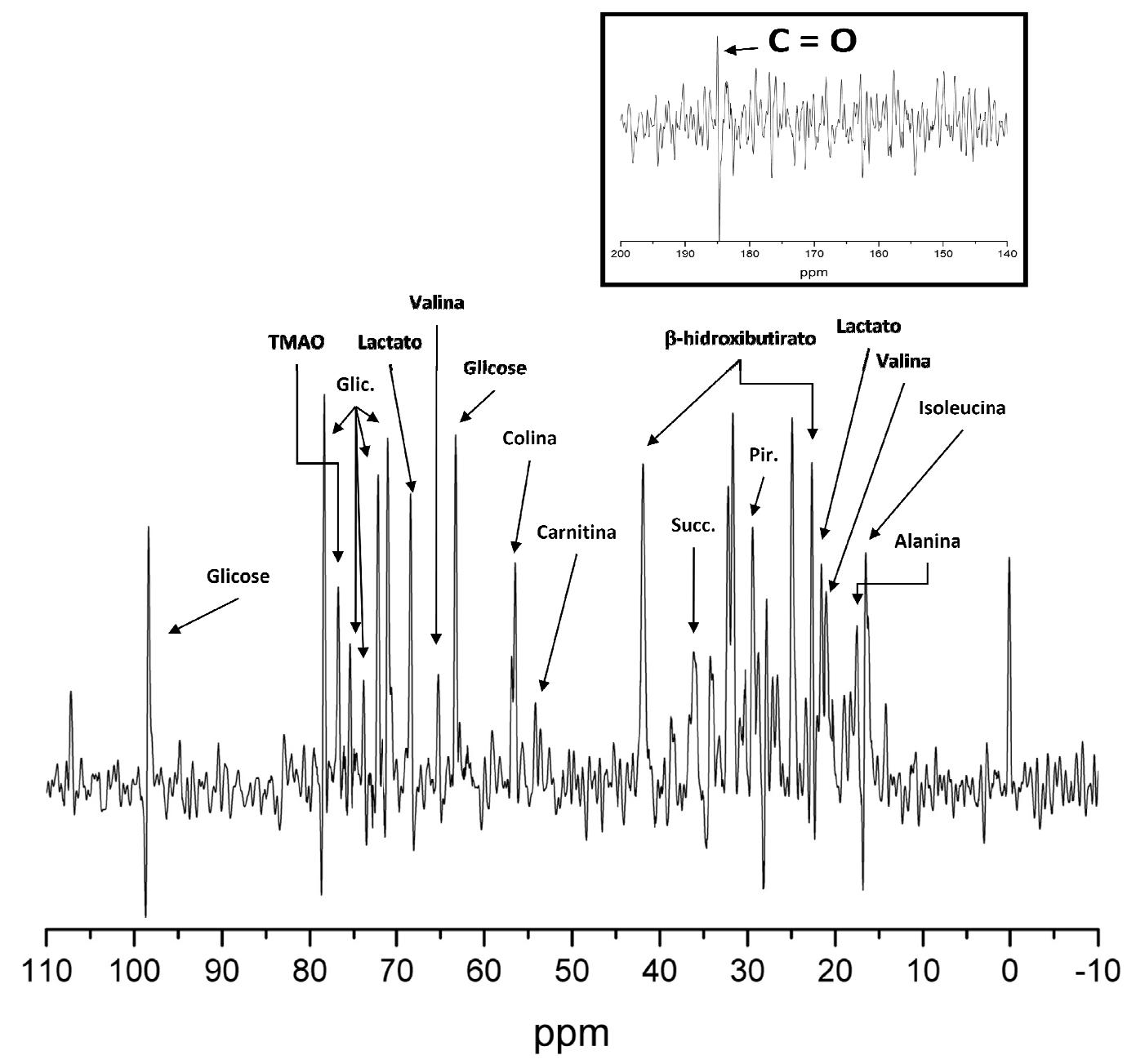

Como já mostrado, a técnica SSFP permite no geral, a aquisição de um conjunto maior de sinais, que aliados a experimentos bidimensionais, pode levar a uma caracterização mais eficiente dos componentes da amostra. Assim, a Ressonância Magnética Nuclear, em várias configurações, associada a ferramentas auxiliares, como análise exploratória, permite que mudanças sejam notadas após a indução de uma alteração metabólica mais incisiva, como a administração de um fármaco em doses mais altas.

Através dos espectros ilustrados, bem como das informações obtidas através de quimiometria, identificou-se que uma das regiões espectrais responsáveis pela distinção entre as amostras estudadas 
encontra-se entre 1,1 e 1,6 ppm (Figura 57). Nesta região, é possível notar uma diminuição significativa no sinal correspondente ao lactato $(1,35 \mathrm{ppm})$ conforme o tratamento avança, bem como um aumento no sinal da treonina $(1,22 \mathrm{ppm})$, e o aparecimento de um dubleto em $1,16 \mathrm{ppm}$, correspondente ao $\beta$-hidroxibutirato, ao mesmo tempo em que 0 dubleto em 1,49 ppm (alanina) permanece praticamente inalterado, evidenciando assim uma mudança sensível no perfil metabólico em diferentes estágios do experimento.

Figura 57 - Comparação entre espectros de $\mathrm{RMN}-{ }^{1} \mathrm{H}$ de um camundongo controle (preto) e um medicado (vermelho), na região de 1,1 a 1,6 ppm.

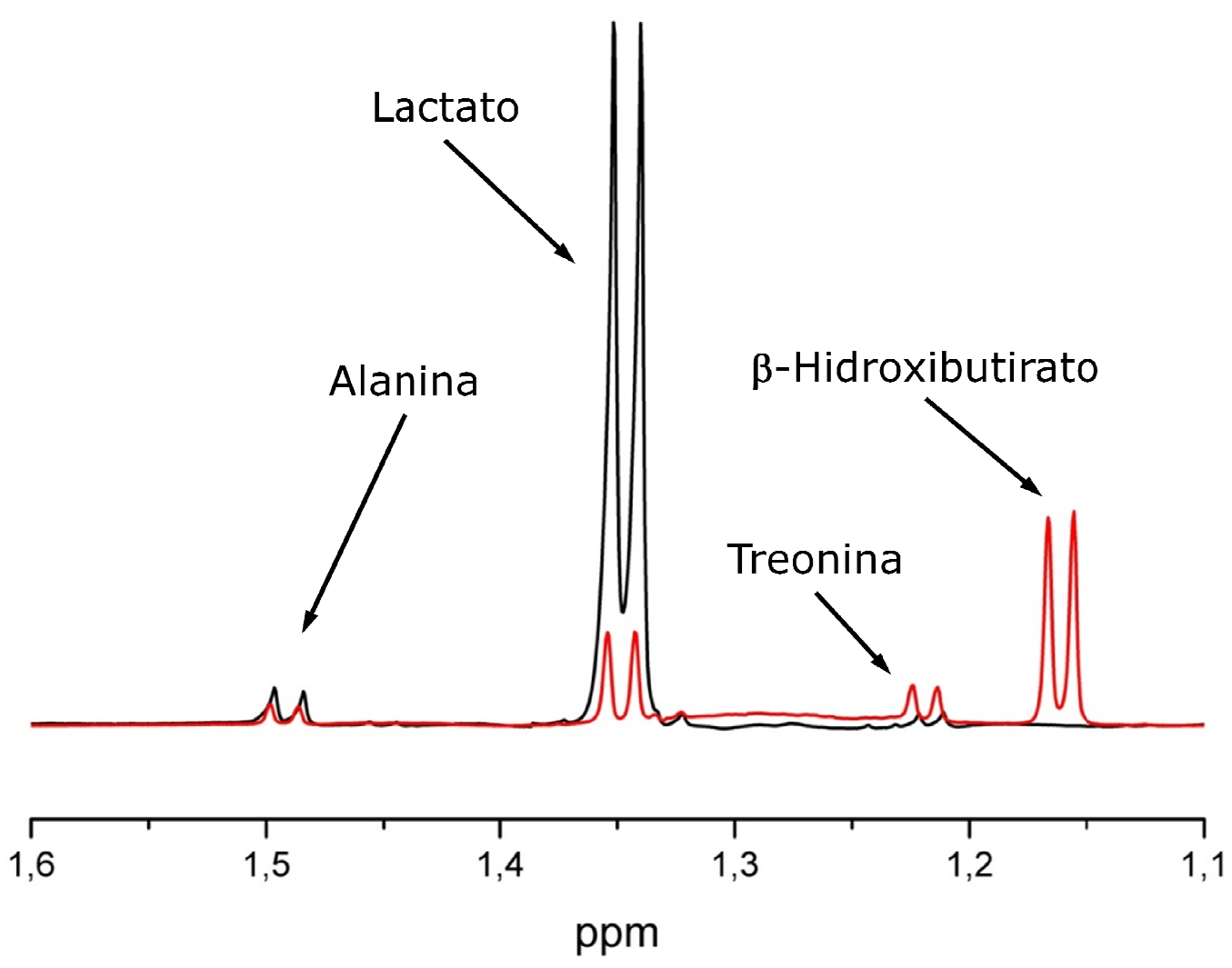

A distinção das amostras através da região mostrada mostra dois aspectos importantes da intoxicação: o consumo do lactato, e o surgimento do $\beta$-hidroxibutirato entre os metabólitos encontrados, 0 
que sugere que a administração de Ivermectina em doses altas interfere fortemente no balanço energético dos animais.

Durante o metabolismo celular, a principal fonte de energia celular provém da conversão de glicose em $\mathrm{CO}_{2}$ e $\mathrm{H}_{2} \mathrm{O}$, gerando a energia necessária para o organismo. A principal fonte de glicose do organismo de mamíferos consiste em depósitos de glicogênio armazenados principalmente no fígado, e disponibilizados no sangue na forma de glicose livre através da ação da insulina. Quando acometido de alguma desordem (por exemplo, má alimentação, doenças, ou intoxicação, entre outros) ${ }^{76}$ e os estoques que glicogênio não são suficientes, este organismo recorre à gliconeogênese, ${ }^{77}$ uma via alternativa para manter os níveis de glicose estáveis, sintetizando-a a partir de precursores como lactato e piruvato, provenientes da oxidação da mesma nos músculos. Este processo ocorre principalmente no fígado, e minoritariamente no córtex renal, e é ilustrado na Figura 58.

Figura 58 - Via de gliconeogênese.

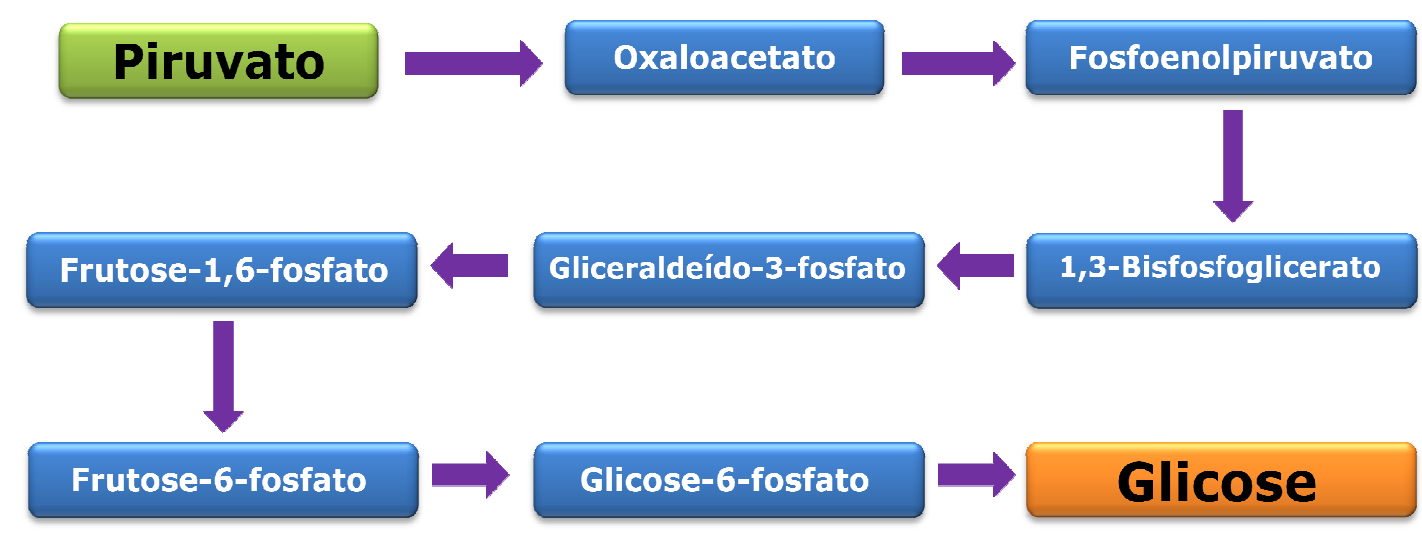

Paralelamente, uma outra forma de obtenção de energia, sobretudo pelo cérebro, é a utilização de corpos cetônicos, que são três produtos da degradação de ácidos graxos pelo organismo, em um processo denominado cetogênese. São conhecidos como corpos 
cetônicos $^{78}$ o acetoacetato, a acetona e o $\beta$-hidroxibutirato (mesmo este não sendo uma cetona de acordo com a IUPAC), e, como na gliconeogênese, sua produção se dá sobretudo no fígado e rins. A cetogênese (Figura 59) é acionada quando, pela degradação de ácidos graxos, ocorre um acúmulo de Acetil-CoA no organismo, que desempenha um papel fundamental no Ciclo de Krebs, mostrado na Figura $60 .{ }^{77}$

Figura 59 - Via de cetogênese.

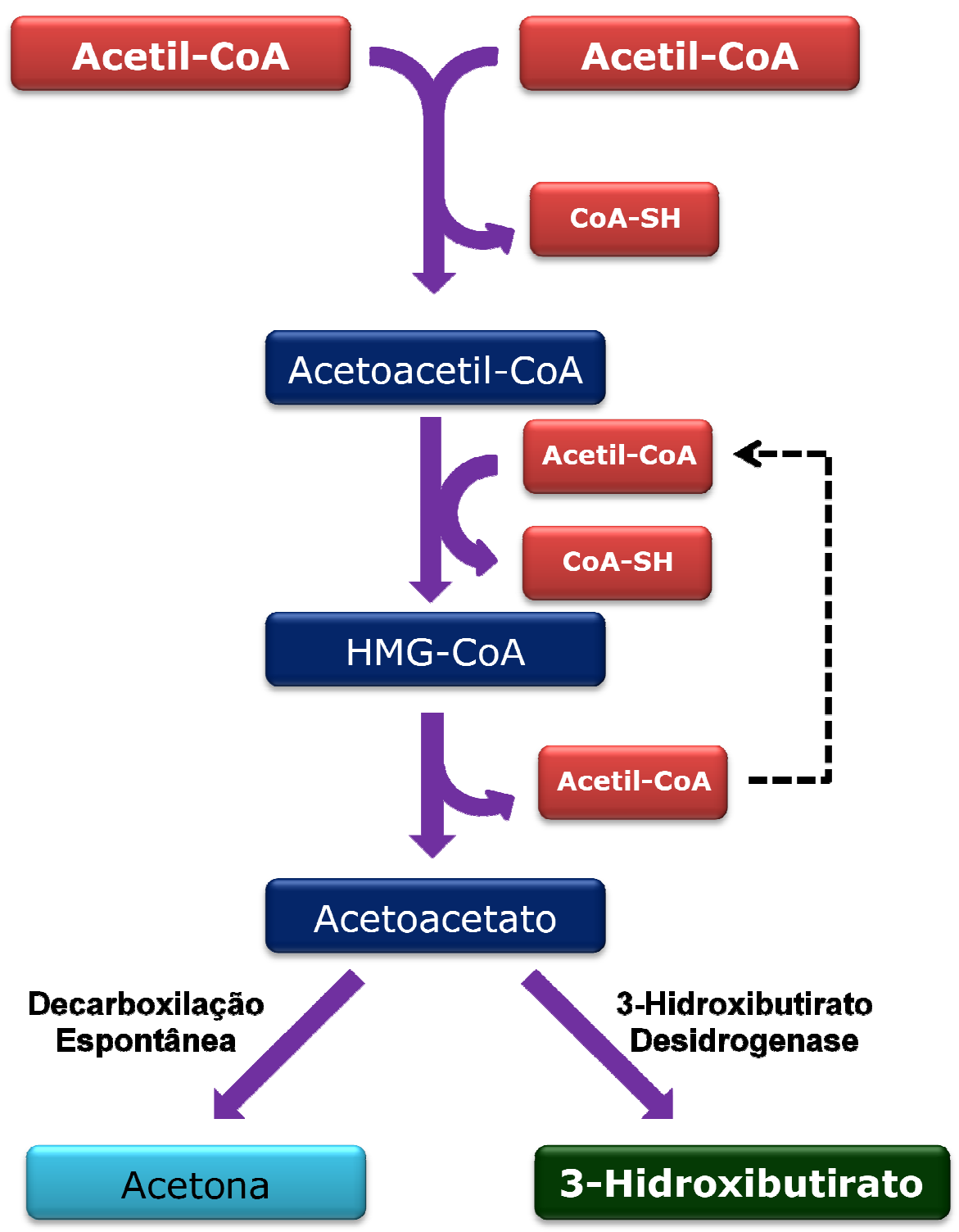


Figura 60 - Ciclo de Krebs

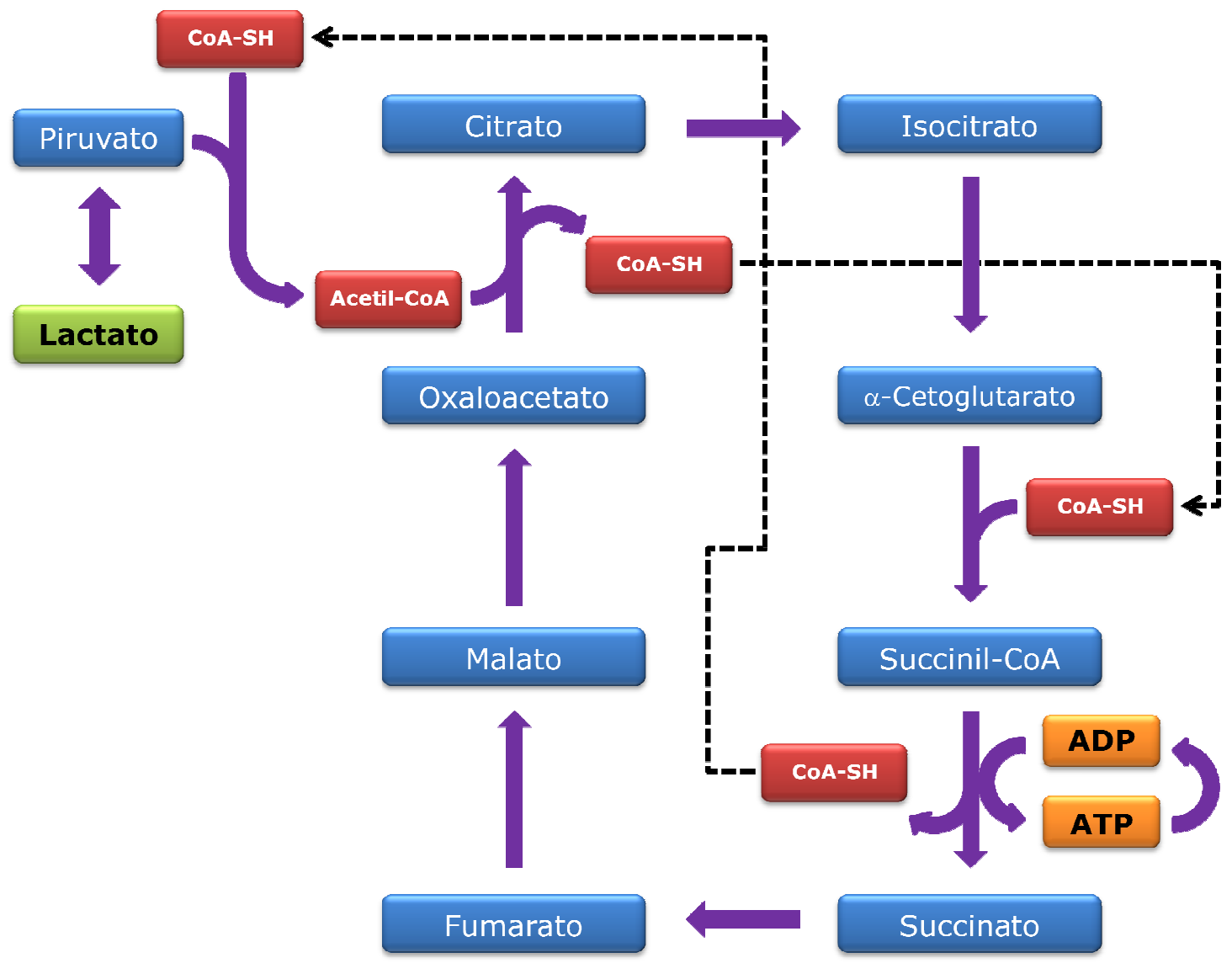

Pela ausência de outros intermediários do ciclo (como piruvato e oxaloacetato, desviados para a gliconeogênese), a Acetil-CoA dá origem, após várias etapas de conversão, ao acetoacetato, reduzido enzimaticamente a $\beta$-hidroxibutirato, e decarboxilado espontaneamente a acetona. Em um dos estágios mais avançados da cetogênese, denominado cetose, alguns sintomas podem tornar-se aparentes, tais como apatia, dificuldades motoras e um hálito característico, causado pela presença de acetona nas vias aéreas. Em estágio avançado, esta desordem pode resultar em um quadro denominado cetoacidose, geralmente fatal, caracterizada pela diminuição sensível do $\mathrm{pH}$ intracelular e sanguíneo, devido ao 
acúmulo de derivados acéticos e cetônicos, como o ácido $\beta$ hidroxibutírico.

Dentre os principais sintomas citados, um dos mais relevantes quando se trata de rebanhos, é a apatia causada pela depressão do sistema nervoso central, resultando em perda de peso devido à alimentação reduzida do animal no período dos sintomas, bem como redução considerável na produção de leite. Em alguns mamíferos (especialmente bovinos e cães) tratados com Ivermectina, alguns efeitos colaterais observados condizem com os sintomas apresentados por animais com cetose. Estudos mostram que bezerros tratados com altas doses de Abamectina ${ }^{59}$ apresentam severos danos motores e letargia acentuada, entre outros sintomas.

A cetose é uma condição comum em bovinos, acometendo sobretudo fêmeas, tanto no período de lactação ( 2 a 6 semanas após o parto) quanto vacas leiteiras, ${ }^{79,80}$ devido ao balanço energético negativo provocado pela produção de leite. De fato, mesmo não havendo separação significativa entre os dados de bovinos por parte dos modelos quimiométricos, análises pontuais de algumas amostras sugerem a presença de derivados cetônicos nas mesmas, sendo que em alguns casos, os sinais aparecem até mesmo em amostras de animais controle (não medicados), conforme mostram as Figuras 61 e 62. 
FIGURA 61 - Espectro de RMN- ${ }^{1} \mathrm{H}$ para uma amostra de plasma bovino de um animal controle, com destaque para o sinal da acetona $(2,24 \mathrm{ppm})$.

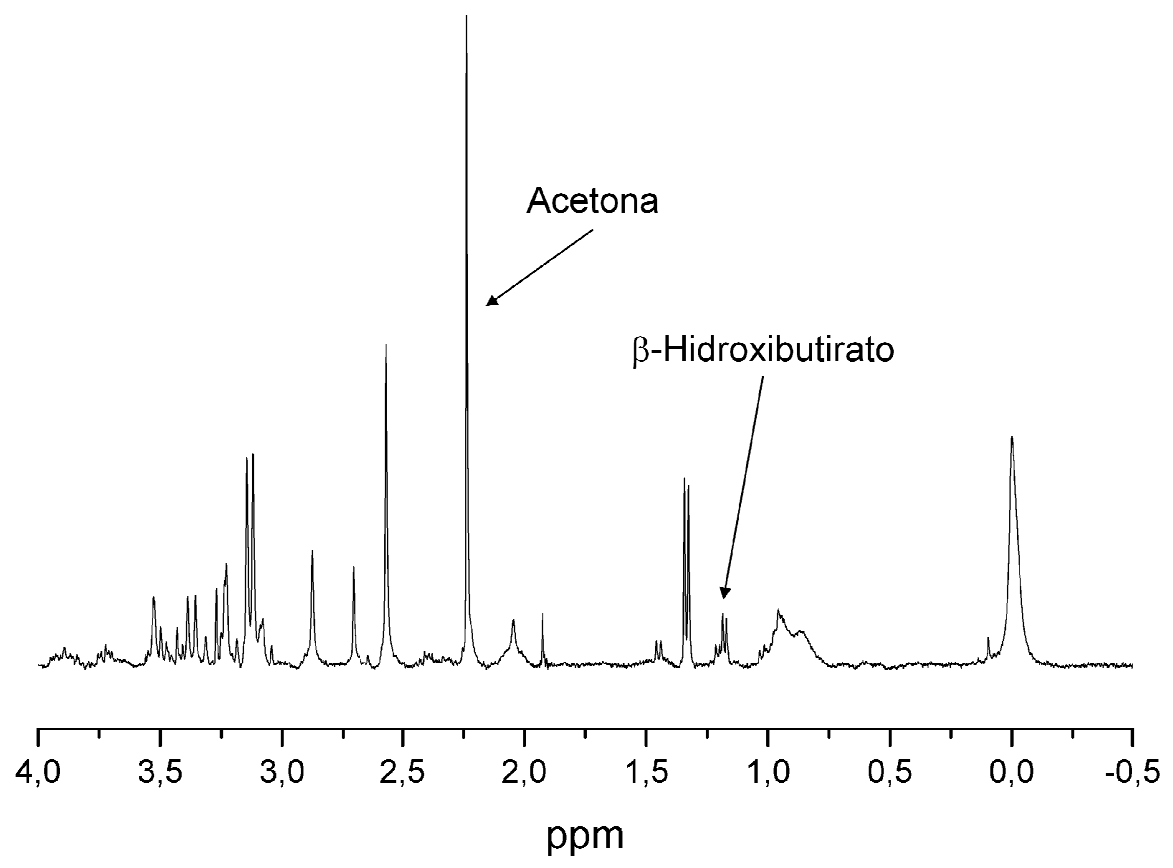

FIGURA 62 - Espectro de $\mathrm{RMN}-{ }^{1} \mathrm{H}$ para plasma bovino de um animal tratado, mostrando o considerável aumento do sinal da acetona e do $\beta$ hidroxibutirato entre $0 \mathrm{~h}$ (animal sem tratamento, A) e $30 \mathrm{~h}$ após a aplicação da primeira de duas doses de Ivermectina (B).

(continua)

A

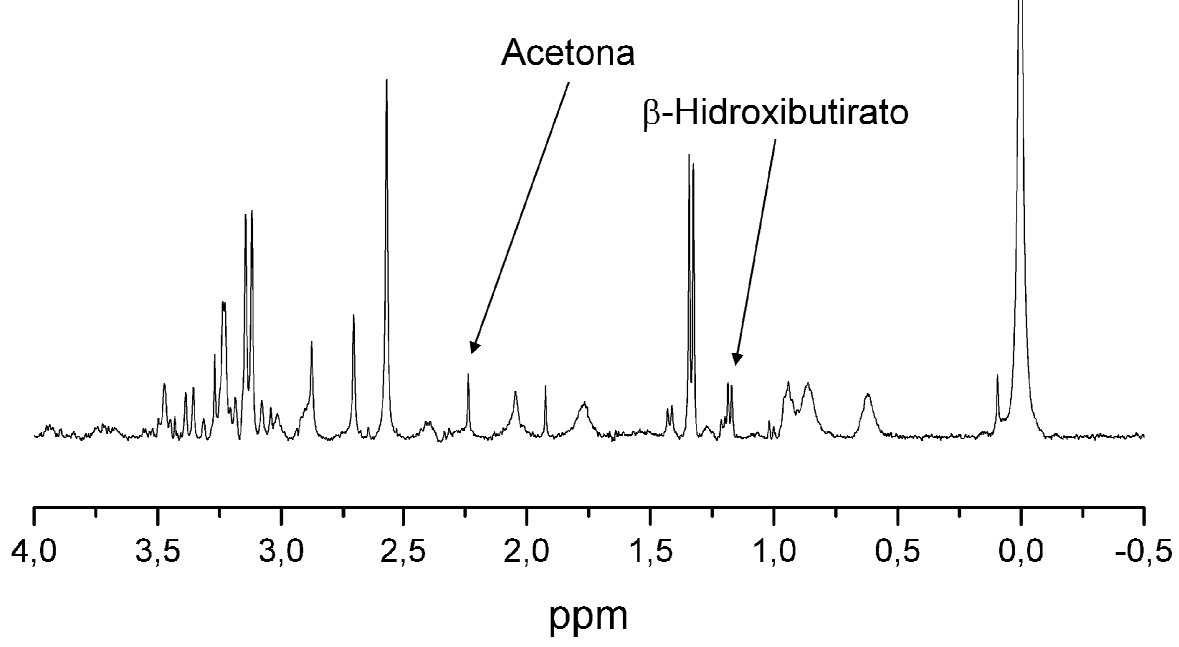


FIGURA 62 - Espectro de $\mathrm{RMN}-{ }^{1} \mathrm{H}$ para plasma bovino de um animal tratado, mostrando o considerável aumento do sinal da acetona e do $\beta$ hidroxibutirato entre $0 \mathrm{~h}$ (animal sem tratamento, A) e $30 \mathrm{~h}$ após a aplicação da primeira de duas doses de Ivermectina (B).

(conclusão)

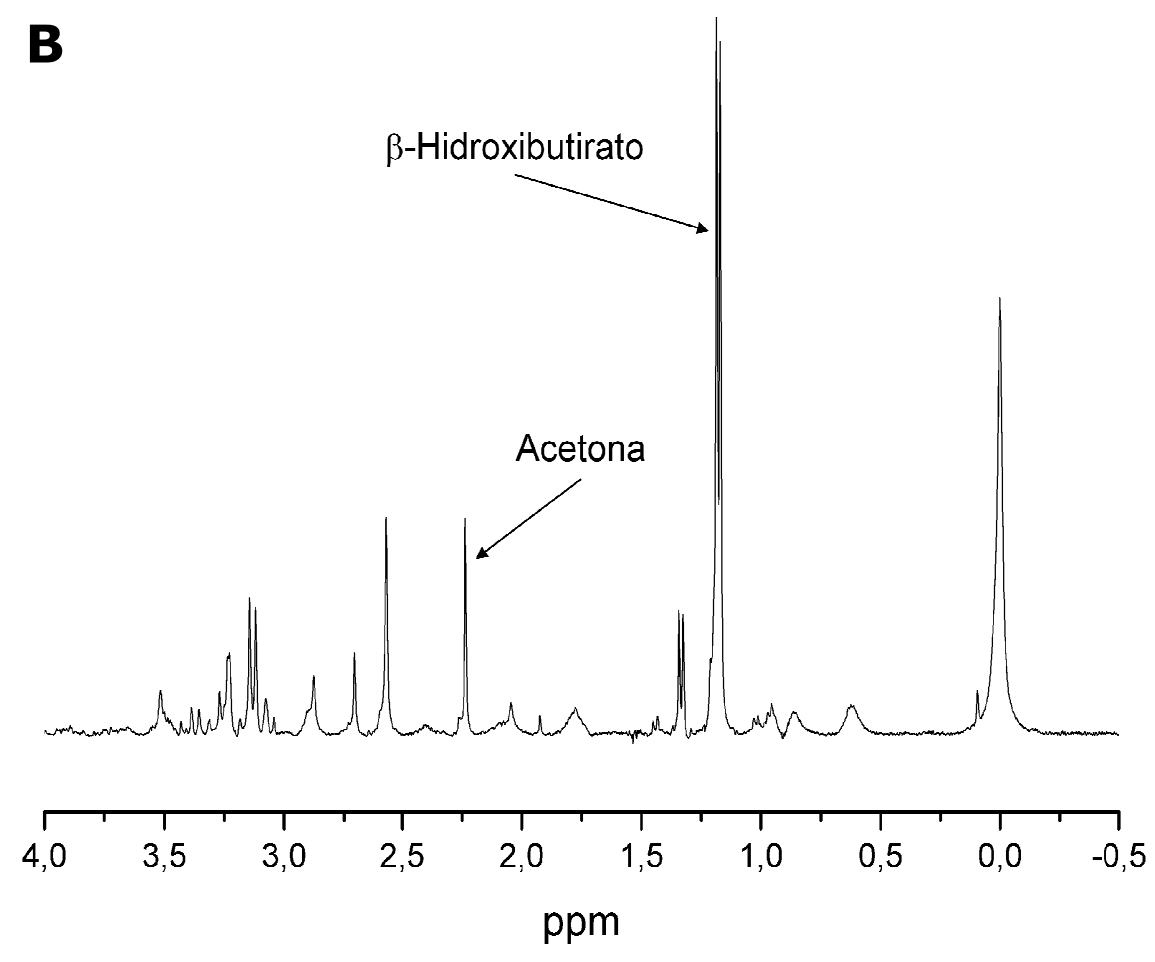

Assim, pode haver uma ligação entre a administração de Ivermectina e o estabelecimento do estado cetótico. Como se trata de um quadro comum em bovinos, sugere-se que a Ivermectina aumente a predisposição destes animais a desenvolver cetose.

Caso seja confirmada no futuro a correlação entre a administração de Ivermectina e uma consequente condição cetótica, os produtores que usam este fármaco em seus rebanhos podem estar sofrendo um prejuízo desnecessário. Estima-se que uma única vaca em lactação acometida de cetose pode deixar de produzir mais de $230 \mathrm{Kg}$ de leite em 100 dias. $^{78}$ Por outro lado, o tratamento desta desordem consiste simplesmente na aplicação de glicose ou propilenoglicol intravenoso, ${ }^{81,82}$ para equilibrar o balanço energético, 
ou complementação alimentar com vitaminas do complexo $B$, especialmente a Niacina $\left(B_{3}\right),{ }^{83}$ para evitar a degradação intracelular de ácidos graxos, um tratamento eficiente e de baixo custo, que pode minimizar uma perda econômica significativa para a economia nacional, fortemente baseada no setor pecuário. 


\section{CONCLUSÕES}

Biofluidos animais, como plasma sanguíneo e urina constituem uma rica e valiosa matriz para o uso de Ressonância Magnética Nuclear de alta resolução, onde, através dos tratamentos de amostra apropriados, é possível, com um único espectro, obter-se simultaneamente os sinais de vários metabólitos.

As amostras utilizadas a priori neste trabalho, no entanto, foram obtidas de bovinos, o que pode ter contribuído para a falta de eficiência dos modelos quimiométricos em descrever os conjuntos de dados obtidos para as amostras de urina e plasma sanguíneo. Por se tratar de animais de grande porte, a experimentação com os mesmos torna-se mais difícil, levando a variáveis indesejadas, como flutuações na dose de Ivermectina aplicada de um animal para outro, uma vez que o tamanho dos animais impede uma pesagem precisa.

Adicionalmente, o histórico médico-veterinário dos indivíduos estudados, que podem ter inclusive idades ligeiramente diferentes, pode contribuir negativamente para diferenciar o metabolismo, conforme visto no modelo quimiométrico gerado para plasma sanguíneo bovino, onde as amostras de um mesmo animal são agrupadas, não havendo nenhuma tendência global aparente para as condições experimentais adotadas. Apesar do aumento na capacidade descritiva dos modelos com o refinamento por regiões de maior poder de modelagem, não parece haver informação relevante no que diz respeito às mudanças metabólicas causadas pela Ivermectina. Nos modelos gerados para urina, essa situação é ainda mais acentuada, onde não existe qualquer tipo de agrupamento, mesmo que o refinamento leve a um ganho expressivo na capacidade descritiva. Isto leva a crer que a composição da urina destes animais sofre influência de uma série de fatores, sendo apenas um dentre estes a aplicação de uma dose terapêutica de Ivermectina. 
Finalmente para estes animais, as limitações impostas pelo Comitê de Ética em Experimentação Animal impedem que doses experimentais acima da terapêutica sejam aplicadas em animais de pesquisa pecuária.

Contudo, um experimento envolvendo camundongos isogênicos medicados com doses controladas e crescentes de Ivermectina mostrou que a Ressonância Magnética Nuclear de alta resolução pode ser uma ferramenta poderosa na obtenção de informação metabólica para estes animais, permitindo que as amostras resultantes de animais medicados e não medicados fossem quimiometricamente distinguidas a partir de seus espectros de $\mathrm{RMN}-{ }^{1} \mathrm{H}$. Adicionalmente, os experimentos bidimensionais de ${ }^{1} \mathrm{H}$ (COSY, HSQC e HMBC) forneceram informações essenciais para a caracterização das moléculas (metabólitos) presentes nas amostras.

O uso da técnica SSFP para aquisição rápida de dados de ${ }^{13} \mathrm{C}$ mostrou-se bastante eficiente e promissora, levando a espectros com melhor razão sinal-ruído, e contendo um número consideravelmente maior de sinais, quando comparada à técnica convencional. Através do uso conjugado dos espectros bidimensionais,bases de dados e espectros SSFP- ${ }^{13} \mathrm{C}$, foi possível a caracterização de um número considerável de metabólitos presentes, conforme mostrado. Este quadro sugere que o uso da RMN-SSFP pode ser estabelecido como forma alternativa para aquisição de dados para núcleos menos sensíveis, como é o caso do ${ }^{13} \mathrm{C}$.

Dentre as variações identificadas, destacam-se a diminuição no nível de lactato (gliconeogênese) e o simultâneo aumento do $\beta$ hidroxibutirato (cetogênese), produzidos no fígado e utilizados como forma de energia alternativa, principalmente pelo cérebro. Ambas asvariações estão correlacionadas a situações de baixa glicose disponível, podendo ser responsáveis pelos efeitos colaterais da Ivermectina, muito similares à condição de Cetose, predisposta em 
bovinos, sobretudo em fêmeas prenhes e/ou lactantes, onde a demanda energética (especialmente durante a produção de leite) leva os animais a um balanço energético negativo.

Por esta razão, muitos produtores que utilizam ivermectina como fármaco preferencial para tratamento de desordens em seus rebanhos podem sofrer um prejuízo latente considerável, uma vez que os efeitos colaterais deste se comparam àquela condição clínica. Por outro lado, uma vez confirmada a correlação entre a aplicação de ivermectina e e o estabalecimento/agravamento da condição cetótica, a reformulação do tratamento pode ser bastante simples, devendo este ser acompanhado de complementação alimentar que possa compensar o déficit energético.

Assim, as ferramentas analíticas e exploratórias aqui mostradas permitiram a observação pioneira de correlações terapêuticas e metabólicas para bovinos tratados com ivermectina. 


\section{BIBLIOGRAFIA}

1 GIL, V. M. S..; GERALDES, C. F. Ressonância magnética nuclear: fundamentos, métodos e aplicações. Lisboa: Calouste Gulbenkian, 2002. 1004 p.

2 CLARIDGE, T. D. W. High-resolution NMR techniques in organic chemistry. Amsterdam: Pergamon, 1999. 382 p.

3 SANDERS, J. K. M.; HUNTER, B. K. Modern NMR spectroscopy: a guide for chemists. Oxford University Press, 1993. v. 25, p. 328.

4 BLOCH, F. Nuclear induction. Physical Review, v. 70, n. 7-8, p. 460-474, 1946.

5 PURCELL, E.; TORREY, H.; POUND R. Resonance absorption by nuclear magnetic moments in a solid. Physical Review, v. 69, n. 1-2, p. 37-38, 1946.

6 TORREY,H. Transient nutations in nuclear magnetic resonance. Physical Review, v. 76, n. 8, p. 1059-1068, 1949.

7 ARNOLD, J. T.; DHARMATTI, S. S.; PACKARD, M. E. Chemical effects on nuclear induction signals from organic compounds. The Journal of Chemical Physics, v. 19, n. 4, p. 507, 1951.

8 ERNST, R. R. Application of Fourier transform spectroscopy to magnetic resonance. Review of Scientific Instruments, v. 37, n. 1, p. 93, 1966.

9 ERNST, R. R.; ANDERSON, W. A. Sensitivity enhancement in magnetic resonance. II. Investigation of intermediate passage conditions. Review of Scientific Instruments, v. 36, n. 12, p. 1696, 1965.

10 SCHWENK, A. NMR pulse technique with high sensitivity for slowly relaxing systems. Journal of Magnetic Resonance, v. 5, n. 3, p. 376-389, 1971.

11 SCHWENK, A. A New technique for measuring the relaxation times $\mathrm{T}_{1}$ and $\mathrm{T}_{2}$ and the equilibrium magnetization $\mathrm{MO}$ of slowly relaxing systems with weak NMR signals. Journal of Magnetic Resonance, v. 165, p. 147-165, 1977.

12 BURKE, P. J.; MATTHEWS, R. W.; GILLIES, D. G. Thallium-205 nuclear magnetic resonance spectra of thallium(I) alkoxides. Journal of the Chemical Society, Dalton Transactions, v. 205, n. 8, p. 1439, 1980. 
13 AZEREDO, R. B. V.; COLNAGO, L. A.; ENGELSBERG, M. Quantitative analysis using steady-state free precession nuclear magnetic resonance. Analytical Chemistry, v. 72, n. 11, p. 2401-2405, 2000.

14 CARR, H. Steady-state free precession in nuclear magnetic resonance. Physical Review, v. 112, n. 5, p. 1693-1701, 1958.

15 FREEMAN, R. Nuclear magnetic double resonance studies by the Fourier transform technique. The Journal of Chemical Physics, v. 53, n. 1, p. $457,1970$.

16 FREEMAN R.; HILL, H. Phase and intensity anomalies in fourier transform NMR. Journal of Magnetic Resonance, v. 4, n. 3, p. 366383, 1971.

17 SCHWENK, A. Steady-state techniques for low sensitivity and slowly relaxing nuclei. Progress in Nuclear Magnetic Resonance Spectroscopy, v. 17, p. 69-140, 1985.

18 COLNAGO, L. A.; ENGELSBERG, M.; AZEREDO, R. B. V. Aplicações da espectroscopia de RMN (CWFP) na medida de umidade em sementes e grãos. São Carlos: Embrapa Instrumentação, 2002. 4 p. (Circular Técnica).

19 SANTOS, P. M. Desenvolvimento da técnica de precessão livre no estado estacionário para aumento da razão sinal ruído em espectros de RMN de alta resolução. 2009. 107 f. Dissertação (Mestrado em Química Analítica) - Instituto de Química de São Carlos, Universidade de São Paulo, São Carlos, 2009.

20 LE ROUX, P. Simplified model and stabilization of SSFP sequences. Journal of Magnetic Resonance, v. 163, n. 1, p. 23-37, 2003.

21 RUDAKOV, T. N.; BELYAKOV, V. Modifications of the steady-state free-precession sequence for the detection of pure nuclear quadrupole resonance. Journal of Physics D: Applied Physics, v. 31, n. 10, p. 1251-1256, 1998.

22 RUDAKOV, T. N.; MIKHALTSEVICH,V. T. Steady-state freeprecession in nitrogen-14 quadrupolar spin-system with axially symmetric electric field gradient tensor. Chemical Physics Letters, June, p. 69-74, 2000.

23 BAUNER, K. U.; SANDNER, T.; NOTOHAMIPRODJO, M.;

SCHMOECKEL, M. REISER, M. F.; HUBER, A. M. Contrast enhanced IRSSFP examination compared with $\mathrm{T}_{1}$-weighted turbo spin-echo imaging of cardiac tumors and tumorlike lesions. European Journal of

Radiology, v. 78, n. 1, p. 93-98, 2011. 
24 KORNAAT, P. R.; REEDER, S. B.; KOO, S.; BRITTAIN, J. H.; YU, $\mathrm{H}$.; ANDRIACCHI, T. P.; GOLD, G. E. MR imaging of articular cartilage at 1.5T and 3.0T: comparison of SPGR and SSFP sequences.

Osteoarthritis and cartilage. Osteoarthritis Research Society, v. 13, n. 4, p. 338-344, 2005.

25 QIU, Y.; RAJAGOPALAN, D.; CONNOR, S.; DAMIAN, D.; ZHU, L.; HANDZEL, A.; HU, G.; AMANULLAH, A.; BAO, S.; WOODY, N.; MACLEAN, D.; LEE, K.; VANDERWALL, D.; RYAN, T. Multivariate classification analysis of metabolomic data for candidate biomarker discovery in type 2 diabetes mellitus. Metabolomics, v. 4, n. 4, p. 337-346, 2008.

26 HODAVANCE, M. S.; RALSTON, S. L.; PELCZER, I. Beyond blood sugar: the potential of NMR-based metabonomics for type 2 human diabetes, and the horse as a possible model. Analytical and Bioanalytical Chemistry, v. 387, n. 2, p. 533-537, 2007.

27 DIAMOND, H. S.; CARTER, A. C.; FELDMAN, E. B. Abnormal regulation of carbohydrate metabolism in primary gout. Annals of the Rheumatic Diseases, v. 33, n. 6, p. 554-562, 1974.

28 MICHALS, K.; MATALON, R. Phenylalanine metabolites, attention span and hyperactivity. The American Journal of Clinical Nutrition, v. 42, n. 2, p. 361-365, 1985.

29 MICHELL, A. W.; MOSEDALE, D.; GRAINGER, D. J.; BARKER, R. A. Metabolomic analysis of urine and serum in Parkinson's disease.

Metabolomics, v. 4, n. 3, p. 191-201, 2008.

30 GATTAZ, W. F.; LEVY, R.; CAIRNS, N. J.; FÖRSTL, H.; BRAUS, D. F.; MARAS, A. Relevance of metabolism of membrane phospholipids for Alzheimer dementia. Fortschritte der Neurologie-Psychiatrie, v. 64 , n. 1, p. 8-12, 1996.

31 MYCIELSKA, M. E.; PATEL, A.; RIZANER, N.; MAZUREK, M. P. ; KEUN, H. ; PATEL, A.; GANAPATHY, V.; DJAMGOZ, M. B. A. Citrate transport and metabolism in mammalian cells: prostate epithelial cells and prostate cancer. Bioessays: News and Reviews in Molecular, Cellular and Developmental Biology, v. 31, n. 1, p. 10-20, 2009.

32 SANTINI, M. .T; ROMANO, R; RAINALDI, G.; INDOVINA, P.; FERRANTE, A.; MOTTA, A.; INDOVINA, P. L. Temporal dynamics of ${ }^{1} \mathrm{H}$-NMR-visible metabolites during radiation-induced apoptosis in MG-

63 human osteosarcoma spheroids. Radiation Research, v. 166, n. 5, p. $734-745,2006$. 
33 SANTINI, M.T.; FERRANTE, A.; ROMANO, R.; RAINALDI, G.; MOTTA, A.; DONELLI, G.; VECCHIA, P.; INDOVINA, P. L. A $700 \mathrm{MHz}{ }^{1} \mathrm{H}-\mathrm{NMR}$ study reveals apoptosis-like behavior in human $\mathrm{K} 562$ erythroleukemic cells exposed to a $50 \mathrm{~Hz}$ sinusoidal magnetic field. International

Journal of Radiation Biology, v. 81, n. 2, p. 97-113, 2005.

34 LINDON, J. C.; NICHOLSON, J. K. Spectroscopic and statistical techniques for information recovery in metabonomics and metabolomics. Annual Review of Analytical Chemistry (Palo Alto, California), v. 1, p. 45-69, 2008.

35 BECKONERT, O.; KEUN, H. C.; EBBELS, T. M.; BUNDY, J.; HOLMES, E.; LINDON, J. C.; NICHOLSON, J. K. Metabolic profiling, metabolomic and metabonomic procedures for NMR spectroscopy of urine, plasma, serum and tissue extracts. Nature Protocols, v. 2, n. 11, p. 26922703, 2007.

36 GAO, X. X.; GE, H. M.; ZHENG, W. F.; TAN, R. X. NMR-based metabonomics for detection of Helicobacter pylori infection in gerbils: which is more descriptive. Helicobacter, v. 13, n. 2, p. 103-111, 2008.

37 CLOAREC, O.; DUMAS, M. E.; TRYGG, J.; CRAIG, A.; BARTON, R. H.; LINDON, J. C.; NICHOLSON, J. K.; HOLMES, E. Evaluation of the orthogonal projection on latent structure model limitations caused by chemical shift variability and improved visualization of biomarker changes in ${ }^{1} \mathrm{H}$ NMR spectroscopic metabonomic studies. Analytical Chemistry, v. 77, n. 2, p. 517-526, 2005.

38 BERTRAM, H. C.; KRISTENSEN, N. B.; MALMENDAL, A.; NIELSEN, N. C.; BRO, R.; ANDERSEN, H. J.; HARMON, D. L. A metabolomic investigation of splanchnic metabolism using $\mathrm{H}$ NMR spectroscopy of bovine blood plasma. Analytica Chimica Acta, v. 536, n. 1-2, p. 1-6, 2005.

39 BERTRAM, H. C.; MALMENDAL, A.; PETERSEN, B. O.; MADSEN, J. C.; PEDERSEN, H.; NIELSEN, N. C. ; HOPPE, C.; MØLGAARD, C.; MICHAELSEN K. F.; DUUS, J. $\varnothing$. Effect of magnetic field strength on NMR-based metabonomic human urine data. Comparative study of 250, 400, 500, and $800 \mathrm{MHz}$. Analytical Chemistry, v. 79, n. 18, p. 7110-7115, 2007.

40 BERTRAM, H. C.; KRISTENSEN, N. B.; JENSEN, S. K.; SEHESTED, J.; NIELSEN, N. C.; MALMENDAL, A. Metabolic characterization of rumen epithelial tissue from dairy calves fed different starter diets using $1 \mathrm{H}$ NMR spectroscopy. Livestock Science, v. 120, n. 1-2, p. 127-134, 2009. 
41 GRONWALD, W.; KLEIN, M. S.; KASPAR, H.; FAGERER, S.

R.; NÜRNBERGER, N.; DETTMER, K.; BERTSCH, T.; OEFNER, P. J. Urinary metabolite quantification employing 2D NMR spectroscopy.

Analytical Chemistry, v. 80, n. 23, p. 9288-9297, 2008.

42 GJERSING, E. L.; HERBERG, J. L.; HORN, J.; SCHALDACH, C. M.; MAXWELL, R. S. NMR metabolomics of planktonic and biofilm modes of growth in Pseudomonas aeruginosa. Analytical Chemistry, v. 79, n. 21, p. 8037-8045, 2007.

43 SAUDE, E. J.; SYKES, B. D. Urine stability for metabolomic studies: effects of preparation and storage. Metabolomics, v. 3, n. 1, p. 1927, 2007.

44 ZHANG, A.; SUN, H.; WANG, P.; HAN, Y.; WANG, X. Modern analytical techniques in metabolomics analysis. The Analyst, v. 137, p. 293-300, 2012.

45 KUMAR, K.; ARCHUNAN, R. G.; JEYARAMAN, R.; NARASIMHAN, S. Chemical characterization of bovine urine with special reference to oestrus. Veterinary Research Communications, v. 24, n. 7, p. 445454, 2000.

46 van GINNEKEN, V.; VERHEY, E.; POELMANN, R.; RAMAKERS, R.; van DIJK K. W. ; HAM, L. ; VOSHOL, P.; HAVEKES, L. ; van ECK, M.; van der GREEF, J. Metabolomics (liver and blood profiling) in a mouse model in response to fasting: a study of hepatic steatosis.

Biochimica et Biophysica Acta, v. 1771, n. 10, p. 1263-1270, 2007.

47 WISHART, D. S. Quantitative metabolomics using NMR. TrAC Trends in Analytical Chemistry, v. 27, n. 3, p. 228-237, 2008.

48 MOCO, S.; BINO, R. J.; VORST, O.; VERHOEVEN, H. A.; DE GROOT, J.; VAN BEEK, T. A.; VERVOORT, J.; DE VOS, C. H. A liquid chromatography-mass spectrometry-based metabolome database for tomato. PLANT PHYSIOLOGY, v. 141, n. 4, p. 1205-1218, 2006.

49 PAN, Z.; RAFTERY, D. Comparing and combining NMR spectroscopy and mass spectrometry in metabolomics. Analytical and

Bioanalytical Chemistry, v. 387, n. 2, p. 525-527, 2007.

50 PAN, Z.; GU, H.; TALATY, N.; CHEN, H.; SHANAIAH, N.; HAINLINE, B. E.; COOKS, R. G.; RAFTERY, D. Principal component analysis of urine metabolites detected by NMR and DESI-MS in patients with inborn errors of metabolism. Analytical and Bioanalytical

Chemistry, v. 387, n. 2, p. 539-549, 2007.

51 CAI, W.; SHIN, DW.; CHEN, K.; GHEYSENS, O.; CAO Q.; WANG, S. X.; GAMBHIR, S. S.; CHEN X. Peptide-labeled near-infrared quantum dots for imaging tumor vasculature in living subjects. Nano Letters, $v$. 6, n. 4, p. 669-676, 2006. 
52 LANUSSE, C.; LIFSCHITZ, A.; VIRKEL, G.; ALVAREZ, L.; SÁNCHEZ, S.; SUTRA J. F.; GALTIER, P.; ALVINERIE, M. Comparative plasma disposition kinetics of ivermectin, moxidectin and doramectin in cattle. Journal of Veterinary Pharmacology and Therapeutics, v. 20, n. 2, p. 91-99, 1997.

53 MARTINS, A. R. L.; ROCHA, R. S.; PORTZ, A. J.; MOITA, S. R.; FEIJÓ, L. D.; R. DANTAS, M. Uso da ivermectina na bovinocultura de corte do Brasil e seus impactos econômicos. In: CONGRESSO

BRASILEIRO DE MEDICINA VETERINÁRIA, 38., 2010, Florianópolis.

Livro de Resumos. Disponível em

<http://www.sovergs.com.br/site/38conbravet/resumos/74.pdf>.

Acesso em: 01 set. 2010.

54 REUTERS. Brazil JBS plant stops Beef exports to U.S. Disponível em: <http://www.reuters.com/article/2010/05/21/jbsidUSN219885220100521>. Acesso em: 14 jun. 2010.

55 IVOMEC: injetável. Responsável técnico Dr. Emílio C. Salani. Paulínia: Merial Saúde Animal, 2011. Bula do Medicamento.

56 COMMON DREAMS. Are Brazil 's Veterinary Drugs in Your Canned Meat? Disponível em:

<http://www.commondreams.org/print/57393>. Accesso em: 30 jul. 2010.

57 PHYSICIAN'S DESK REFERENCE (PDR). 64th ed. Montvale: PDR Network, 2009. 3500 p.

58 ROCHA, T. L. Metabolômica: aplicações e perspectivas. Brasília: Embrapa Recursos Genéticos e Biotecnologia, 2006. 38 p.

59 SEIXAS, J. N.; PEIXOTO, P. V.; ARMIÉN, A. G.; JABOUR, F. F.; BRITO, M. F. Aspectos clínicos e patogenéticos da intoxicação por abamectina em bezerros. Pesquisa Veterinária Brasileira, v. 26, n. 3, p. 161-166, 2006.

60 MEDEIROS, J. P.; SIMÕES, M. D. J. Efeito da ivermectina sobre a ciclicidade, gestação e desenvolvimento neonatal em ratos. Brazilian Journal of Veterinary Research and Animal Science, v. 45, p. 472-480, 2008.

61 DELAYTE, E. H.; OTSUKA, M.; LARSSON, C. E.; CASTRO, R. C. C. Eficácia das lactonas macrocíclicas sistêmicas (ivermectina e moxidectina) na terapia da demodicidose canina generalizada. Arquivo Brasileiro de Medicina Veterinária e Zootecnia, v. 58, n. 1, p. 31$38,2006$. 
62 RIEDMAIER, I.; BECKER, C.; PFAFFL, M. W.; MEYER, H. H. D. The use of omic technologies for biomarker development to trace functions of anabolic agents.. Journal of Chromatography A, v. 1216, n. 46, p. 8192-8199, 2009.

63 STANLEY, E. G.; BAILEY, N. J.; BOLLARD, M. E.; HASELDEN, J. N.; WATERFIELD, C. J.; HOLMES, E.; NICHOLSON, J. K. Sexual dimorphism in urinary metabolite profiles of Han Wistar rats revealed by nuclear-magnetic-resonance-based metabonomics. Analytical Biochemistry, v. 343, n. 2, p. 195-202, 2005.

64 LINDON, J. C.; NICHOLSON, J. K. Analytical technologies for metabonomics and metabolomics, and multi-omic information recovery. TrAC Trends in Analytical Chemistry, v. 27, n. 3, p. 194204, 2008.

65 ZHENG, G.; PRICE, W. S. Solvent signal suppression in NMR.

Progress in Nuclear Magnetic Resonance Spectroscopy, v. 56, n. 3, p. 267-288, 2010.

66 SORENSEN, M.; KRISTENSEN, S. M.; LED, J. J. Overcoming the Solvent-saturation transfer problem in ${ }^{1} \mathrm{H}-{ }^{15} \mathrm{~N}$ NOE measurements. Application of jump-return pulses. Journal of Magnetic Resonance, Series B, v. 107, n. 1, p. 83-87, 1995.

67 LOUIS-JOSEPH, A.; ABERGEL, D.; LEBARS, I.; LALLEMAND, J. -Y. Enhancement of water suppression by radiation damping-based manipulation of residual water in Jump and Return NMR experiments. Chemical Physics Letters, v. 337, p. 92-96, 2001.

68 BRAUN, S.; KALINOWSKI, H. -O.; BERGER, S. 150 and more basic NMR experiments: a practical course. 2nd ed. Weinheim: Wiley-VCH, 1998. 610 p.

69 REZZI, S.; RAMADAN, Z.; FAY, L. B.; KOCHHAR, S. Nutritional metabonomics: applications and perspectives. Journal of Proteome Research, v. 6, n. 2, p. 513-525, 2007.

70 da SILVA, R. A. B.; ASSED, S.; NELSON-FILHO, P.; da SILVA, L. A. B.; CONSOLARO, A. Subcutaneous tissue response of isogenic mice to calcium hydroxide-based pastes with chlorhexidine. Brazilian Dental Journal, v. 20, n. 2, p. 99-106, 2009.

71 DADARKAR, S. S.; DEORE, M. D.; GATNE, M. M. Comparative evaluation of acute toxicity of ivermectin by two methods after single subcutaneous administration in rats. Regulatory Toxicology and Pharmacology: RTP, v. 47, n. 3, p. 257-260, 2007. 
72 WISHART, D. S.; TZUR, D.; KNOX, C.; EISNER, R.; GUO, A. C. ; YOUNG, N.; CHENG, D.; JEWELL, K.; ARNDT, D.; SAWHNEY, S.; FUNG, C.; NIKOLAI, L.; LEWIS, M.; COUTOULY, M.; FORSYTHE, I.; TANG, P.; SHRIVASTAVA, S.; JERONCIC, K.; STOTHARD, P.; AMEGBEY, G. ; BLOCK, D.; HAU, D. D. ; WAGNER, J.; MINIACI, J.; CLEMENTS, M. ; GEBREMEDHIN, M.; GUO, N.; ZHANG, Y.; DUGGAN, G. E.; MACINNIS, G. D.; WELJIE, A. M.; DOWLATABADI, R.; BAMFORTH, F.; CLIVE, D.; GREINER, R.; LI, L.; MARRIE, T.; SYKES, B. D.; VOGEL, H. J.; QUERENGESSER, L. HMDB: the Human Metabolome Database. Nucleic Acids Research, v. 35, p. D521-526, 2007.

73 CUI, Q.; LEWIS, I. A.; HEGEMAN, A. D.; ANDERSON, M. E.; LI, J.; SCHULTE C. F.; WESTLER, W. M.; EGHBALNIA, H. R.; SUSSMAN, M. R.; MARKLEY, J. L. Metabolite identification via the Madison Metabolomics Consortium Database. Nature Biotechnology, v. 26, n. 2, p. 162-164, 2008.

74 LUNDBERG, P.; VOGEL, T.; MALUSEK, A.; LUNDQUIST, P.-O., COHEN, L.; DAHLQVIST, O. The Magnetic Resonance Metabolomics Database (mdl.imv.liu.se). Basel: ESMRMB, 2005.

75 SANTOS, P. M.; DE SOUZA, A. A.; COLNAGO, L. A. Supressão das anomalias de fase e batimentos laterais em espectros de RMN ${ }^{13} \mathrm{C}$ obtidos com a sequência de precessão livre no estado estacionário. Química Nova, v. 33, n. 4, p. 954-956, 2010.

76 CAMPBELL, M. K.; FARRELL, O. Biochemistry. 5th ed. Belmont: Brooks Cole, 2006. 792 p.

77 NELSON, D. L.; COX, M. M. Lehninger: principles of biochemistry, 4th ed. New York: W.H. Freeman, 2004. 1100 p.

78 MARUTA, C. A. Perfil metabólico e ruminal de garrotes submetidos às condições de alimentação normal, jejum e realimentação. 2005. 120 f. Tese (Doutorado em Medicina Veterinária) - Faculdade de Medicina Veterinária e Zootecnia, Universidade de São Paulo, São Paulo, 2005.

79 HEIDRICH, H.D.; GRUNER, J.; VASKE, T. R. Enfermidades metabólicas e carências. In: MANUAL de Patologia Bovina. São Paulo: J. M Varela livros, 1980. p. 191-192.

80 AROEIRA, L. J. M. Cetose e infiltração gordurosa no fígado em vacas leiteiras. Juiz de Fora: Embrapa Gado de Leite, 1998. 23 p. (Embrapa Gado de Leite. Documentos, 65).

81 GRUMMER, R. R., WINKLER, J. C, BERTICS, S. e STUDER, V.A. Effect of propilene glycol dosage during feed restriction on metabolites in blood of Holstein heifers. Journal Dairy Science, v. 77, n. 12, p. 3618-3623, 
82 STUDER, V. A. Effect of prepartum propylene glycol administration on periparturient fatty liver in dairy cows. Journal Dairy Science, $v$. 76, n. 10, p. 2931-2939, 1993.

83 BORGES, F. B. Utilização de ionóforos e antibióticos na alimentação de bovinos. Disponível em:

<http://www.zootec.com.br/ionoforo.html>. Accesso em: 18 nov. 2010. 